University of Rhode Island

DigitalCommons@URI

Open Access Dissertations

2020

\title{
MOLECULAR MECHANISM OF POLYPEPTIDE INSERTION INTO BILAYER AND EXIT
}

Gregory Slaybaugh

University of Rhode Island, chipmunk@my.uri.edu

Follow this and additional works at: https://digitalcommons.uri.edu/oa_diss

\section{Recommended Citation}

Slaybaugh, Gregory, "MOLECULAR MECHANISM OF POLYPEPTIDE INSERTION INTO BILAYER AND EXIT" (2020). Open Access Dissertations. Paper 1147.

https://digitalcommons.uri.edu/oa_diss/1147

This Dissertation is brought to you for free and open access by DigitalCommons@URI. It has been accepted for inclusion in Open Access Dissertations by an authorized administrator of DigitalCommons@URI. For more information, please contact digitalcommons-group@uri.edu. 
MOLECULAR MECHANISM OF POLYPEPTIDE INSERTION INTO BILAYER AND EXIT

BY

GREGORY SLAYBAUGH

A DISSERTATION SUBMITTED IN PARTIAL FULFILLMENT OF THE

REQUIREMENTS FOR THE DEGREE OF

DOCTOR OF PHILOSOPHY

IN

PHYSICS

UNIVERSITY OF RHODE ISLAND 


\title{
DOCTOR OF PHILOSOPHY DISSERTATION \\ $\mathrm{OF}$
}

\section{GREGORY SLAYBAUGH}

\section{APPROVED:}

Dissertation Committee:

Major Professor

\author{
Yana K. Reshetnyak \\ Gerhald Müller \\ Natallia Katenka \\ Nasser H. Zawia \\ DEAN OF THE GRADUATE SCHOOL \\ UNIVERSITY OF RHODE ISLAND




\section{ABSTRACT}

The $\mathrm{pH}$-low insertion peptide (pHLIP) and $\mathrm{pH}-\mathrm{low}$ insertion cycle (pHLIC) have been shown to target cancer cells and inflammation due to the acidic environment present at those sites. It has been demonstrated that pHLIP's and pHLIC's $\mathrm{pH}$ dependent behavior stems from the protonation and deprotonation of aspartic acid (Asp) and glutamic acid (Glu) residues. A decrease in $\mathrm{pH}$ leads to the protonation of Asp/Glu located in membrane-inserting part of peptides, which increases the overall hydrophobicity of pHLIP and pHLIC and triggers the insertion across a lipid bilayer.

Despite similarity of pHLIP and pHLIC ability to sense $\mathrm{pH}$ at cell surfaces the mechanisms of peptides insertion into membrane is different. pHLIP, which is a flexible polymer in solution at high $\mathrm{pH}$, undergoes $\mathrm{pH}$-triggered folding in membrane to transition from coil to transmembrane helix. pHLIC, which is a rigid cyclic peptide, undergoes $\mathrm{pH}$-triggered partition into membrane without changes of its structure.

pHLIP peptide insertion occurs in several steps, with a rapid interfacial helix formation (folding) completed within $100 \mathrm{~ms}$ followed by the rate limiting step of peptide insertion across membrane to form a transmembrane helix. Exit from the bilayer and unfolding is triggered by deprotonation of Asp/Glu residues induced by $\mathrm{pH}$ raise. The reverse process of unfolding and exit proceeds through different intermediate states. The detailed kinetics study of pHLIP variants $\mathrm{pH}$-triggered insertion and exit from the membrane of liposomes allowed to elucidate the molecular mechanism of membrane-associated folding and unfolding, and design and test new pHLIP variants with tunable $\mathrm{pH}$-dependent properties. 
Biophysical investigation of several $\mathrm{pH}$-sensitive and $\mathrm{pH}$-insensitive cyclic peptides led to the selection of best pHLIC candidate for targeting and imaging of neuroinflammation, which is associated with development of variety of neurodegenerative diseases. 


\section{ACKNOWELEDGEMENT}

First and foremost, I want to share my appreciation for the incredible display of guidance, encouragement, and patience shown to me by my advisor, Dr. Yana K. Reshetnyak. I will be forever indebted to her for the opportunity she gave me as an undergraduate student by accepting me into her lab and asking me join a team of such inspiring people. The amount of time and energy Dr. Yana dedicates to her students is extraordinary, and her ability to do this all while making tremendous strides in research is unparalleled. I look up to her, and I think she is the greatest scientist I have ever known. I feel excited and prepared for my future after graduate school, and I owe so much of that to her.

I'd like to say thank you to another one of my mentors, Dr. Oleg A. Andreev, for being such an inspirational and motivational person for me. I am appreciative for Dr. Oleg's openness and willingness to share his knowledge.

Throughout my entire time here in the research lab, Dr. Anuradha Weerakkody, has been a crucial presence. He took me under his wing when I joined the lab and has shared with me an immeasurable amount of wisdom. He showed me what a passionate, brilliant, and hard-working scientist looks like, and it has been a privilege to have someone like him to look up to everyday. I owe much of my research knowledge, technical skills, and passion for this research to him.

Another amazing scientist I've had the privilege of working with is Dr. Anna Moshnikova. She has been incredibly helpful over the years. Her willingness to help me when I have issues in the lab is truly special. Her hard work-ethic, proficiency in the lab, and kindness have made her a role model I look up to. 
Last, but not least are my lab mates. First, I'd like to give a shout out to Hannah, who has been my sidekick for the last couple of years. I had the honor of being her mentor when she joined the lab. I hope I've been able to instill in her the wisdom and passion I've gained while working in Dr. Yana's lab, and I look forward to watching her become an absolute boss of a scientist. Next is Troy, who has gone through the PhD program with me almost from the beginning. He's been a great friend and a great motivator when it comes to deadlines. I can't wait to see all the great things he'll do as a medical physicist. And finally Mike, it has been an absolute pleasure working in the lab together. Although we never directly worked on any project together, the trip to the Biophysical Society Annual Meeting in San Francisco was a blast.

I could not conclude this acknowledgment without mentioning the rock in my life, my Mom. Since I started college, no one has been there for me more than Dr. Mimi, and without her, I would have never made it this far -- or truly understood the importance of double integrals.

Thank you to all of my professors, I think the Physics department at URI has the finest collection of faculty of any department at the university. I want to thank my friends who have been incredibly supportive and present throughout my time at URI. I want to thank my family, especially my sister, Anna, my brother, Charlie, and Doc who have been with me from the beginning -- GO RAMS. Also, I want to thank my Namalene and my uncles who try their hardest to pretend to understand pHLIP. And lastly, I'd like to give thanks to my partner in life and closest friend, Catherine. She has been by my side through my entire college career and I owe her so much gratitude for all that she is. 


\section{PREFACE}

This dissertation is written in "Manuscript" format, using the Thesis/Dissertation template of the University of Rhode Island. There are three manuscripts included in this dissertation, each of which comprises a chapter. The tables and figures of each manuscript are listed under the corresponding chapter in the list of tables and figures.

The results of our studies presented in the first two chapters were published in the following papers:

1. Weerakkody D, Moshnikova A, El-Sayed NS, Adochite RC, Slaybaugh G, Golijanin J, Tiwari RK, Andreev OA, Parang K, Reshetnyak YK. Novel pHsensitive cyclic peptides. Sci Rep, 2016

2. Vila-Viçosa D, Silva TFD, Slaybaugh G, Reshetnyak YK, Andreev OA, Machuqueiro M. The membrane-induced pK(a) shifts in wt-pHLIP and its L16H variant. J Chem Theory Comput, 2018

The final chapter is composed of research that is currently under peer-review.

3. Slaybaugh G, Weerakkody D, Engelman D, Andreev OA, Reshetnyak YK. Kinetics of pH-triggered pHLIP insertion into membrane and exit, under review in PNAS 


\section{TABLE OF CONTENTS}

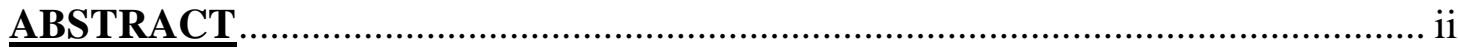

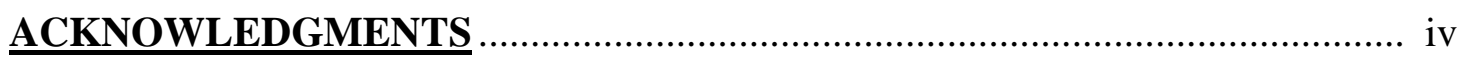

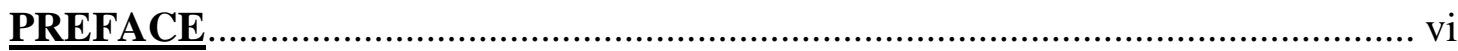

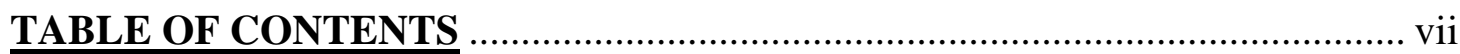

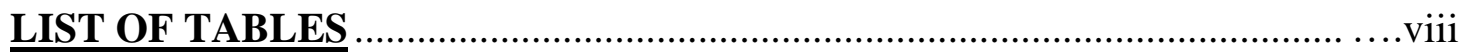

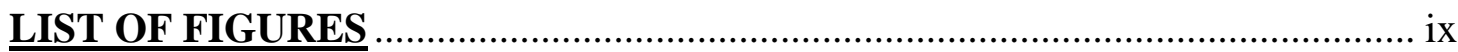

CHAPTER 1 Novel pH-sensitive cyclic peptides ......................................................

CHAPTER 2 The Membrane-induced $\mathrm{pK}_{\mathrm{a}}$ Shifts in $w t$-pHLIP and its L16H variant...39

CHAPTER 3 Kinetics of pHLIP peptide insertion into and exit from a membrane...75 


\section{LIST OF TABLES}

CHAPTER 1

There are no tables in Chapter 1.

\section{CHAPTER 2}

Table 1. Sequences of $w t$ and L16H pHLIP variants

\section{CHAPTER 3}

Table 1. Thermodynamic parameters 


\section{LIST OF FIGURES}

\section{CHAPTER 1}

Figure 1. Chemical structures of six pHLIC and one linear peptide

Figure 2. pH dependent insertion into lipid bilayer

Figure 3. Quenching of fluorescence by acrylamide and 10-DN

Figure 4. NBD fluorescence

Figure 5 (a-c). Concentration and $\mathrm{pH}$-dependent inhibition of HeLa cells proliferation

Figure 5 (d). HeLa cells treated with FITC-labelled peptide conjugate

Figure 5 (e). Cellular uptake of Alexa546-labelled peptide conjugates

Figure 6. Ex vivo fluorescence imaging of tumor and organs after administration of Alexa546-peptides

Figure 7(a,b). Ex vivo fluorescence imaging of tumor and organs after administration of Alexa546-peptides at various times

Figure 7 (c). Tumor/organ ratios calculated from images

Figure 8. Schematic of cyclic peptide partitioning into lipid bilayer

\section{CHAPTER 2}

Figure 1 (a). Probability density of distance to membrane center of key titrable groups in $w t$-pHLIP

Figure 1 (b). Secondary structure of pHLIP inserted in lipid bilayer

Figure 2. Monolayer thickness profiles for $w t$-pHLIP at $\mathrm{pH} 6.0$

Figure 3. $\mathrm{pK}_{\mathrm{a}}$ profile of Asp14 and C-terminus acidic residues of $w t$-pHLIP

Figure 4. Schematic representation of the pH-dependent mechanism of L16H pHLIP

Figure 5. $\mathrm{pK}_{\mathrm{a}}$ profiles of Asp14 and His16

Figure 6 (a). pH dependent transitions of $\mathrm{L} 16 \mathrm{H}$

Figure 6 (b). Circular dichroism measurements of L16H 


\section{CHAPTER 3}

Figure 1. pH dependent insertion into lipid bilayer

Figure 2. Acrylamide quenching

Figure 3. Kinetics of insertion and exit

Figure 4. Kinetics of insertion

Figure 5. Kinetics of exit

Figure 6. Model of pHLIP insertion and exit 


\title{
CHAPTER 1
}

Published in Scientific Reports in August 2016

\author{
Dhammika Weerakkody ${ }^{1}$, Anna Moshnikova ${ }^{1}$, Naglaa Salem El-Sayed ${ }^{2,3,4}$, Ramona-

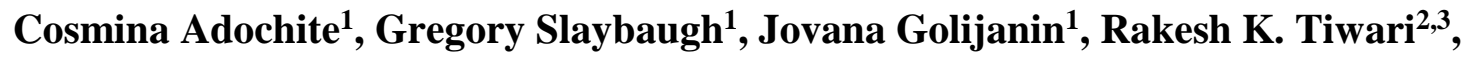 \\ Oleg A. Andreev ${ }^{1}$, Keykavous Parang ${ }^{2,3}$ \& Yana K. Reshetnyak ${ }^{1}$ \\ ${ }^{1}$ Department of Physics, University of Rhode Island, Kingston, RI 02881, US. \\ ${ }^{2}$ Department of Biomedical and Pharmaceutical Sciences, Chapman University School of \\ Pharmacy, 9401 Jeronimo Road, Irvine, CA 92618, US. \\ ${ }^{3}$ Department of Biomedical and Pharmaceutical Sciences, College of Pharmacy, University \\ of Rhode Island, 7 Greenhouse Road Kingston, RI 02881, US. \\ ${ }^{4}$ Cellulose and Paper Department, National Research Center, Dokki 12622, Cairo, Egypt. \\ *Correspondence: reshetnyak@uri.edu (Yana K. Reshetnyak)
}




\begin{abstract}
A series of cyclic peptides containing a number of tryptophan (W) and glutamic acid (E) residues were synthesized and evaluated as $\mathrm{pH}$-sensitive agents for targeting of acidic tissue and $\mathrm{pH}$-dependent cytoplasmic delivery of molecules. Biophysical studies revealed the molecular mechanism of peptides action and localization within the lipid bilayer of the membrane at high and low pHs. The symmetric, $\mathrm{c}\left[(\mathrm{WE})_{4} \mathrm{WC}\right]$, and asymmetric, $\mathrm{c}\left[\mathrm{E}_{4} \mathrm{~W}_{5} \mathrm{C}\right]$, cyclic peptides translocated amanitin, a polar cargo molecule of similar size, across the lipid bilayer and induced cell death in a $\mathrm{pH}$ - and concentration-dependent manner. Fluorescently-labelled peptides were evaluated for targeting of acidic 4T1 mammary tumors in mice. The highest tumor to muscle ratio (5.6) was established for asymmetric cyclic peptide, $\mathrm{c}\left[\mathrm{E}_{4} \mathrm{~W}_{5} \mathrm{C}\right]$, at 24 hours after intravenous administration. $\mathrm{pH}$-insensitive cyclic peptide $c\left[\mathrm{R}_{4} \mathrm{~W}_{5} \mathrm{C}\right]$, where glutamic acid residues (E) were replaced by positively charged arginine residues (R), did not exhibit tumor targeting. We have introduced a novel class of cyclic peptides, which can be utilized as a new $\mathrm{pH}$-sensitive tool in investigation or targeting of acidic tissue.
\end{abstract}




\section{INTRODUCTION}

Tissue acidity is linked to various pathological states such as ischemia, tumor, inflammation, arthritis, infection, atherosclerosis and others ${ }^{1-3}$. Tumor progression and development is associated with acidosis ${ }^{4-6}$. Extracellular acidity is established already at early stages of tumor development, during the avascular phase of carcinoma in situ. As tumor continues to grow, acidosis is increasing due to the poor blood perfusion, switch of cancer cells to the glycolytic mechanism of energy production even in the presence of oxygen and overexpression of carbonic anhydrases $(\mathrm{CA})^{7,8}$. Adaptations to the highly acidic microenvironment are critical steps in the transition from an avascular pre-invasive tumor to a malignant invasive carcinoma. Thus, targeting of acidity might serve as a predictive marker for tumor invasiveness and disease development. $\mathrm{pH}$ is especially lower in the vicinity of the mem- brane of cancer cells due to the work of proton pumps and CAIX/CAXII ${ }^{9}$. Also, $\mathrm{pK}$ of protonation of Asp and Glu residues is higher $(\mathrm{pK} \sim 6-7)$ near the surface of the hydrophobic membrane compared to bulk aqueous solution, where $\mathrm{pK}$ $3-4^{10,11}$. The most effective $\mathrm{pH}$-sensitive tumor targeting agents should sense $\mathrm{pH}$ at the surface of cancer cells, where it is the lowest ${ }^{12}$. There are a number of approaches under development for delivery of imaging and therapeutic agents to diseased tissue in a $\mathrm{pH}$ dependent manner. They are based on the use of $\mathrm{pH}$-sensitive polymers, liposomes, nanoparticles and small molecules ${ }^{13-19}$. Among peptides, family of pHLIP peptides, linear peptides of 25-35 residues, which insert into cellular membrane and form transmembrane helices are used for targeting of acidic tumors of various origins and other acidic diseased tissues $^{20}$. Application of cyclic peptides in biological sciences has become a subject of major interest because of their enhanced enzymatic stability versus linear peptides ${ }^{21}$. 
Recently we reported the design and synthesis of homochiral L-cyclic peptides containing arginine (R), tryptophan $(\mathrm{W})$ residues and their application for the nuclear targeting delivery of anti-HIV drugs, phosphopeptides, anticancer drugs, and siRNA ${ }^{22-24}$. These peptides offered several advantages including nuclear delivery of doxorubicin, low cytotoxicity, biocompatibility, hydrophobic drug entrapment through non-covalent interactions, and drug delivery through conjugation. Herein, we designed and introduced for the first time the $\mathrm{pH}$-sensitive negatively charged cyclic peptides and studied their interactions with the lipid bilayer of liposomal and cellular membranes in vitro and in vivo.

\section{RESULTS}

Among the investigated peptides were one linear and six cyclic peptides (Fig. 1 and Table S1, Supplementary Information). All peptides contained: i) single cysteine (Cys, C) residue for conjugation purposes, ii) at least one tryptophan (Trp, W) for ability to record fluorescence signal, iii) 3-5 protonatable glutamic acid (Glu, E) residues to trigger $\mathrm{pH}-$ dependent interaction with the membrane. Three peptides, $c\left[(\mathrm{WE})_{3} \mathrm{WC}\right], c\left[(\mathrm{WE})_{4} \mathrm{WC}\right]$ and $c\left[(\mathrm{WE})_{5} \mathrm{WC}\right]$ had 3,4 , and 5 repeating units of $\mathrm{WE}$, respectively, where $\mathrm{W}$ and $\mathrm{E}$ were alternating in the cyclic of the peptide. Another peptide, $c\left[(\mathrm{LE})_{4} \mathrm{WC}\right]$, had leucine (Leu, $\mathrm{L}$ ) instead of Trp. The main goal was to investigate the role of aromatic Trp residues in peptide's interaction with the membrane. Fifth peptide, $c\left[\mathrm{E}_{4} \mathrm{~W}_{5} \mathrm{C}\right]$, was an asymmetric; it had five Trp residues located on one side of the cycle, while four Glu residues were located on the other side of the cycle. The positively charged cyclic peptide control, $c\left[\mathrm{R}_{4} \mathrm{~W}_{5} \mathrm{C}\right]$, was also investigated, where Glu residues were replaced by positively charged arginine (Arg, R) residues. Finally, we synthesized one linear $l\left(\mathrm{CW}(\mathrm{EW})_{4}\right)$ 10-residue peptide for the comparison with the cyclic peptides. The peptides were synthesized by employing 
Fmoc/tBu-based solid phase chemistry. As representative examples, the synthesis of $l\left(\mathrm{CW}(\mathrm{EW})_{4}\right.$ and $c\left[(\mathrm{WE})_{4} \mathrm{CW}\right]$ peptides are depicted in the Scheme (Scheme S1, Supplementary Information). All peptides were purified (95-99\%) by reverse phase HPLC.

Fluorescence and $\mathrm{CD}$ spectroscopies were employed to monitor $\mathrm{pH}$-dependent peptide's interaction with the lipid bilayer of liposomes (Figures S1 and S2, Table S2). Biophysical studies were carried out at $\mathrm{pH} 8$ and $\mathrm{pH} 3$ to ensure completeness of the transitions, and to perform measurements in the states of thermodynamic equilibrium. All peptides demonstrated $\mathrm{pH}$-dependent partitioning into the membrane. Asymmetric cyclic peptide with Trp residues located on one side of the cycle, $c\left[\mathrm{E}_{4} \mathrm{~W}_{5} \mathrm{C}\right]$, most probably partitioned into the membrane facing Trp residues into the bilayer and exposing charged Glu residues to the extracellular space. The drop of $\mathrm{pH}$ led to the protonation of carboxyl groups of Glu residues, which increased peptides hydrophobicity and promoted further partitioning of the peptides into the bilayer. As a result, positions of maximum of fluorescence spectra shifted to $6-9 \mathrm{~nm}$ to short wavelengths, which is indicative of changes of microenvironment of Trp residues from polar to hydrophobic ${ }^{25,26}$ (Figure S1 and Table $\mathrm{S} 2) . c\left[(\mathrm{WE})_{3} \mathrm{WC}\right], c\left[(\mathrm{WE})_{4} \mathrm{WC}\right]$ and $c\left[(\mathrm{WE})_{5} \mathrm{WC}\right]$ peptides showed similar $\mathrm{CD}$ signals at $\mathrm{pH} 8$, which were altered by interaction with lipid bilayer and drop of $\mathrm{pH}$. The $\mathrm{CD}$ signal of $c\left[\mathrm{E}_{4} \mathrm{~W}_{5} \mathrm{C}\right]$ peptide was different but was also $\mathrm{pH}$-dependent. We did not observe characteristic CD signal of exciton (delocalized, shared electron density) with a characteristic minimum at $232-235 \mathrm{~nm}^{27}$. Such an exciton might be formed only in a result of stacking of aromatic amino acids due to the cyclic peptide's aggregation to form tubular structures. Thus, we concluded that at the concentrations of the peptides used in this study, the formation of tubular structures is unlikely. 
By monitoring shift of the position of the maximum of fluorescence spectra for the peptides in the result of the $\mathrm{pH}$ drop, we established apparent $\mathrm{pK}$ of peptide's partitioning into the bilayer. The $\mathrm{pK}$ for most cyclic and linear peptides varied in the range of 5.7-6.4, while the smallest $\mathrm{pK}$ value was observed for the cyclic Leu-containing peptide, $c\left[(\mathrm{LE})_{4} \mathrm{WC}\right]$ (Fig. 2).

To establish localization of the peptides within a lipid bilayer of membrane, dual quenching assay ${ }^{28}$ was employed (Fig. 3 and Table S3). Effective quenching of fluorescence by acrylamide would occur only for tryptophan residues exposed to polar parts of the outer or inner leaflets of the bilayer. At the same time, tryptophan residues located in the middle of a membrane would be effectively quenched by 10-DN. The result of the dual quenching assay allows establishing if tryptophan residues were located in the middle of a membrane or close to the polar headgroups of the bilayer. However, it does not allow distinguishing between locations at the outer or inner leaflets of the bilayer. Therefore, we also performed Förster resonance energy transfer (FRET) assay ${ }^{29}$ (Fig. 4). First, symmetrically-labelled by NBD dye, POPC liposomes were prepared. Then, membrane-impermeable dithionite was used to chemically modify exposed NBD, which led to the quenching of NBD fluorescence. Thus, NBD dyes located at the outer leaflet of the bilayer were deactivated and excess of dithionite was removed by gel filtration. As a result, asymmetrically-labelled liposomes with active NBD at the inner leaflet were obtained. FRET was monitored from tryptophan residues of the peptides to NBD. Energy transfer might occur only when both fluorophores are in proximity to each other (within 5$15 \AA$ ). Thus, when tryptophan residues located at the outer leaflet of the bilayer no significant energy transfer to NBD at the inner leaflet would occur (the distance is about 
50-60 ̊). The $c\left[\mathrm{E}_{4} \mathrm{~W}_{5} \mathrm{C}\right]$ demonstrated the highest quenching by 10-DN and the highest FRET at $\mathrm{pH} 8$ indicating the internal position of Trp residues within the bilayer of a membrane. All other peptides were located at the outer leaflet of the bilayer at $\mathrm{pH}$ 8. Drop of $\mathrm{pH}$ promoted partitioning of all cyclic peptides into bilayer, which highest FRET for the $c\left[\mathrm{E}_{4} \mathrm{~W}_{5} \mathrm{C}\right]$ at $\mathrm{pH} 3$. Among $c\left[(\mathrm{WE})_{3} \mathrm{WC}\right], c\left[(\mathrm{WE})_{4} \mathrm{WC}\right]$ and $c\left[(\mathrm{WE})_{5} \mathrm{WC}\right]$ peptides, the peptide with the smallest cycle, $c\left[(\mathrm{WE})_{3} \mathrm{WC}\right]$, showed the deeper partitioning into the membrane. Linear peptide, $l\left(\mathrm{CW}(\mathrm{EW})_{4}\right)$, also demonstrated some partitioning into bilayer in the result of the $\mathrm{pH}$ drop.

Since all peptides exhibited $\mathrm{pH}$-dependent interactions with the lipid bilayer of membrane and no cytotoxicity was observed (Figure S3), we proceeded to the experiments on cultured cancer cells. Symmetric, $c\left[(\mathrm{WE})_{4} \mathrm{WC}\right]$, and asymmetric, $c\left[\mathrm{E}_{4} \mathrm{~W}_{5} \mathrm{C}\right]$, cyclic peptides were evaluated for their ability to move polar cargo across the membrane. The experiments on live cells were performed at physiologically relevant $\mathrm{pHs}$, such as $\mathrm{pH} 7.4$ (extracellular $\mathrm{pH}$ of normal cells) and $\mathrm{pH} 6.0$ (extracellular $\mathrm{pH}$ in the vicinity of cancer cells ${ }^{12}$ ). As a polar cargo, we used amanitin, which is a cell-impermeable cyclic peptide of molecular mass similar to the masses of investigated $\mathrm{pH}$-sensitive cyclic peptides. Amanitin is a deadly toxin, which inhibits RNA polymerase II if transferred across the lipid bilayer of the plasma membrane ${ }^{30}$. The $\mathrm{pH}$ - and concentration-dependent cell death was observed after treatment of HeLa cells for just 3 hours with $c\left[(\mathrm{WE})_{4} \mathrm{WC}\right]-\mathrm{S}-\mathrm{S}$-amanitin $\left(c\left[(\mathrm{WE})_{4} \mathrm{WC}\right]-\mathrm{SPDP}\right.$-amanitin) and $c\left[\mathrm{E}_{4} \mathrm{~W}-{ }_{5} \mathrm{C}\right]-\mathrm{S}-\mathrm{S}$-amanitin $\left(c\left[\mathrm{E}_{4} \mathrm{~W}_{5} \mathrm{C}\right]-\mathrm{SPDP}\right.$-amanitin) (Fig. 5a,b). The calculated $\mathrm{IC}_{50}$ values for symmetric cyclic pep- tide amanitin construct, $c\left[(\mathrm{WE})_{4} \mathrm{WC}\right]-\mathrm{S}-\mathrm{S}$-amanitin, at $\mathrm{pH} 7.4$ and 6.0 were $3.39 \pm 0.12 \mu \mathrm{M}$ and $1.06 \pm 0.02 \mu \mathrm{M}$, respectively. The calculated $\mathrm{IC}_{50}$ values for asymmetric cyclic peptide amanitin 
construct, $c\left[\mathrm{E}_{4} \mathrm{~W}_{5} \mathrm{C}\right]-\mathrm{S}-\mathrm{S}$-amanitin, at $\mathrm{pH} 7.4$ and 6.0 were $1.68 \pm 0.13 \mu \mathrm{M}$ and $0.74 \pm 0.08$ $\mu \mathrm{M}$, respectively. Previously we showed that amanitin alone does not induce cell death at the concentrations used in this study and for the duration of treatment of $2-4$ hours ${ }^{31}$. We also tested construct, where amanitin was conjugated to the asymmetric $c\left[\mathrm{E}_{4} \mathrm{~W}_{5} \mathrm{C}\right]$ cyclic peptide via non-cleavable bond $\left(c\left[\mathrm{E}_{4} \mathrm{~W}_{5} \mathrm{C}\right]\right.$-GMBS-amanitin) (Fig. 5c). The cytotoxic effect for the non-cleavable construct was reduced significantly at both pHs. It might indicate that the peptide-amanitin construct remained within the membrane and cleavage of amanitin from the peptide was required to allow amanitin to reach RNA polymerase II in the nucleus. Alternatively, if peptide-amanitin was translocated into the cytoplasm, the cleavage of amanitin might be required, since affinity of the peptide-amanitin to the RNA polymerase II might be reduced compared to the affinity of free amanitin to the RNA polymerase II.

Based on the obtained results, we proposed that at high/normal $\mathrm{pH}$ cyclic peptides were located at the outer leaflet of the bilayer. Triggered by $\mathrm{pH}$ drop the protonation of Glu residues enhanced peptide's hydrophobicity and induced partitioning of the peptides into the bilayer of the membrane. This assumption was further con- firmed by quenching of fluorescence of FITC-labelled asymmetric cyclic peptide by cell impermeable Trypan Blue (Fig. 5d). Trypan Blue is used to quench fluorescence of FITC located in the extracellular space $^{32}$. Cells treated with the FITC-labelled peptide at low $\mathrm{pH}$ followed by Trypan Blue quenching showed higher fluorescent signal on cells opposed to the cells treated with the FITC-labelled peptide at normal $\mathrm{pH}$ followed by Trypan Blue quenching. It indicates that at normal $\mathrm{pH}$ FITC is more exposed to extracellular space (to Trypan Blue) in contrast to low $\mathrm{pH}$ treatment. Since FITC fluorescence is a $\mathrm{pH}$-sensitive and significantly quenched at low $\mathrm{pH}(\mathrm{pH} 5.0-5.5)$ in endosomal compartment, we concluded that the FITC-labelled 
peptide was localized at the inner leaflet of the plasma membrane rather than in endosomes. Also, the cellular uptake of Alexa546-labelled $c\left[\mathrm{E}_{4} \mathrm{~W}_{5} \mathrm{C}\right]$ peptide at normal and low $\mathrm{pHs}$ in presence and absence of FBS was investigated (Fig. 5e). We observed statistically significant difference in cellular uptake of peptide at normal and low $\mathrm{pHs}$, and no reduction of the uptake in the presence of FBS.

Next we proceeded to animal studies to identify the lead peptide demonstrating best tumor targeting. The murine 4T1 xenograft model, which closely mimics stage IV of human breast cancer ${ }^{33,34}$, was used in our study. Small $4 \mathrm{~T} 1$ tumor (tumor volume $<150$ mm3) generates a significant level of lactate and serves as a good model of an aggressive, acidic tumor ${ }^{35}$. All peptides were covalently conjugated with Alexa546-malemide. The fluorescent constructs were given as a single IV injection, and at 4 hours after administration, animals were euthanized followed by necropsy. The mean fluorescence of tumor, muscle, kidney, liver and lungs were recorded and analyzed (Fig. 6). The least targeting was observed for Leu-containing peptide, $c(\mathrm{LE})_{4} \mathrm{CW}$. At the same time, the highest tumor targeting was monitored for linear peptide, $l\left(\mathrm{CW}(\mathrm{EW})_{4}\right)$, symmetric, $c\left[(\mathrm{WE})_{4} \mathrm{WC}\right]$, and asymmetric, $c\left[\mathrm{E}_{4} \mathrm{~W}_{5} \mathrm{C}\right]$, cyclic peptides.

To prove $\mathrm{pH}$-dependent tumor targeting of WE cyclic peptides we tested positivelycharged asymmetric cyclic peptide, $c\left[\mathrm{R}_{4} \mathrm{~W}_{5} \mathrm{C}\right]$, where Glu residues were replaced by $\mathrm{Arg}$ residues. This WR-peptide interacted with the lipid bilayer of the membrane at high $\mathrm{pH}$ (Figure S4) due to the presence of Trp residues, similar to WE-peptide. At the same time, it does not exhibit $\mathrm{pH}$-dependent changes in interaction with the lipid bilayer of membrane, thus it can serve as a $\mathrm{pH}$-insensitive control for $\mathrm{pH}$-sensitive WE-cyclic asymmetric peptide, $c\left[\mathrm{E}_{4} \mathrm{~W}_{5} \mathrm{C}\right]$. 
We performed side-by-side 4T1 tumor targeting and biodistribution investigation of asymmetric $\mathrm{pH}$-sensitive, $c\left[\mathrm{E}_{4} \mathrm{~W}_{5} \mathrm{C}\right]$, and $\mathrm{pH}$-insensitive, $c\left[\mathrm{R}_{4} \mathrm{~W}_{5} \mathrm{C}\right]$, peptides. A significant difference in tumor targeting was observed at all-time points after IV administration of the constructs (Figs 7a and S5). It resulted in a significant difference between tumor/organ ratios for $\mathrm{pH}$-sensitive and insensitive peptides (Fig. $7 \mathrm{~b}$ and Table S4). The accumulation of the $\mathrm{pH}$-insensitive peptide in tumor and other organs was very minimal and varied in the range of 0.8 to 1.6 values, which could be attributed to the passive diffusion with blood flow. We have introduced a novel class of cyclic peptides, which demonstrate $\mathrm{pH}$-sensitive interaction with lipid bilayer of membrane of liposomes, cultured cancer cells and tumors in animal model. We tested six cyclic peptides of three different cycle sizes, and different localization of Trp, Glu, Leu and Arg residues within the cycles. The size of investigated peptides is an optimal for the straightforward synthesis. The significantly smaller or larger sized cycles are more challenging to synthesize. The interaction of cyclic peptides with lipid bilayer of membrane has different mechanism compared to the action of linear $\mathrm{pH}$-sensitive peptides such as pHLIP peptides. Negatively charged Glu residues of cyclic peptides, especially asymmetric one, which showed the best $\mathrm{pH}-\mathrm{dependent} \mathrm{performance,} \mathrm{are} \mathrm{exposed} \mathrm{to} \mathrm{the} \mathrm{aqueous} \mathrm{solution} \mathrm{at} \mathrm{normal} \mathrm{pH}$. At the same time, indole rings of Trp residues most probably interact with the lipid headgroups (Figs 8 and S6). It was demonstrated previously that aromatic Trp residues have high affinity to lipid headgroups ${ }^{11,36-39}$. Our biophysical titration data indicate that $c\left[\mathrm{E}_{4} \mathrm{~W}_{5} \mathrm{C}\right]$ cyclic peptide partitions into the lipid bilayer at $\mathrm{pH}$. About $7.3 \mathrm{kcal} / \mathrm{mol}$ of free energy is released during the process (Figure S7), which indicates on strong interactions of the peptide with the membrane. The high affinity of the peptides to the cellular membranes at 
normal $\mathrm{pH}$ might explain long time of circulation in mice. When $\mathrm{pH}$ is lowered, Glu residues are protonated. The $\mathrm{pK}$ of Glu residue protonation in the vicinity of the hydrophobic membrane is higher compared to the $\mathrm{pK}$ in a solution. Protonation leads to the increase of hydrophobicity of the peptide, which promotes partitioning of the peptide into the bilayer. As a result, about $0.7 \mathrm{kcal} / \mathrm{mol}$ of additional free energy is released at low $\mathrm{pH}$ (Figure S7). This energy could be used to move cell-impermeable cargo, such as amanitin, across membrane and target acidic tumors. Because Trp residues have higher affinity to the headgroups region compared to the central hydrophobic part of the bilayer, the peptide is equilibrated in the regions of head-groups between inner and outer leaflets of the bilayer. We and others showed that $\mathrm{pH}$ equilibrates fast inside a liposome ${ }^{40,41}$. Thus, an equal amount of the peptide molecules is distributed between both leaflets of the liposomal membrane with low $\mathrm{pH}$ outside and inside of it (Figure S6). However, in the case of live cells, $\mathrm{pH}$ inside a cell is normal (7.2-7.4), while bulk extracellular $\mathrm{pH}$ is slightly lower $(6.5-6.8)^{42-44}$. However, the $\mathrm{pH}$ is at its lowest at the surfaces of cells ${ }^{9}$ and increases with distance from the cellular membrane, becoming normal in the vicinity of blood vessels $^{45}$. Recently, we were able to measure in vitro and in vivo $\mathrm{pH}$ in the vicinity of plasma membrane of cancer cells, the $\mathrm{pH}$ values drops to 6.0-6.5 at the surface of cancer cells $^{12}$. The most aggressive cancer cells are the most acidic. Thus, peptides reaching inner leaflet of the bilayer could expose their Glu residues to the cytoplasm, where they are expected to be de-protonated and became charged again. It would reduce the rate of the peptide diffusion back into the membrane and should lead to the shift of the equilibrium toward the accumulation of the peptides at inner leaflet of bilayer of the plasma membrane of cells (Fig. 8). 
Thus, cyclic peptides could be considered as a weak acid with multiple protonatable groups, which can diffuse across the bilayer. For weak acids, the intracellular-extracellular distribution, $C_{i} / C_{e}$, should be calculated according to the following equation:

$$
\frac{C_{i}}{C_{e}}=\frac{1+10^{p H_{i}-p K_{a}}}{1+10^{p H_{e}-p K_{a}}}
$$

where $\mathrm{pH}_{\mathrm{i}}$ and $\mathrm{pH}_{\mathrm{e}}$ are the intracellular and extracellular $\mathrm{pH}$ values, respectively. Since the have affinity to the membrane, we consider $C_{i}$ and $C_{e}$ as the concentrations of the peptide on inner and outer leaflets, respectively. We established the $\mathrm{pK}_{\mathrm{a}}$ of membrane partition for the asymmetric cyclic peptide, which equals to 5.7. The calculation shows that at $\mathrm{pH}_{\mathrm{e}}=7.4$ and $\mathrm{pH}_{\mathrm{i}}=7.2$ the concentration ratio at the inner and outer leaflets for asymmetric cyclic peptides is 0.6. However, the same ratio increases to $4.5,7.8$, and 10.9 if extracellular $\mathrm{pH}_{\mathrm{e}}$ would be $6.5,6.2$ and 6.0 , respectively. We assume that the symmetrical WE peptides have the same mechanism of action as an asymmetric peptide, however they have less favorable localization of Trp and Glu residues, which reduces their ability to accumulate at the inner leaflet of bilayer of cellular membranes and target acidic tumors. Leu-containing peptides are less advantageous due to their reduced affinity to the headgroup part of the bilayer and high affinity to the center of the membrane.

A novel class of $\mathrm{pH}$-sensitive cyclic peptides containing tryptophan and glutamic acid residues have potential applications for targeting tumors and translocation of polar cargo molecules across cellular membrane. These peptides might have application not only 
in targeting of acidic diseased tissue, they might find very interesting applications in cosmetics. It is well known that the natural skin surface $\mathrm{pH}$ is on average below $5^{46}$. Thus, topical application of short (8-10 residues long), very stable cyclic peptides might open an opportunity to tether various cosmetic and skin care products to the skin surface.

\section{METHODS}

Materials. The materials including Fmoc-L-amino acid building blocks, preloaded amino acids on 2-chlorotrityl resin as solid support, and 2-(1H-benzotriazol-1-yl)-1,1,3,3tetramethyluronium hexafluoro- phosphate (HBTU) used for coupling reagents were purchased from Chem-Impex Int'l Inc., Wood Dale, IL. Piperidine and $\mathrm{N}$ methylmorpholine were purchased from Sigma-Aldrich Chemical Co. (Milwaukee, WI). The other chemicals such as $N, N$-diisopropylethylamine (DIPEA), cleavage cocktail reagents trifluoroacetic acid (TFA), 1-hydroxy-7-azabenzotriazole (HOAt), N,N'diisopropylcarbodiimide (DIC), acetic acid (AcOH), 2,2,2-trifluoroethanol (TFE), anisole, thioanisole, ethanedithiol (EDT), and anhydrous solvents such as $N, N$-dimethylformamide (DMF), dichloromethane (DCM), hexane, acetic acid (AcOH), and 2,2,2-trifluoroethanol (TFE) were purchased from Fisher Scientific, Pittsburg, PA.

Methodology of Peptide Synthesis. In brief, the linear protected peptide was first assembled. Direct cleavage of peptide-attached resin in the presence of AcOH/TFE/DCM $(1: 2: 7 \mathrm{v} / \mathrm{v} / \mathrm{v})$ generated the linear peptide. Cyclization in dilute condition using DIC/HOAt in DMF/DCM solution for 12 hours, followed by the depro- tection of the side chain by using cleavage cocktail (TFA:thioanisole:anisole:EDT (90:5:2:3 v/v/v/v) afforded the 
cyclic peptide. The peptides were synthesized by employing the $N$-(9fluorenyl)methoxycarbonyl (Fmoc)-solid phase chemistry using PS3 automated peptide synthesizer (Rainin Instrument Co., Inc.) at room temperature. The peptide sequence was assembled on preloaded amino acid on 2-chlorotriyl resin using coupling, activating, and deprotecting reagents using HBTU, $N$-methylmorpholine $(0.4 \mathrm{M})$, and piperidine in DMF (20\% v/v), respectively. The amino acids in the peptide sequence were coupled using coupling reagents and activating reagent in DMF for 1 hour followed by washing with DMF 3 times. The deprotection was carried using piperidine (20\%, v/v) in DMF for 2 times, 10 minute for each time, followed by washing with DMF (3 times). The appropriate sequence of linear protected peptide was assembled using the synthesizer. $N$ - to $C$-terminal cyclization of peptide were achieved by cleavage of protected peptidyl resin by stirring the peptidyl resin in freshly prepared cleavage cocktail of AcOH/TFE/DCM (1:2:7, v/v/v) for 1 hour at room temperature followed by washing the resin with TFE:DCM $(2: 8 \mathrm{v} / \mathrm{v}, 2$ times). The collected filtrate was evaporated using a rotary evaporator followed by azeotropic removal of acetic acid by addition of hexane and dichloromethane to afford high viscous liquid or solid-protected linear peptide. The crude linear protected peptide was dissolved in excess of solvents DMF:DCM (4:1 v/v) followed by the addition of HOAt/DIC (1:1.1 equiv) for cyclization for $12-48$ hours confirmed by MALDI TOF-TOF mass spectrometry. The solvent was evaporated under high reduced pressure in a rotatory evaporator at $40-45^{\circ} \mathrm{C}$ to remove DMF. The final cleavage of side chain protection from the peptide were carried out after confirming the peptide cyclization by MALDI mass spectrometer data by shaking the cyclized peptide mixture in cleavage cocktail reagent $\mathrm{R}$ (TFA/thioanisole/anisole/EDT (90:5:2:3 v/v/v/v, 10-15 mL) for 2-4 hours followed by 
pre- cipitation of peptide using cold ether, centrifugation at $2500 \mathrm{rpm}$ and washing with excess of cold ether at $25{ }^{\circ} \mathrm{C}$ for $5 \mathrm{~min}$. The crude peptide was purified with semi preparative reversed phase high performance liquid chro- matography (RP-HPLC) by using Hitachi L-2455 on a C18 Phenomenex Prodigy reversed-phase column (10 $\mu$ m, 250 $\mathrm{cm} \times 21.2 \mathrm{~cm}$ ). The pure peptide was eluted at $15.0 \mathrm{~mL} / \mathrm{min}$ using a gradient of binary solvent system using water and acetonitrile with $0.1 \%$ TFA for $0-100 \%$ over $60 \mathrm{~min}$. The pure collected peptide fractions were pooled and lyophilized to provide solid powder in purity of $\geq 98 \%$. All peptides were characterized by using high resolution time of flight AXIMA-performance MALDI TOF-TOF mass spectrometer (Shimadzu). The above mentioned protocol was applied for the synthesis of all cyclic peptides. The concentration of the peptides was calculated spectrophotometrically by measuring absorbance at $280 \mathrm{~nm}$. The extinction coefficients, $\varepsilon_{280}, \mathrm{M}^{-1} \mathrm{~cm}-1$, for the peptides are the following: $c\left[(\mathrm{WE})_{4} \mathrm{WC}\right]=28,000 ; c\left[(\mathrm{WE})_{5} \mathrm{WC}\right]=33,600 ; c\left[(\mathrm{WE})_{3} \mathrm{WC}\right]=2,400 ; c\left[(\mathrm{LE})_{4} \mathrm{WC}\right]=$ 5,$600 ; c\left[\mathrm{E}_{4} \mathrm{~W}_{5} \mathrm{C}\right]=28,000 ; l\left(\mathrm{CW}(\mathrm{EW})_{4}\right)=28,000$.

Synthesis of Cyclic Peptides. The linear peptide sequence was synthesized on PS3 automated synthesizer as described above in the scale of 0.3 mmol. H-Trp(Boc)-2chlorotrityl resin ( $384.6 \mathrm{mg}, 0.3 \mathrm{mmol}, 0.78 \mathrm{mmol} / \mathrm{g}$ ) was swelled in DMF, followed by coupling and deprotection cycles to assemble respective amino acids on the pep- tidyl resin using respective amino acids, such as Fmoc-Glu(OtBu)-OH (382.9 mg, 0.9 mmol), FmocTrp(Boc)-OH (473.9 mg, 0.9 mmol), Fmoc-Cys(Trt)-OH (527.1 mg, 0.9 mmol), and HBTU (341 mg, $0.9 \mathrm{mmol}$ ) as the coupling reagent. Fmoc group of $N$-terminal in the peptidyl resin was removed using deprotection cycle, and the resin was transferred to 100 $\mathrm{mL}$ round bottom flask. The linear protected peptide was cleaved by shaking peptidyl resin 
in cleavage cocktail AcOH/TFE/DCM (1:2:7 v/v/v, $50 \mathrm{~mL})$ for 1 hour followed by washing the resin using TFE:DCM (2:8 v/v, $10 \mathrm{~mL}, 2$ times). The combined filtrate was evaporated to dryness with the subsequently addition of hex- ane $(50 \mathrm{~mL} \times 3)$ and $\mathrm{DCM}(10 \mathrm{~mL} \times 3)$ to remove acetic acid, which provided solid white crude protected peptide ready for cyclization. The cyclization was carried out by dissolving the solid peptide in anhydrous DMF/DCM (250 mL, 4:1 v/v) under nitrogen using DIC (155.0 $\mu \mathrm{L}, 0.99 \mathrm{mmol})$ and HOAt $(122.5 \mathrm{mg}, 0.9 \mathrm{mmol})$ with stirring at room temperature for 24 hours. The cyclized product was confirmed by taking a small aliquot of the reaction mixture and cleavage with reagent $\mathrm{R}$ and using MALDI. After cyclization was confirmed, the solvents were evap- orated under high reduced pressure, and the side chain protections were removed by addition of cleavage cock- tail of reagent R, TFA/thioanisole/anisole/EDT (15 mL, 90:5:2:3 v/v/v/v), and shaking at room temperature for 3 hours. The peptides were precipitated, centrifuged, and washed with cold diethyl ether to yield the crude white solid peptide. The peptides were dissolved in $\mathrm{H}_{2} \mathrm{O} / \mathrm{CH}_{3} \mathrm{CN}$ with $0.1 \%$ TFA and purified using RP HPLC. Then, the pure fractions were collected, concentrated and lyophilized to afford pure solid white powder of $c\left[(\mathrm{WE})_{4} \mathrm{WC}\right]$ peptide. MALDI-TOF $(\mathrm{m} / \mathrm{z})\left[\mathrm{C}_{78} \mathrm{H}_{83} \mathrm{~N}_{15} \mathrm{O}_{18} \mathrm{~S}\right]$ : calcd, 1549.6; found, $1572.3[\mathrm{M}+\mathrm{Na}]+; c\left[(\mathrm{WE})_{5} \mathrm{WC}\right]$ : MALDI-TOF $(\mathrm{m} / \mathrm{z})\left[\mathrm{C}_{94} \mathrm{H}_{100} \mathrm{~N}_{18} \mathrm{O}_{22} \mathrm{~S}\right]$ : calcd, 1864.7; found, $1865.4[\mathrm{M}+\mathrm{H}]+; c\left[(\mathrm{WE})_{3} \mathrm{WC}\right]$ : MALDI-TOF (m/z) $\left[\mathrm{C}_{62} \mathrm{H}_{66} \mathrm{~N}_{12} \mathrm{O}_{14} \mathrm{~S}\right]$ : calcd, 1234.5; found, 1234.7 [M]+; $c\left[(\mathrm{LE})_{4} \mathrm{WC}\right]$ : MALDI-TOF (m/z) $\left[\mathrm{C}_{58} \mathrm{H}_{87} \mathrm{~N}_{11} \mathrm{O}_{18} \mathrm{~S}\right]$ : calcd, 1257.6; found, $1258.2[\mathrm{M}+\mathrm{H}]+; c\left[\mathrm{E}_{4} \mathrm{~W}_{5} \mathrm{C}\right]$ : MALDI-TOF $(\mathrm{m} / \mathrm{z})\left[\mathrm{C}_{78} \mathrm{H}_{83} \mathrm{~N}_{15} \mathrm{O}_{18} \mathrm{~S}\right]$ : calcd, 1549.6; found, 1549.1 [M]+. A similar procedure was used for the synthesis of $c\left[\mathrm{R}_{4} \mathrm{~W}_{5} \mathrm{C}\right]$ except using Fmoc-Arg(Pbf)-OH instead of Fmoc-Glu(OtBu)-OH. $c\left[\mathrm{R}_{4} \mathrm{~W}_{5} \mathrm{C}\right]$ : MALDI-TOF (m/z) [ $\left.\mathrm{C}_{82} \mathrm{H}_{103} \mathrm{~N}_{27} \mathrm{O}_{10} \mathrm{~S}\right]$ : calcd, 1657.8; found, 1658.5 [M + H]+. 
Synthesis of $l\left(\mathbf{C W}(\mathbf{E W})_{4}\right)$. The linear peptide was assembled as described above using H$\operatorname{Trp}($ Boc)- 2-chlorotrityl resin $(384.6 \mathrm{mg}, 0.3 \mathrm{mmol} 0.78 \mathrm{mmol} / \mathrm{g}$ ) in reaction vessel. The peptide sequence was assem- bled using the appropriate amino acid building blocks FmocGlu(OtBu)-OH (382.9 mg, 0.9 mmol), Fmoc-Trp(Boc)-OH (473.9 mg, 0.9 mmol), FmocCys(Trt)-OH (527.1 mg, $0.9 \mathrm{mmol})$, and HBTU (0.9 mmol, $341 \mathrm{mg})$ as the coupling reagent. The final $N$-terminal Fmoc group was deprotected. The peptide was cleaved from the resin and side chain was deprotected by reaction of the peptidyl resin with freshly prepared cleavage cocktail reagent R, TFA/thioanisole/anisole/EDT (15 mL, 90:5:2:3 $\mathrm{v} / \mathrm{v} / \mathrm{v} / \mathrm{v})$, for 3 hours at room temperature. The linear protected peptide was precipitated, centrifuged, and purified by using RP-HPLC as mentioned above to yield $l\left(\mathrm{CW}(\mathrm{EW})_{4}\right)$. MALDI-TOF (m/z) [ $\left.\mathrm{C}_{78} \mathrm{H}_{85} \mathrm{~N}_{15} \mathrm{O}_{19} \mathrm{~S}\right]$ : calcd, 1567.6; found, $1606.1[\mathrm{M}+\mathrm{K}]+$.

Labeling of Peptides with Fluorescent Dyes. Peptides were conjugated with Alexa546and Fluorescein- 5-maleimide (Life Technologies) in DMF at a ratio of 1.2:1 and incubated at room temperature for about 6 hours and then at $4{ }^{\circ} \mathrm{C}$ until the conjugation reaction was completed. $50 \mathrm{mM}$ of sodium phosphate/150 mM NaCl buffer $\mathrm{pH} 7.0$ (saturated with argon) was added to the reaction mixture (1/10 of the total volume). The reaction progress was monitored by the reverse phase HPLC. The products were purified by the reverse phase HPLC, lyophilized and characterized by SELDI-TOF mass spectrometry. The concentration of the constructs was deter- mined by absorbance at 556 and $494 \mathrm{~nm}$ using molar extinction coefficients of $93,000 \mathrm{M}-1 \cdot \mathrm{cm}-1$ for Alexa546 and $68,000 \mathrm{M}-1 \cdot \mathrm{cm}-1$ for Fluorescein-5 (FITC).

Synthesis of Peptide-Amanitin Constructs. We conjugated symmetric $c\left[(\mathrm{WE})_{4} \mathrm{WC}\right]$ and asymmetric $c\left[\mathrm{E}_{4} \mathrm{~W}_{5} \mathrm{C}\right]$ peptides with alpha-amanitin (Sigma-Aldrich) via cleavable S-S 
bond. Furthermore, asymmetric $c\left[\mathrm{E}_{4} \mathrm{~W}_{5} \mathrm{C}\right]$ peptide was labelled with amanitin via noncleavable bond. The conjugation scheme consisted of 2 steps: i) $\mathrm{OH}$ group of amanitin was conjugated with NHS group of the cleavable crosslinker, SPDP, $N$-succinimidyl 3-(2pyridyl-dithio)-propionate or the non-cleavable crosslinker, GMBS, $N-\gamma$ maleimidobutyryl-oxysuccinimide ester (both crosslinkers were from (Thermo Scientific) in $50 \mathrm{mM}$ sodium phosphate $/ 150 \mathrm{mM} \mathrm{NaCl}$ buffer $\mathrm{pH} 8.0$ at a ratio $1: 20$ at room temperature for 4 hours to get SPDP-amanitin or GMBS-amanitin. The products were purified by the reverse phase HPLC on Zorbax SB-C18 column $(9.4 \times 250 \mathrm{~mm}$, 5-Micron). SPDP-amanitin was eluted using a gradient: 0-25\%, $40 \mathrm{~min}$ (water and acetonitrile with $0.05 \%$ TFA $)$ and lyophilized. $c\left[(\mathrm{WE})_{4} \mathrm{WC}\right]$ and $c\left[\mathrm{E}_{4} \mathrm{~W}_{5} \mathrm{C}\right]$ peptides were incubated with SPDP-amanitin or GMBS-amanitin in $100 \mathrm{mM}$ sodium phosphate/150 mM NaCl buffer $\mathrm{pH} 7.8$ (saturated with argon) at a ratio 1:1 at room temperature for 1 hour to obtain amanitin-SPDP-peptides or amanitin-GMBS-peptide, respectively. The products were purified by the reverse phase HPLC on Zorbax SB-C18 column $(9.4 \times 250 \mathrm{~mm}$, 5-Micron) using gradient $10-55 \%, 40 \mathrm{~min}$ (water and acetonitrile with $0.05 \%$ TFA). The products were lyophilized and characterized by SELDI-TOF mass-spectrometry. The calculated and obtained masses for the peptides were the following: $c\left[\mathrm{E}_{4} \mathrm{~W}_{5} \mathrm{C}\right]-\mathrm{SPDP}$-amanitin: SELDI$\mathrm{TOF}(\mathrm{m} / \mathrm{z})\left[\mathrm{C}_{120} \mathrm{H}_{139} \mathrm{~N}_{25} \mathrm{O}_{33} \mathrm{~S}_{3}\right]$ : calcd, 2553.9; found 2555.5 [M + H]+; $c\left[\mathrm{E}_{4} \mathrm{~W}_{5} \mathrm{C}\right]-\mathrm{GMBS}-$ amanitin: SELDI-TOF (m/z) $\left[\mathrm{C}_{125} \mathrm{H}_{144} \mathrm{~N}_{26} \mathrm{O}_{35} \mathrm{~S}_{2}\right]$ : calcd, 2632.9; found $2634.6[\mathrm{M}+\mathrm{H}]+$, and $2657.8[\mathrm{M}+\mathrm{Na}]+; \quad c\left[(\mathrm{WE})_{4} \mathrm{WC}\right]-\mathrm{SPDP}-$ amanitin: $\quad$ SELDI-TOF $\quad(\mathrm{m} / \mathrm{z})$ $\left[\mathrm{C}_{120} \mathrm{H}_{139} \mathrm{~N}_{25} \mathrm{O}_{33} \mathrm{~S}_{3}\right]$ : calcd, 2553.9; found $2554.5[\mathrm{M}+1]+$.

Liposome Preparation. Large unilamellar vesicles (LUVs) were prepared by extrusion. POPC, 1-palmitoyl-2-oleoyl-sn-glycero-3-phosphocholine (Avanti Polar Lipids), or a 
mixture of POPC with $0.5 \%$ of 18:1 NBD-PE, 1,2-dioleoyl-sn-glycero-3phosphoethanolamine-N-7-nitro-2-1,3-benzoxadiazol-4-yl ammonium salt (Avanti Polar Lipids) were dissolved in chloroform, desolvated on a rotary evaporator, and dried under high vacuum for several hours. The phospholipid film was then rehydrated in $10 \mathrm{mM}$ phosphate buffer $\mathrm{pH} 8.0$, vortexed until the lipid bilayer was completely dissolved, and repeatedly (15-21 times) extruded through the membranes with $50 \mathrm{~nm}$ pore sizes to obtain LUVs.

Steady-State Fluorescence and CD. Freshly prepared peptides and POPC vesicles were mixed to have $5 \mu \mathrm{M}$ of a peptide and $1.25 \mathrm{mM}$ of lipids in the final solution. Steady-state fluorescence measurements were carried out on a PC1 spectrofluorometer (ISS, Inc.) under temperature control at $25{ }^{\circ} \mathrm{C}$. Tryptophan fluorescence was excited at $280 \mathrm{~nm}$ (there is no Phe or Tyr in the peptides) and recorded with the excitation and emission slits set at $1 \mathrm{~nm}$. The polarizers in the excitation and emission paths were set at the "magic" angle $\left(54.7^{\circ}\right.$ from the vertical orientation) and vertically $\left(0^{\circ}\right)$, respectively. Steady state $\mathrm{CD}$ measurements were carried out in MOS 450 spectropolarimeter (Bio-Logic, Inc.) with the same concentrations of peptide and lipids used in fluorescence measurements.

pH-Dependence. $\mathrm{pH}$-dependent partitioning of the peptides into a lipid bilayer of the membrane was investigated by the shift of the position of the fluorescence spectral maximum for the peptides in the presence POPC liposomes induced by a drop of $\mathrm{pH}$ from 8 to 2.5 by the addition of $\mathrm{HCl}$. The peptides were incubated overnight with 50 -nm POPC liposomes (final concentration of the peptides and POPC in solution was $5 \mu \mathrm{M}$ and $1 \mathrm{mM}$, respectively), and $\mathrm{pH}$ decrease was achieved by the addition of aliquots of $4,2,1$ and 0.1 M HCl. $\mathrm{pH}$ was measured by micro-electrode probe (Thermo Electron Corporation, Orion 
Ross Micro $\mathrm{pH}$ electrode). Fluorescence spectra were recorded at each $\mathrm{pH}$ value. The spectra were analyzed by the decomposition algorithms using on-line PFAST toolkit ${ }^{47}$ (Protein Fluorescence and Structural Toolkit: http://pfast.phys.uri.edu/) to establish the position of the emission maximum. Finally, the positions of the fluorescence spectral maxima $\left(\lambda_{\max }\right)$ were plotted versus $\mathrm{pH}$, and the Henderson-Hasselbalch equation was used to fit the data (using Origin 8.5 software):

$$
\lambda_{\max }=\lambda_{1_{\max }}+\frac{\left(\lambda_{1_{\max }}-\lambda_{2 \max }\right.}{1+10^{(p H-p k a)}}
$$

where $\lambda_{1 \max }$ and $\lambda_{2 \max }$ are the beginning and the end of the transition, respectively, and $p K a$ - is the midpoint of the transition.

Titration. Samples containing $5 \mu \mathrm{M}$ of peptides at $\mathrm{pH} 8$ and $\mathrm{pH} 3$, and varying concentrations of lipids of the $50 \mathrm{~nm}$ POPC liposomes were prepared. The fluorescence spectra of peptides in all samples were measured at $280 \mathrm{~nm}$ excitation at $25^{\circ} \mathrm{C}$. A series of POPC blanks with the same concentrations of lipids were measured with the same instrument settings and were subtracted from the corresponding fluorescence spectra of peptides in the presence of POPC. The areas under the emission spectra were calculated and the values were normalized to the first point (the emission of the peptide in the absence of POPC). The titration data were fitted by the peptide-membrane partition model to calculate the mole-fraction partition coefficient, $\mathrm{K}$

$$
F=F_{0}+\Delta F \frac{K \cdot C_{l i p}}{W+K \cdot C_{l i p}}
$$


$F_{0}$ is the fluorescence intensity at zero concentration of lipids (in our case $F_{0}=1$ ); $\Delta F$ if the fluorescence increase in the result of the titration with lipids; $C_{\text {lipids }}$ is the concentration of lipids; $W$ is the molar concentration of water $(55.3 \mathrm{M})$. Nonlinear least squares curve fitting procedure using Levenberg-Marquardt algorithm was implemented in Origin 8.5.0 SR1. The Gibbs free energy $(\Delta G)$ was calculated according to the equation:

$$
\Delta G=-R T \cdot \ln (K)
$$

where $R$ is the gas constant and $T$ is the temperature in Kelvin.

Dual Quenching. POPC liposomes without and with $10 \%$ of the lipids replaced by 10 doxylnonadecane (10-DN) (Avanti Polar Lipids) were prepared in $10 \mathrm{mM}$ citratephosphate buffer $\mathrm{pH}$ 8.0. Peptides and POPC liposomes were mixed to generate final concentrations of $7 \mu \mathrm{M}$ peptide and $2.1 \mathrm{mM}$ POPC without and with 10-DN. In some of the samples, the $\mathrm{pH}$ was lowered to $\mathrm{pH} 4$ by addition of aliquot of $2 \mathrm{M}$ citric acid, and other samples were kept at $\mathrm{pH}$ 8. Quencher, acrylamide (Sigma-Aldrich), was added to the samples of POPC liposomes containing no 10-DN, to have final concentration of $235 \mathrm{mM}$ acrylamide. Concentration of peptides in all samples was kept constant. To observe quenching of tryptophan fluorescence by 10-DN or acrylamide, the tryptophan fluorescence was recorded as described above. The appropriate POPC blanks were measured and subtracted from the measured spectra before analysis. The percentage of quenching was calculated.

NBD-FRET. First, symmetrically NBD-labelled POPC liposomes containing $0.5 \%$ of 
NBD-PE were prepared. Next, $1.2 \mathrm{~mL}$ of $6 \mathrm{mM}$ of symmetrically NBD-labelled POPC liposomes were incubated with $150 \mu \mathrm{L}$ of $1 \mathrm{M}$ freshly prepared membrane-impermeable dithionite in buffer at $\mathrm{pH} 8.0$ to chemically deactivate of NDB only at the outer leaflet of the bilayer and obtain asymmetrically NBD-labelled POPC liposomes. The decrease of NBD fluorescence occurring in the result of quenching of NBD by dithionite was monitored at the excitation of $463 \mathrm{~nm}$ and emission at $530 \mathrm{~nm}$. The dithionite quenching led to the reduction of about $60-65 \%$ of NBD fluorescence signal corresponding to the quenching of NBD at the outer leaflet of the bilayer. Next, POPC solution was passed through a G-10 sephadex (Sigma-Aldrich) fast spin column to remove the excess of dithionite. Asymmetrically labelled POPC liposomes were incubated with peptides at concentrations indicated above, and FRET from tryptophan residues to NBD at the inner leaflet of bilayer was monitored at $280 \mathrm{~nm}$ excitation wavelength, and emission was recorded from 310 to $580 \mathrm{~nm}$.

Cell Lines. Human cervix adenocarcinoma (HeLa) cells were acquired from the American Type Culture Collection. Cells were cultured in Dulbecco's Modified Eagle's Medium (DMEM) supplemented with $10 \%$ fetal bovine serum (FBS), $10 \mu \mathrm{g} / \mathrm{mL}$ of ciprofloxacin in a humidified atmosphere of $5 \% \mathrm{CO}_{2}$ and $95 \%$ air at $37{ }^{\circ} \mathrm{C}$.

Cytotoxic Assay. HeLa cells were loaded in the wells of 96 -well plates $(\sim 5,000$ cells per well) and incubated overnight. Growth medium was replaced with the medium without FBS pH 6.2 or $\mathrm{pH} 7.4$ containing increasing amounts of constructs $(5,10,20$, and $40 \mu \mathrm{M})$. The same volume of DMEM medium supplemented with 20\% FBS, pH 7.4 was added after 2 hours of treatment. After 48 hours of incubation a colorimetric reagent (CellTiter $96 \mathrm{AQ}_{\text {ueous }}$ One Solution Assay, Promega) was added for 1 hour followed by measuring 
absorbance at $490 \mathrm{~nm}$ to assess cell viability. All samples were prepared in triplicate.

Proliferation Assay. HeLa cells were loaded in the wells of 96-well plates $(\sim 5,000$ cells per well) and incubated overnight. Growth medium was replaced with the medium without FBS pH 6.0 or $\mathrm{pH} 7.4$ containing increasing amounts of peptide-amanitin construct $(0.5$, $1,2$, and $4 \mu \mathrm{M})$. The construct was removed from cells after 3 hours. After 48 hours of cell incubation in standard growth medium, a colorimetric reagent (Cell Titer $96 \mathrm{AQ}_{\text {ueous }}$ One Solution Assay, Promega) was added for 1 hour followed by measurements of absorbance at $490 \mathrm{~nm}$ to assess cell viability. All samples were prepared in triplicate.

Fluorescent Microscopy. HeLa cells (8,000 cells per dish) were seeded in the center of a 35-mm dish with a 10-mm glass-bottom window coated with collagen (MatTek Corp). Next day cells were incubated with $5 \mu \mathrm{M}$ of FITC-labelled $c\left[\mathrm{E}_{4} \mathrm{~W}_{5} \mathrm{C}\right]$ peptide for $30 \mathrm{~min}$ in DMEM medium without FBS at pH 7.4 or 6.2. Cells were washed 5 times at $\mathrm{pH} 7.4$ and 0.4\% Trypan Blue was added for $5 \min (1 / 10$ of the total volume). Fluorescent images were acquired with a Retiga CCD camera (Qimaging) mounted to an inverted Olympus IX71 microscope (Olympus America, Inc.).

Cellular uptake. HeLa cells $(150,000$ cells per sample of total volume of $500 \mu \mathrm{L})$ were incubated with $5 \mu \mathrm{M}$ of Alexa546-labelled peptide in Leibovitz's (L15) medium at pH 6.2 and 7.4 in the presence or absence of $4 \%$ of fetal bovine serum (FBS) for 6 hours, followed by extensive washing with L15 medium. The cellular uptake of the constructs was measured by fluorescent signal from cells counted using cellometer (Cellometer Vision CBA, Nexcelom). $4 \%$ of FBS was used to mimic the amount of albumin in whole blood, which contains $45 \%$ of red blood cells, white blood cells and platelets suspended in plasma (about $55 \%$ of volume). Plasma is composed of about $92 \%$ of water, $1 \%$ of vitamins, 
sugars, salts, minerals, hormones and $7 \%$ of vital proteins including albumin, gamma globulins and other clotting factor. Thus, the amount of albumin in whole blood is expected to be less than $3.6 \%$.

Ex Vivo Fluorescence Imaging. All animal studies were conducted according to the animal protocol AN04-12-011 approved by the Institutional Animal Care and Use Committee at the University of Rhode Island, in compliance with the principles and procedures outlined by NIH for the Care and Use of Animals. 4T1 breast tumors were established by subcutaneous injection of $4 \mathrm{~T} 1$ cells $(8 \times 105$ cells $/ 0.1 \mathrm{~mL} / \mathrm{flank})$ in the right flank of adult female BALB/c mice (about 19-22 g weight) obtained from Harlan Laboratories. When tumors reached about $6 \mathrm{~mm}$ in diameter single tail vein injections of $100 \mu \mathrm{l}$ of $40 \mu \mathrm{M}$ Alexa546-peptides were performed. Control mice bearing tumor used to establish an auto fluorescence signal did not receive fluorescent peptides. At 4 hours postinjection euthanization and necropsy was performed followed by ex vivo imaging of tumor, kidneys, liver, lungs and muscle. Mean fluorescence intensity of tumor and organs was calculated using Kodak software.

Statistical analysis. Statistically significant differences were determined by two-tailed unpaired Student's t-test ( $\mathrm{p}$-level $<0.05$ was taken as significant).

\section{REFERENCES}

1.Pezzulo, A. A. et al. Reduced airway surface $\mathrm{pH}$ impairs bacterial killing in the porcine cystic fibrosis lung. Nature 487, 109-113, doi: 10.1038/nature11130 (2012).

2.Paschen, W., Djuricic, B., Mies, G., Schmidt-Kastner, R. \& Linn, F. Lactate and pH in 
the brain: association and dissociation in different pathophysiological states. $J$ Neurochem 48, 154-159 (1987).

3.Kedika, R. R., Souza, R. F. \& Spechler, S. J. Potential anti-inflammatory effects of proton pump inhibitors: a review and discussion of the clinical implications. Dig Dis Sci 54, 2312-2317, doi: 10.1007/s10620-009-0951-9 (2009).

4.Warburg, O., Wind, F. \& Negelein, E. The metabolism of tumors in the body. J Gen Physiol 8, 519-530 (1927).

5.Gillies, R. J., Robey, I. \& Gatenby, R. A. Causes and consequences of increased glucose metabolism of cancers. $J$ Nucl Med 49 Suppl 2, 24S-42S, doi: 10.2967/jnumed.107.047258 (2008).

6.Newell, K., Franchi, A., Pouyssegur, J. \& Tannock, I. Studies with glycolysis-deficient cells suggest that production of lactic acid is not the only cause of tumor acidity. Proc Natl Acad Sci USA 90, 1127-1131 (1993).

7.Swietach, P., Vaughan-Jones, R. D. \& Harris, A. L. Regulation of tumor $\mathrm{pH}$ and the role of carbonic anhydrase 9. Cancer Metastasis Rev 26, 299-310, doi: 10.1007/s10555-0079064-0 (2007).

8.Ihnatko, R. et al. Extracellular acidosis elevates carbonic anhydrase IX in human glioblastoma cells via transcriptional modulation that does not depend on hypoxia. Int $J$ Oncol 29, 1025-1033 (2006).

9.Chiche, J., Brahimi-Horn, M. C. \& Pouyssegur, J. Tumour hypoxia induces a metabolic shift causing acidosis: a common feature in cancer. $J$ Cell Mol Med 14, 771-794, doi: 10.1111/j.1582-4934.2009.00994.x (2010). 
10. Harris, T. K. \& Turner, G. J. Structural basis of perturbed pKa values of catalytic groups in enzyme active sites. IUBMB Life 53, 85-98, doi: 10.1080/15216540211468 (2002).

11. Johansson, A. C. \& Lindahl, E. Amino-acid solvation structure in transmembrane helices from molecular dynamics simulations. Biophys $J$ 91, 4450-4463, doi: 10.1529/biophysj.106.092767 (2006).

12. Anderson, M., Moshnikova, A., Engelman, D. M., Reshetnyak, Y. K. \& Andreev, O. A. Probe for the measurement of cell surface $\mathrm{pH}$ in vivo and ex vivo. Proc Natl Acad Sci USA, doi: 10.1073/pnas.1608247113 (2016).

13. Karanth, H. \& Murthy, R. pH-Sensitive liposomes-principle and application in cancer therapy. Journal of pharmacy and pharmacology 59, 469-483 (2007).

14. Chu, C.-J., Dijkstra, J., Lai, M.-Z., Hong, K. \& Szoka, F. C. Efficiency of cytoplasmic delivery by $\mathrm{pH}$-sensitive liposomes to cells in culture. Pharmaceutical research 7, 824-834 (1990).

15. Subbarao, N. K., Parente, R. A., Szoka Jr, F. C., Nadasdi, L. \& Pongracz, K. The pH-dependent bilayer destabilization by an amphipathic peptide. Biochemistry 26, 29642972 (1987).

16. Poon, Z., Chang, D., Zhao, X. \& Hammond, P. T. Layer-by-layer nanoparticles with a $\mathrm{pH}$-sheddable layer for in vivo targeting of tumor hypoxia. ACS nano 5, 42844292 (2011).

17. Okada, S. et al. Ratiometric MRI sensors based on core-shell nanoparticles for quantitative $\mathrm{pH}$ imaging. Adv Mater 26, 2989-2992, doi: 10.1002/adma.201305018 
18. Liu, K. C. \& Yeo, Y. Zwitterionic chitosan-polyamidoamine dendrimer complex nanoparticles as a pH-sensitive drug carrier. Mol Pharm 10, 1695-1704, doi: 10.1021/mp300522p (2013).

19. Nwe, K., Huang, C. H. \& Tsourkas, A. Gd-labeled glycol chitosan as a pHresponsive magnetic resonance imaging agent for detecting acidic tumor microenvironments. J Med Chem 56, 7862-7869, doi: 10.1021/jm4012565 (2013).

20. Andreev, O. A., Engelman, D. M. \& Reshetnyak, Y. K. Targeting diseased tissues by pHLIP insertion at low cell surface pH. Front Physiol 5, 97, doi: 10.3389/fphys.2014.00097 (2014).

21. Katsara, M. et al. Round and round we go: cyclic peptides in disease. Curr Med Chem 13, 2221-2232 (2006).

22. Mandal, D., Nasrolahi Shirazi, A. \& Parang, K. Self-assembly of peptides to nanostructures. Org Biomol Chem 12, 3544-3561, doi: 10.1039/c4ob00447g (2014).

23. Mandal, D., Nasrolahi Shirazi, A. \& Parang, K. Cell-penetrating homochiral cyclic peptides as nuclear-targeting molecular transporters. Angew Chem Int Ed Engl 50, 96339637, doi: 10.1002/anie.201102572 (2011).

24. Nasrolahi Shirazi, A. et al. Surface decorated gold nanoparticles by linear and cyclic peptides as molecular transporters. Mol Pharm

25. 10, 3137-3151, doi: 10.1021/mp400199e (2013). Reshetnyak, Y. K., Koshevnik, Y. \& Burstein, E. A. Decomposition of protein tryptophan fluorescence spectra into log- 
normal components. III. Correlation between fluorescence and microenvironment parameters of individual tryptophan residues. Biophys $J$ 81, 1735-1758, doi: 10.1016/S0006-3495(01)75825-0 (2001).

26. Reshetnyak, Y. K., Segala, M., Andreev, O. A. \& Engelman, D. M. A monomeric membrane peptide that lives in three worlds: in solution, attached to, and inserted across lipid bilayers. Biophys J 93, 2363-2372, doi: 10.1529/biophysj.107.109967 (2007).

27. Roy, R. S. et al. Peptide hairpins with strand segments containing alpha- and betaamino acid residues: cross-strand aromatic interactions of facing Phe residues. Biopolymers 80, 787-799, doi: 10.1002/bip.20294 (2005).

28. Caputo, G. A. \& London, E. Using a novel dual fluorescence quenching assay for measurement of tryptophan depth within lipid bilayers to determine hydrophobic alphahelix locations within membranes. Biochemistry 42, 3265-3274, doi: 10.1021/bi0266961 (2003).

29. McIntyre, J. C. \& Sleight, R. G. Fluorescence assay for phospholipid membrane asymmetry. Biochemistry 30, 11819-11827 (1991).

30. Chafin, D. R., Guo, H. \& Price, D. H. Action of alpha-amanitin during pyrophosphorolysis and elongation by RNA polymerase II. J Biol Chem 270, 1911419119 (1995).

31. Moshnikova, A., Moshnikova, V., Andreev, O. A. \& Reshetnyak, Y. K. Antiproliferative effect of pHLIP-amanitin. Biochemistry 52, 1171-1178, doi: 10.1021/bi301647y (2013).

32. Nuutila, J. \& Lilius, E. M. Flow cytometric quantitative determination of ingestion 
by phagocytes needs the distinguishing of overlapping populations of binding and ingesting cells. Cytometry A 65, 93-102, doi: 10.1002/cyto.a.20139 (2005).

33. Tao, K., Fang, M., Alroy, J. \& Sahagian, G. G. Imagable 4T1 model for the study of late stage breast cancer. BMC Cancer 8, 228, doi: 10.1186/1471-2407-8-22814712407-8-228 (2008).

34. Eckhardt, B. L. et al. Genomic analysis of a spontaneous model of breast cancer metastasis to bone reveals a role for the extracellular matrix. Mol Cancer Res 3, 1-13 (2005).

35. Serganova, I. et al. Metabolic imaging: a link between lactate dehydrogenase A, lactate, and tumor phenotype. Clin Cancer Res 17, 6250-6261, doi: 10.1158/10780432.CCR-11-0397 (2011).

36. Killian, J. A. \& von Heijne, G. How proteins adapt to a membrane-water interface. Trends Biochem Sci 25, 429-434 (2000).

37. White, S. H. \& Wimley, W. C. Membrane protein folding and stability: physical principles. Аппи Rev Biophys Biomol Struct 28, 319-365, doi: 10.1146/annurev.biophys.28.1.319 (1999).

38. van der Wel, P. C. et al. Tryptophan-anchored transmembrane peptides promote formation of nonlamellar phases in phosphatidylethanolamine model membranes in a mismatch-dependent manner. Biochemistry 39, 3124-3133 (2000).

39. van der Wel, P. C., Reed, N. D., Greathouse, D. V. \& Koeppe, R. E. 2nd. Orientation and motion of tryptophan interfacial anchors in membrane-spanning peptides. Biochemistry 46, 7514-7524, doi: 10.1021/bi700082v (2007). 
40. Karabadzhak, A. G. et al. Modulation of the pHLIP transmembrane helix insertion pathway. Biophys J 102, 1846-1855, doi: 10.1016/j.bpj.2012.03.021 (2012).

41. Elamrani, K. \& Blume, A. Effect of the lipid phase transition on the kinetics of $\mathrm{H}+/ \mathrm{OH}-$ diffusion across phosphatidic acid bilayers. Biochim Biophys Acta 727, 22-30 (1983).

42. Gerweck, L. E. \& Seetharaman, K. Cellular pH gradient in tumor versus normal tissue: potential exploitation for the treatment of cancer. Cancer Res 56, 1194-1198 (1996).

43. Raghunand, N. et al. Plasmalemmal pH-gradients in drug-sensitive and drugresistant MCF-7 human breast carcinoma xenografts measured by 31P magnetic resonance spectroscopy. Biochem Pharmacol 57, 309-312 (1999).

44. Hashim, A. I., Zhang, X., Wojtkowiak, J. W., Martinez, G. V. \& Gillies, R. J. Imaging pH and metastasis. NMR Biomed 24, 582-591, doi: 10.1002/nbm.1644 (2011).

45. Parks, S. K., Chiche, J. \& Pouyssegur, J. Disrupting proton dynamics and energy metabolism for cancer therapy. Nat Rev Cancer 13, 611-623 (2013).

46. Lambers, H., Piessens, S., Bloem, A., Pronk, H. \& Finkel, P. Natural skin surface $\mathrm{pH}$ is on average below 5, which is beneficial for its resident flora. International journal of cosmetic science 28, 359-370, doi: 10.1111/j.1467-2494.2006.00344.x (2006).

47. Shen, C. et al. The protein fluorescence and structural toolkit: Database and programs for the analysis of protein fluorescence and structural data. Proteins 71, 17441754, doi: 10.1002/prot.21857 (2008). 


\section{FIGURES}
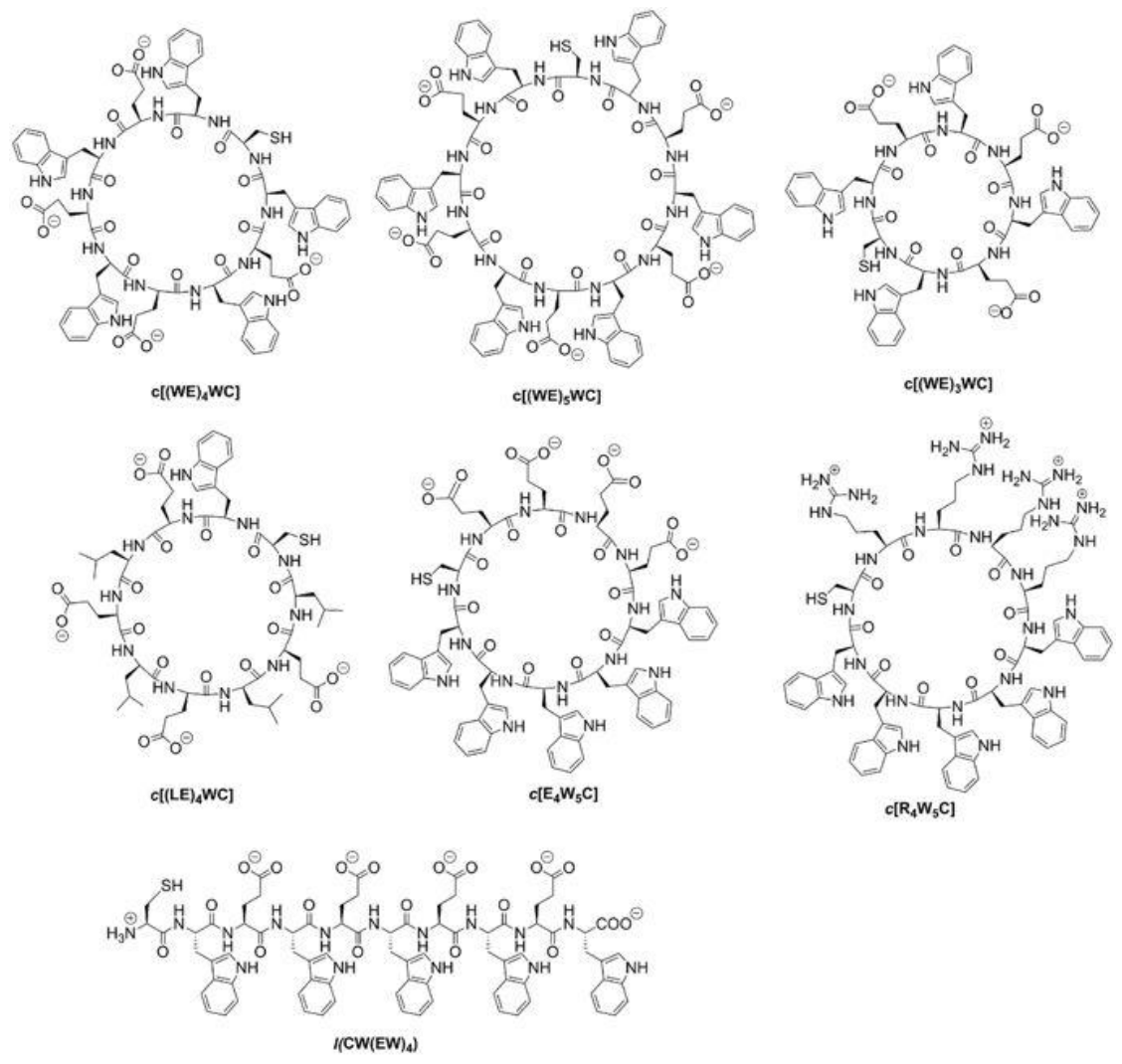

Figure 1: Chemical structures of six cyclic and one linear peptides containing tryptophan (Trp, W), leucine (Leu, L), glutamic acid (Glu, E), arginine (Arg, R) and cysteine (Cys, C) residues. 

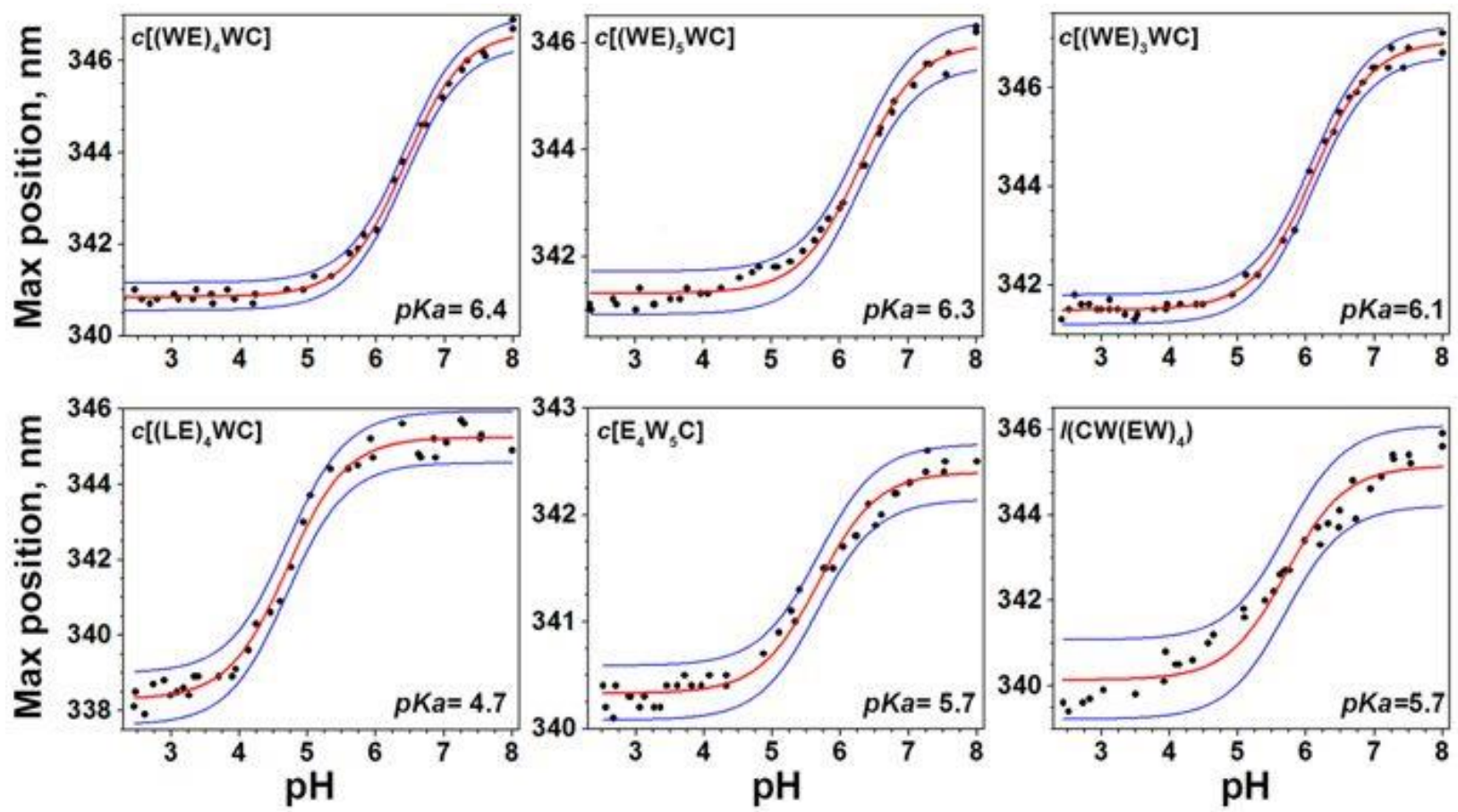

Figure 2: The changes of tryptophan fluorescence are used to follow the partition of the peptides into POPC liposomes as a function of $\mathrm{pH}$.

Fitting curves (red lines) and 95\% confidence interval (blue lines) are shown. 

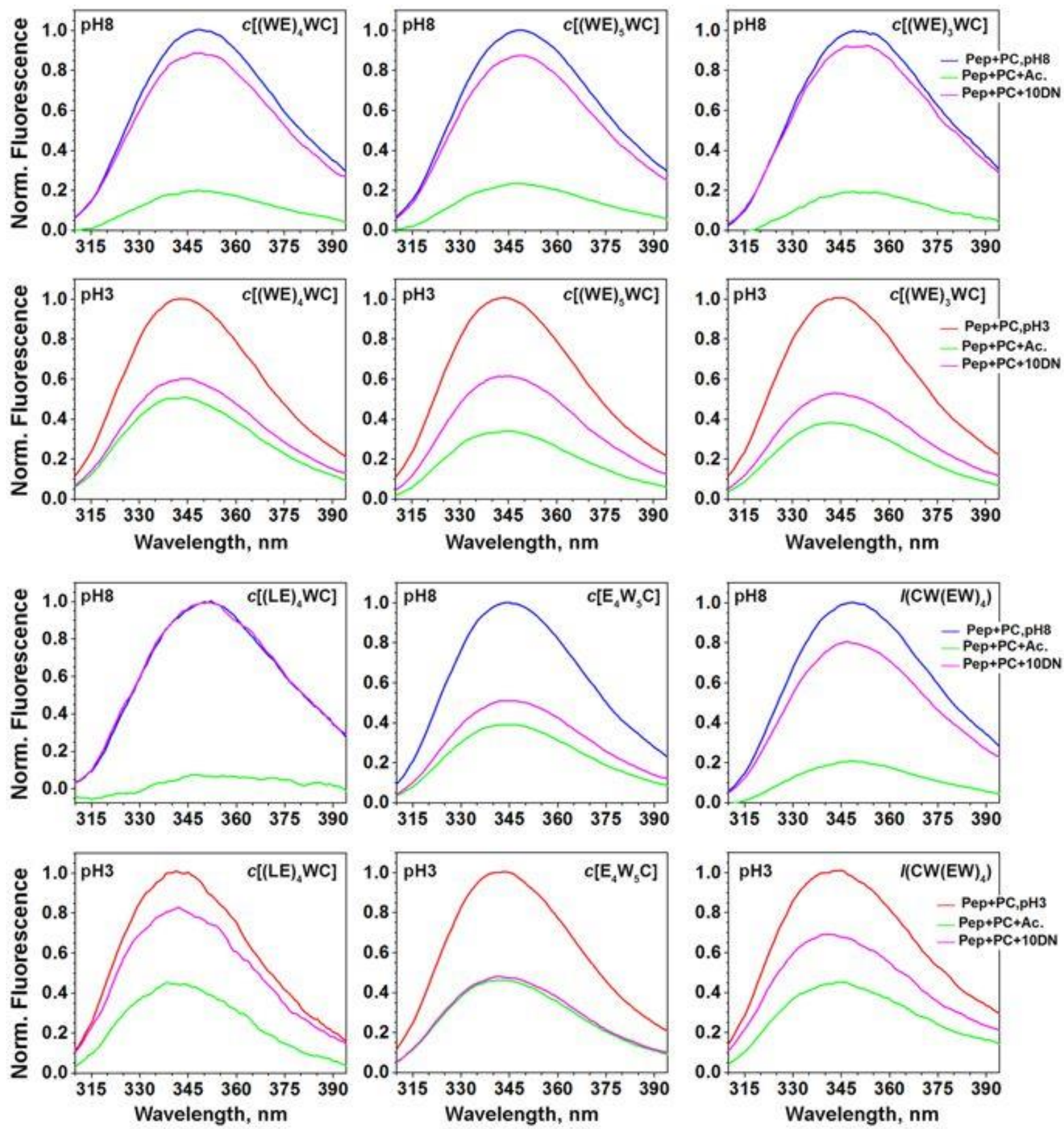

Figure 3: Quenching of fluorescence of peptides in the presence of POPC liposomes at $\mathrm{pH}$ 8 (blue lines) or at $\mathrm{pH} 3$ (red lines) by acrylamide (green lines) and 10-DN (magenta lines) are shown.

The percentage of quenching is given in Table S3. 

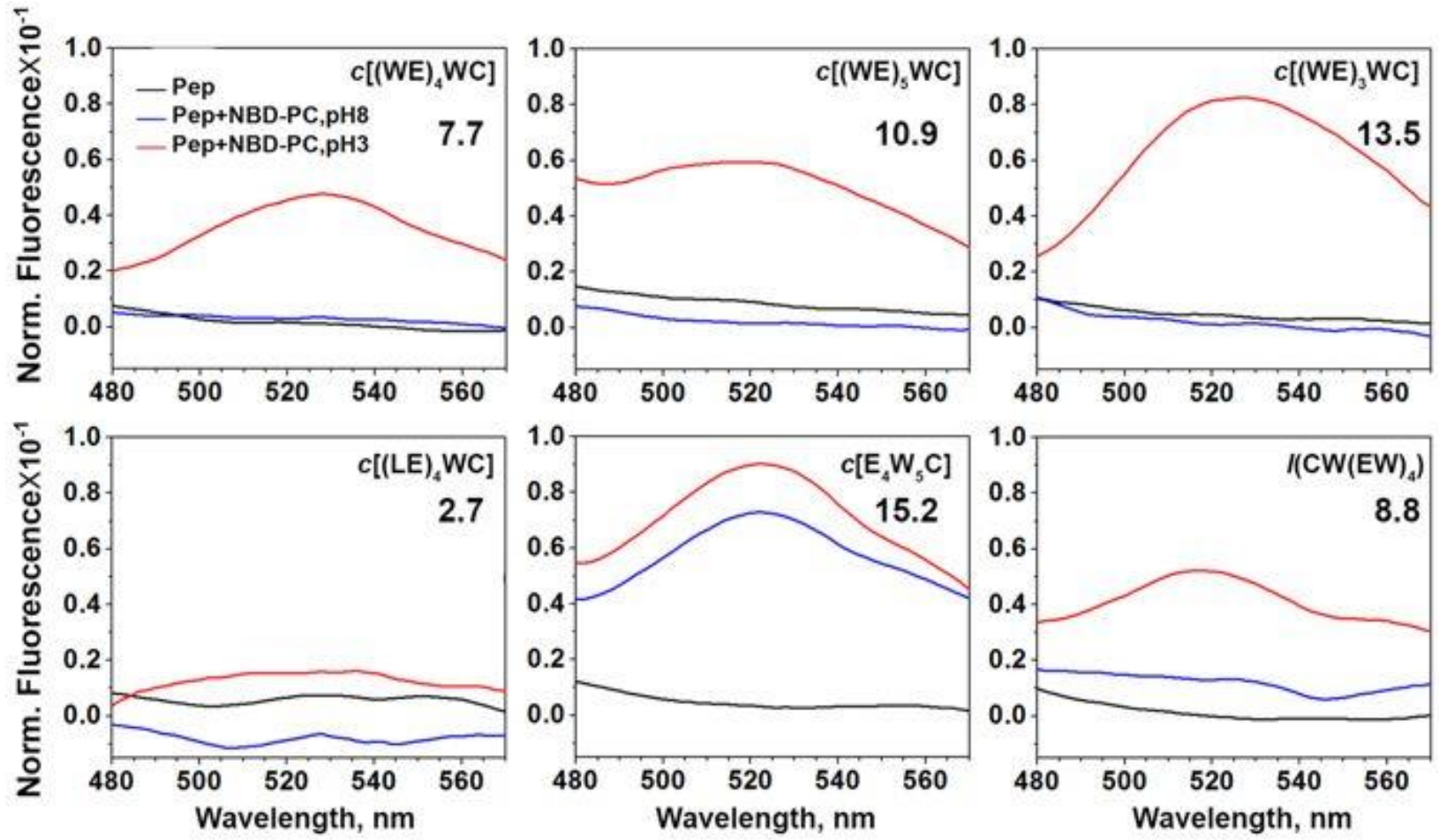

Figure 4: NBD fluorescence spectra of peptides in phosphate buffer at $\mathrm{pH} 8$ (black lines) and in presence of asymmetrically labelled POPC liposomes containing NBD at the inner leaflet at $\mathrm{pH} 8$ (blue lines) and at $\mathrm{pH} 3$ (red lines) are shown.

The numbers indicate an increase of FRET at $\mathrm{pH} 3$ compared to the peptide fluorescence in phosphate buffer at $\mathrm{pH} 8$. 

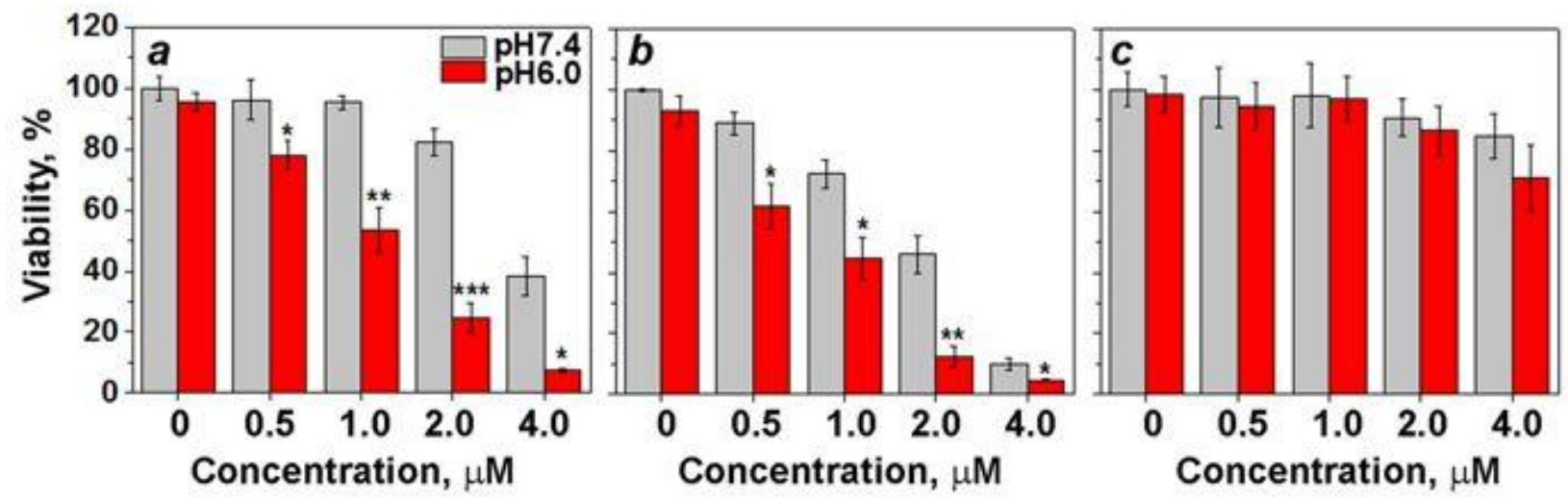

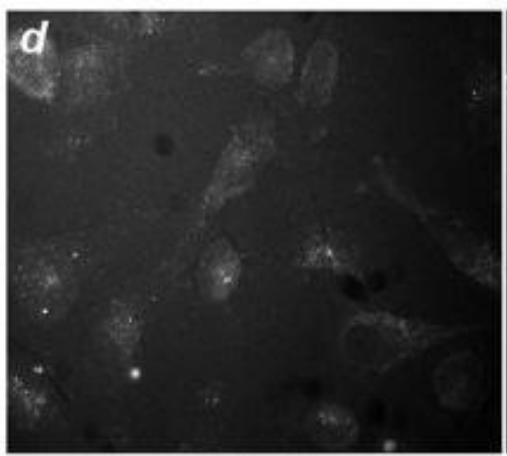

pH7.4

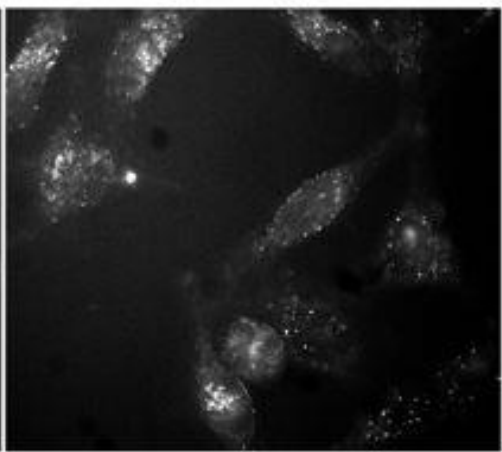

pH6.2

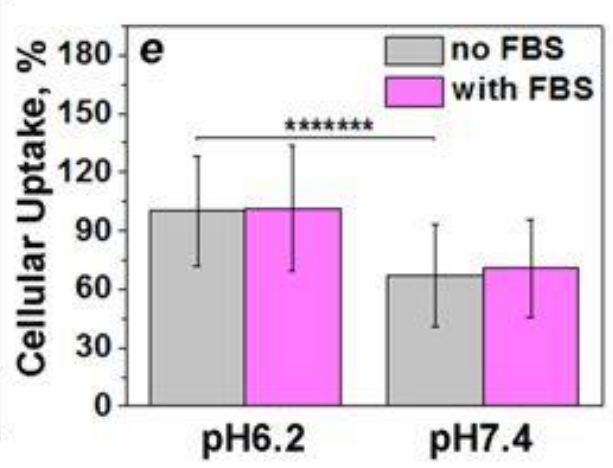

Figure $5(\mathbf{a}-\mathbf{c})$ Concentration- and $\mathrm{pH}$-dependent inhibition of HeLa cells proliferation was monitored at 48 hours after incubation of cells within (a) cleavable $c\left[(\mathrm{WE})_{4} \mathrm{WC}\right]-\mathrm{S}-\mathrm{S}$ amanitin, (b) cleavable $c\left[\mathrm{E}_{4} \mathrm{~W}_{5} \mathrm{C}\right]-\mathrm{S}$-S-amanitin and (c) non-cleavable $c\left[\mathrm{E}_{4} \mathrm{~W}_{5} \mathrm{C}\right]$-amanitin constructs for 3 hours at normal ( $\mathrm{pH}$ 7.4) and low ( $\mathrm{pH}$ 6.0) $\mathrm{pHs}$ followed by constructs removal and keeping cells in DMEM with 10\% FBS at pH 7.4. (d) HeLa cells were treated with FITC-labelled $c\left[\mathrm{E}_{4} \mathrm{~W}_{5} \mathrm{C}\right]$ peptide conjugate $(5 \mu \mathrm{M})$ for $30 \mathrm{~min}$ at $\mathrm{pH} 7.4$ or 6.2, followed by washing at $\mathrm{pH} 7.4$ in both cases, addition of Trypan Blue for $5 \mathrm{~min}$ and live cell imaging. (e) Cellular uptake of Alexa546-labelled $c\left[\mathrm{E}_{4} \mathrm{~W}_{5} \mathrm{C}\right]$ peptide conjugates (5 $\mu \mathrm{M})$ treated with HeLa cells for 6 hours in L-15 media at $\mathrm{pH} 6.2$ in absence and presence of $4 \%$ of FBS, followed by washing and counting of fluorescent signal from cells using cellometer. Data are presented as mean \pm St.D. The two-tailed unpaired Student's t-test was used to calculate p-levels. 


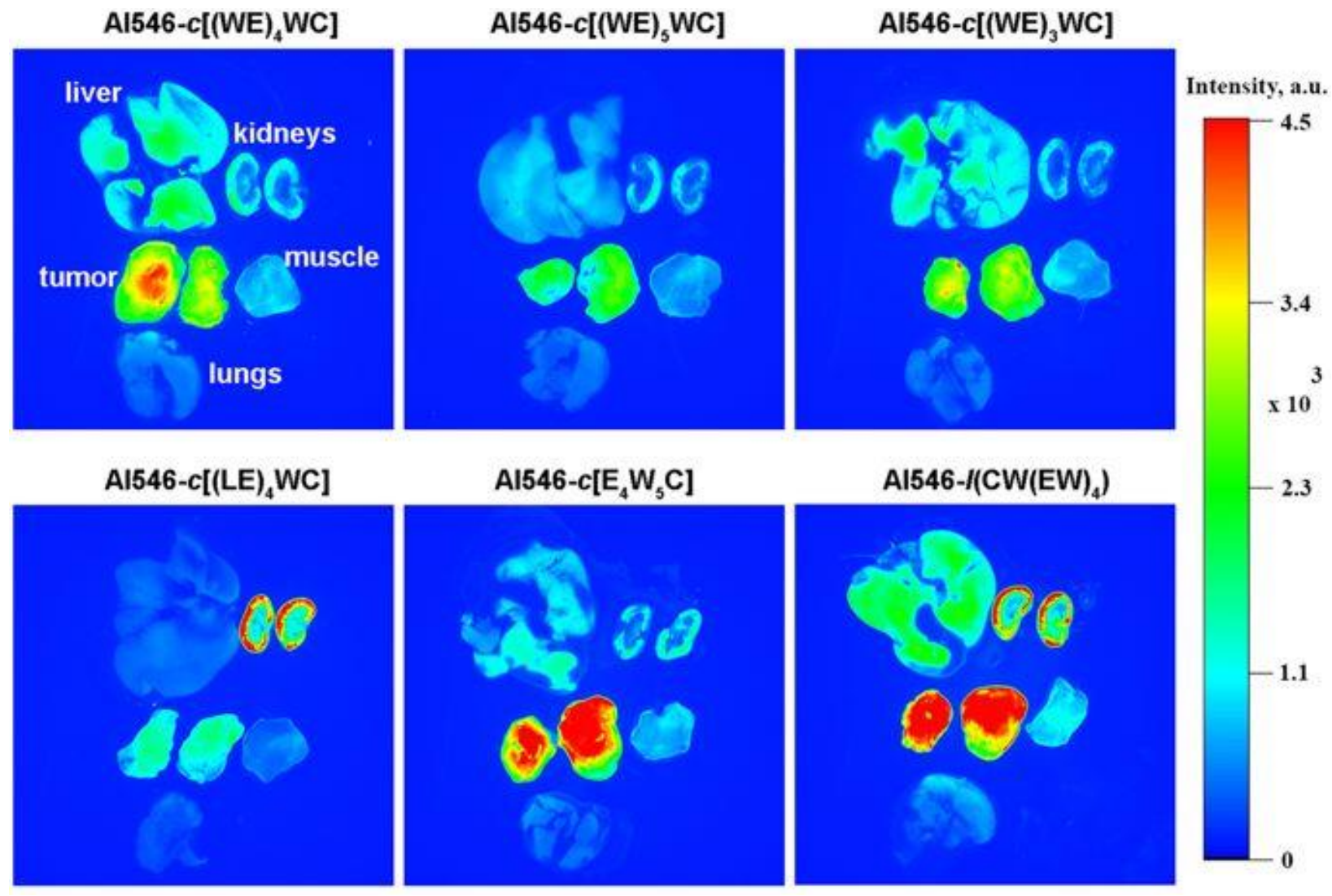

Figure 6: Ex vivo fluorescence imaging of tumor, muscle, lungs, liver and kidneys collected at 4 hours after intravenous administration of Alexa546-peptides are shown. Three mice per peptide were used in the study. 

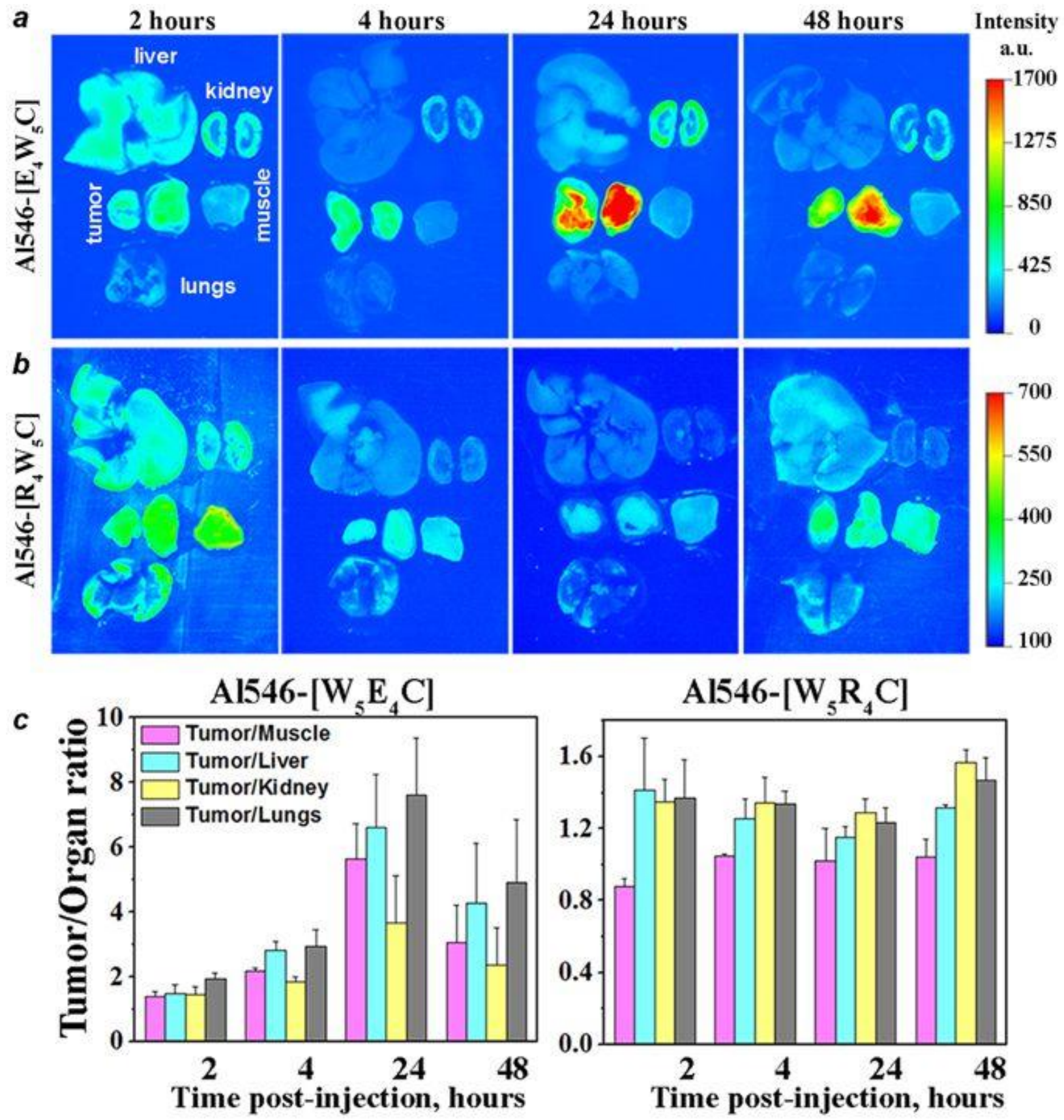

Figure 7: Ex vivo fluorescence imaging of tumor, muscle, lungs, liver and kidneys collected at various time points after intravenous administration of Alexa546 asymmetric $c\left[\mathrm{E}_{4} \mathrm{~W}_{5} \mathrm{C}\right](\mathbf{a})$ and $c\left[\mathrm{R}_{4} \mathrm{~W}_{5} \mathrm{C}\right](\mathbf{b})$ peptides; (c) Tumor/organ ratios calculated from the obtained data. Three mice per time point, per peptide were used in the study. 


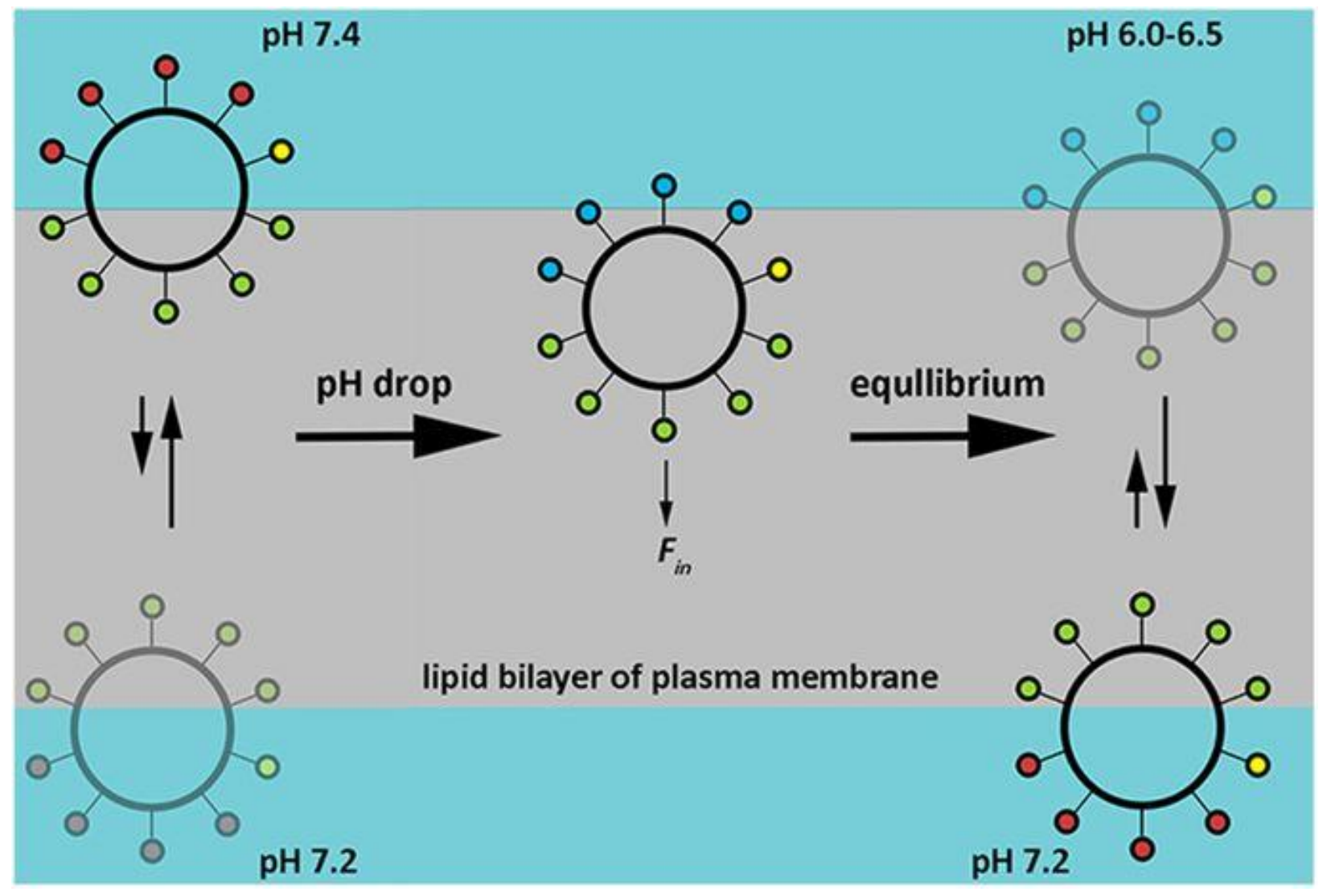

Figure 8: The cyclic peptide molecules distribution between outer and inner leaflets of the lipid bilayer of plasma membrane.

At neutral and high pHs, Glu residues are negatively-charged (red circles). Trp residues (green circles) interact with polar headgroups. Cys residue (yellow circle) could be directed into bilayer or away depending on cargo hydrophobicity conjugated with Cys. The majority of cyclic peptides could be found on the outer bilayer of plasma membrane of normal cells compared to the inner bilayer due to the small $\mathrm{pH}$ gradient $(\mathrm{pHe}=7.4$ and $\mathrm{pHi}=7.2$ ). A drop of a $\mathrm{pH}$ leads to the protonation of Glu residues (blue circles), which enhances peptides hydrophobicity and induces partition into the bilayer. 


\title{
CHAPTER 2
}

Published in J Chem Theory Comput (2018)

\section{The membrane-induced $\mathrm{p} K_{\mathrm{a}}$ shifts in $w t$-pHLIP and its $\mathrm{L16H}$ variant}

\author{
Diogo Vila-Viçosa $\nmid$ II, Tomás F. D. Silva $\nmid$ II, Gregory Slaybaughł, Yana K. \\ Reshetnyak $f$, Oleg A. Andreev $\neq$, and Miguel Machuqueiro $* \dagger$
}

†Centro de Qu'ımica e Bioqu'ımica, BioISI: Biosystems and Integrative Sciences Institute, Departamento de Qu'ımica e Bioqu'ımica, Faculdade de Cîencias, Universidade de Lisboa, 1749-016 Lisboa, Portugal

$\ddagger$ Department of Physics, University of Rhode Island, 2 Lippitt Rd., Kingston, RI 02881, USA

IIContributed equally to this work

*Correspondence: machuque@ ciencias.ulisboa.pt (Miguel Machuqueiro) 


\section{Abstract}

The $\mathrm{pH}$ (low) insertion peptide (pHLIP) is a family of peptides that are able to insert into a lipid bilayer at acidic $\mathrm{pH}$. The molecular mechanism of pHLIPs insertion, folding and stability in the membrane at low $\mathrm{pH}$ is based on multiple protonation events, which are challenging to study at molecular level. More specifically, the relation between the experimental $\mathrm{p} K$ of insertion ( $\mathrm{p} K^{\mathrm{exp}}$ ) of $\mathrm{pHLIPs}$ and the $\mathrm{p} K_{\mathrm{a}}$ of the key residues is yet to be clarified. We carried out a computational study, complemented with new experimental data, and established the influence of (de)protonation of key titrable residues on the stability of the peptide membrane-inserted state. Constant-pH molecular dynamics simulations were employed to calculate the $\mathrm{p} K_{\mathrm{a}}$ values of these residues along the membrane normal. In the $w t$-pHLIP, we identified Asp14 as the key residue for the stability of the membrane-inserted state, and its $\mathrm{p} K_{\mathrm{a}}$ value is strongly correlated with the experimental $\mathrm{p} K^{\exp }$ measured in thermodynamics studies. Also, in order to narrow down the $\mathrm{pH}$ range at which pHLIP is stable in the membrane, we designed a new pHLIP variant, L16H, where Leu in the 16th position was replaced by a titrable His residue. Our results showed that the $\mathrm{L} 16 \mathrm{H}$ variant undergoes two transitions. The calculated $\mathrm{p} K_{\mathrm{a}}$ and experimentally observed $\mathrm{p} K^{\exp }$ values are in good agreement. Two distinct $\mathrm{p} K^{\exp }$ values delimit a $\mathrm{pH}$ range where the $\mathrm{L} 16 \mathrm{H}$ peptide is stably inserted in the membrane while, outside this range, the membrane-inserted state is destabilized and the peptide exits from the bilayer. pHLIP peptides have been successfully used to target cancer cells for the delivery of diagnostics and therapeutic agents to acidic tumors. The fine tuning of the stability of pHLIP inserted state and its restriction to a narrow well-defined $\mathrm{pH}$ range might allow the design of new pHLIPs, able 
to discriminate between tissues with different extracellular $\mathrm{pH}$ values.

\section{INTRODUCTION}

The $\mathrm{pH}$ (low) insertion peptides (pHLIP) is a family of peptides that insert into lipid bilayers at low $\mathrm{pH} .{ }^{1-8}$ The original version of this peptide was derived from a transmembrane $\mathrm{C}$ helix of bacteriorhodopsin. ${ }^{1}$ Biophysical studies revealed three major states of pHLIPs (see Figure 1 in Ref. 9): (State I) when the peptide is in solution and does not adopt a defined structure; (State II) in the presence of a membrane at neutral or high $\mathrm{pH}$ the peptide is mostly unstructured yet adsorbed to the bilayer surface (pHLIPs with different sequences adopt different configurations in this state ${ }^{10,11}$ );

finally (State III), by lowering $\mathrm{pH}$, the key residues protonate, leading to an increase of the peptide hydrophobicity and insertion across the membrane to form a stable transmembrane (TM) $\alpha$-helix. ${ }^{3}$ This behaviour from pHLIP peptides is significantly different from other typical transmembrane peptides, such as the WALP/KALP peptide family. ${ }^{12-16}$ In this case, the high membrane affinities are $\mathrm{pH}$-independent and lead to inserted transmembrane helical structures, even when ionized residues are introduced in the middle of the WALP sequence. ${ }^{16,17}$

pHLIP sequences share common features: a TM region, with hydrophobic residues and one or more acids (Asp or Glu), and N- and C-terminus flanking sequences. Both flanking sequences have several charged residues, which are essential for peptide solubility. In most pHLIPs, C-terminus flanking sequences are transient membrane inserting segments ${ }^{18}$ ), which contain a variable number of anionic groups, affecting the rate of pHLIP insertion withdrawal from the bilayer. ${ }^{5}$ The TM sequence (WARYA ${ }^{14}$ DWLFTTPLLLL ${ }^{25}$ DLALLV) of wild- type $(w t)$ pHLIP contains many hydrophobic residues (including two Trp residues, which are used to monitor the 
propagation of the peptide into the lipid bilayer) and two Asp residues at positions 14 and 25. These titrable residues play an essential role in both the $\mathrm{pH}$-dependent insertion of pHLIP into the lipid bilayer and the stability of the membrane-inserted state, since they must be protonated (at least partially) for insertion process to occur. ${ }^{19}$ Thermodynamics studies of Trp fluorescence changes in pHLIP with $\mathrm{pH}$ on liposomes allow to investigate the stability of the membrane-inserted state at different $\mathrm{pH}$ values, which is typically presented by a $\mathrm{p} K$ of the peptide insertion ( $\mathrm{p} K_{\text {ins }}-$ onward referred as $\mathrm{p} K^{\exp }$ ). This $\mathrm{p} K$ value is expected to be related with the $\mathrm{p} K_{\mathrm{a}}$ of one or both Asp residues at the mem- brane/water interface. In fact, the $\mathrm{p} K^{\exp }$ of the $w t$-pHLIP is $6.0,{ }^{20}$ which is the expected value for Asp at the interface. ${ }^{21}$ Moreover, pHLIP peptides with single mutations D14E or D25E (Asp $->$ Glu) show an increase in the $\mathrm{p} K^{\mathrm{exp}}$ of $\sim$ $0.5 \mathrm{pK}$ units, ${ }^{20}$ which is approximately the difference in the $\mathrm{p} K_{\mathrm{a}}$ values between Asp and Glu in solution. This suggests that the $\mathrm{p} K_{\mathrm{a}}$ values of these acids are strongly related with $\mathrm{p} K^{\mathrm{exp}}$. The effect of shifting Asp14 to the 13th or 15th positions which, in principle, changes the solvent exposure of this residue, has also been studied. ${ }^{22}$ These results, where the $\mathrm{p} K^{\exp }$ decrease is concomitant with an increase of solvent exposure (13th position) and vice versa, ${ }^{22}$ suggest a crucial role of Asp14 in the stability of the membrane-inserted state.

A typical pHLIP variant has a single value of $\mathrm{p} K^{\text {exp }}$ a a $\mathrm{pH}$ below which more than $50 \%$ of the peptide population is inserted in the bilayer. Since acidosis is a universal marker for tumor identification, the $\mathrm{pH}$-sensitive interaction of pHLIPs with the cell membrane renders it a good transport system for tumor targeting, delivering drugs and imaging agents to cancer cells. pHLIP can target and accumulate in tissues with the extracellular $\mathrm{pH}$ below $\mathrm{p} K^{\text {exp }}$, usually cancer cells in tumors, but also naturally acidic organs, such as kidneys and stomach (in the case of oral administration). ${ }^{20,23,24}$ It would be advantageous to control the stability of pHLIP's inserted state and restrict it to a narrow well-defined $\mathrm{pH}$ range. Cationic residues, when protonated (charged), 
have been shown to hinder pHLIP membrane insertion. ${ }^{23} \mathrm{~A}$ histidine residue, when inserted in a lipid bilayer, has its $\mathrm{p} K_{\mathrm{a}}$ value shifted below the $\mathrm{p} K_{\mathrm{a}}$ of aspartic acid, ${ }^{21}$ leading to a protonation event (generation of a positive charge), which could destabilize the membrane-inserted state and induce the peptide withdrawal from the membrane. In theory, it is required a large enough difference between the His and Asp $\mathrm{p} K_{\mathrm{a}}$ values to generate a significant population of the inserted peptide (where His and Asp are in their neutral forms), but narrow enough to allow the peptide to discriminate between organs/tumors with slightly different acidities.

The investigation of the protonation states of the titrable residues in pHLIPs is an essential step to understand the molecular mechanism of pHLIP action and might open an opportunity to design new peptide variants with desirable targeting properties. Computational approaches are well suited to address this challenge. In particular, molecular dynamics (MD) simulations have been used to investigate the membrane insertion mechanism ${ }^{25,26}$ and the stability of pHLIP. ${ }^{27}$ However, in classical MD simulations all protonation states are fixed, which means that $\mathrm{pH}$ is not explicitly modeled. Constant-pH molecular dynamics (CpHMD) methods ${ }^{21,28-51}$ have been developed over the years to allow the inclusion of $\mathrm{pH}$ effects in MD simulations. In the stochastic titration method, the Poisson-Boltzmann estimated energies are used in Monte-Carlo calculations to obtain protonation states that are representative of the system conformation/configuration. The use of continuum electrostatics to obtain the free energies of changing protonation states has been successfully adopted by many methods, ${ }^{21,30-45}$ while offering the important advantage of computational speed. We have extended the stochastic titration method ${ }^{30,34}$ to include lipid bilayers (CpHMDL) ${ }^{43,44}$ in order to study the protonation profiles of peptides and proteins interacting with lipid bilayers. ${ }^{21}$ This methodology was recently used to calculate the $\mathrm{p} K_{\mathrm{a}}$ values of individual titrable amino acids when inserting in a lipid bilayer and showed that, despite sampling limitations, it was possible to estimate $\mathrm{p} K_{\mathrm{a}}$ values at deep inserted 
positions, right before losing contact with bulk water, hence with the proton buffer. ${ }^{21}$ Here, we used our recently developed CpHMD-L method to study the protonation profile of all titrable amino acids in pHLIP when inserted in a lipid bilayer (State III). These simulations were performed to identify the key residues determining the stability of pHLIP in the membrane, which is reflected by the observed experimental $\mathrm{p} K^{\mathrm{exp}}$. We also proposed a new $\mathrm{pHLIP}$ sequence with a histidine located near the key Asp14 (L16H pHLIP variant). Computer simulations predicted a second protonation event at lower $\mathrm{pH}$ values, that experimental results confirmed to be also related with a peptide withdrawal from the membrane.

\section{METHODS}

\subsection{System setup and CpHMD simulations}

In this work, we focused our efforts on the $w t$ sequence of $\mathrm{pHLIP}^{24}$ and $\mathrm{L} 16 \mathrm{H}$ variant (see Table 1). In the case of $\mathrm{L} 16 \mathrm{H}$ variant, we replaced the Leu residue at the 16th position with Table 1: pHLIP sequences used in this work. Asp14 and His16 positions are underlined.

\section{Variant Sequence \\ $w t \quad$ ACEQNPIYWARYA ${ }^{14}{ }^{14}$ WLFTTPLLLL ${ }^{25}$ DLALLVDADEGT \\ L16H ACEQNPIYWARYA ${ }^{14} \underline{\text { DWHFTTPLLLL }}{ }^{25}$ DLALLVDADEGT}

a His since, being two positions below Asp14 in a $\alpha$-helical structure, the two residues should point to opposite directions. The rationale is based on the assumption that these residues do not interact strongly, thus, they should have their $\mathrm{p} K_{\mathrm{a}}$ values only weakly correlated $w t$ and L16H pHLIP sequences were simulated using the stochastic titration CpHMD- L method. ${ }^{21,30,34,43,44}$ The peptides were built inserted in a bilayer of 2562 oleoyl-1-palmitoyl- sn-glycero-3-phosphocholine (POPC) lipid molecules and placed with Asp14 and Asp25, in their protonated (neutral) forms, equidistant to the 
membrane center. This unbiased configuration was chosen to avoid favouring the solvent exposure of one acidic residue over the other. The protonation states of Asp, Glu, His, Cys, C-ter and N-ter were allowed to titrate in the $\mathrm{pH}$ range of 4.0 to 7.0, with a $1.0 \mathrm{pH}$ step. Each CpHMD cycle was $20 \mathrm{ps}$ long $\left(\tau_{\mathrm{prt}}\right)$ and each solvent relaxation step was $0.2 \mathrm{ps}$ long $\left(\tau_{\mathrm{rlx}}\right)$. At each $\mathrm{pH}$ value, three replicates were performed for $100 \mathrm{~ns}$. Within this short time scale, the peptides are expected to remain inserted in the membrane which allows us to characterize the $\mathrm{pH}$ effects on the membrane- inserted state of pHLIP (State III). The first $20 \mathrm{~ns}$ were disregarded in the analyses to allow for system equilibration.

\subsection{Molecular dynamics settings}

All molecular dynamics simulations were performed with the GROMOS 54A7 force field ${ }^{52}$ using a modified version ${ }^{34}$ of GROMACS 4.0.7. ${ }^{53}$ A twin-range scheme was used with short- and long-range cutoffs of 8 and $14 \AA$, respectively, with neighbor lists between the two cutoff values being updated every 5 steps. Long-range electrostatic interactions were treated with the generalized reaction field (RF) method. ${ }^{54}$ Although the RF method is not optimal to capture the long range electrostatics of membrane systems, due to its anisotropic nature, there are several advantages in its use within the CpHMD framework, namely the high computation speed and its consistency with the recent GROMOS force fields (including lipid parameters), ${ }^{55}$ where all parametrization and validation were performed with this method. Recently, it has been shown that the system net charge can introduce systematic errors in $\mathrm{p} K_{\mathrm{a}}$ values obtained with a $\lambda$ dynamics based CpHMD method. ${ }^{56}$ However, with our CpHMD method, which uses GRF and an implicit ionic strength in the protonation calculations (see below), we have not observed such effects. ${ }^{34,45}$ The RF dielectric constant used was $54^{57}$ and an ionic strength of 0.1 M was also employed. The lipid and protein bond lengths were constrained using the P-LINCS algorithm, ${ }^{58}$ while the SETTLE algorithm ${ }^{59}$ was used 
for water molecules (simple point charge, $\mathrm{SPC}^{60}$ ). Newton equations of motion were integrated using a time step of 2 fs keeping constant the number of molecules, the pressure, and the temperature (NPT ensemble). The temperature of the systems was separately coupled to a v-rescale ${ }^{61}$ temperature bath at $310 \mathrm{~K}$ and relaxation times of $0.1 \mathrm{ps}$. A semiisotropic Parrinello-Rahman pressure coupling ${ }^{62}$ was used at 1 bar with a relaxation time of 5 ps and a compressibility of $4.5 \times 10^{-5}$ bar $^{-1}$.

\subsection{Poisson-Boltzmann/Monte-Carlo calculations}

The Poisson-Boltzmann (PB) calculations were performed using the program DelPhi V5.1, ${ }^{63}$ using partial charges from the GROMOS 54A7 and radii obtained from the Lennard-Jones parameters of this force field. These calculations were performed on the fully atomistic pHLIP/POPC system. The molecular surface of the solute (here the solute can be seen as the membrane + peptide supramolecular complex) was defined using a probe of radius $1.4 \AA$, the ion exclusion layer was $2.0 \AA$, and the ionic strength was $0.1 \mathrm{M}$. A dielectric constant of 2 was used for the solute and 80 for the solvent. A twostep focusing procedure was used with grid spacing of approximately 1 and 0.25 $\AA$ in the large and small grids, respectively (corresponding to 91 grid points). In the coarse grid, relaxation parameters of 0.20 and 0.75 were used in the linear and nonlinear iterations processes and periodic boundary conditions were applied in the $x$ and $y$ directions. The background interactions were calculated up to $25 \AA$ and the convergence threshold for the electrostatic potential was set to 0.01 .

The PB-derived free energy terms were then used to sample protonation states within a Monte Carlo (MC) scheme performed using the PETIT program. ${ }^{64}$ Proton tautomerism was taken into account in all titrable groups. $\times 10^{5} \mathrm{MC}$ cycles were performed for each conformation where a cycle corresponds to a trial change of each 
individual site.

\section{$2.4 \mathrm{pK}_{\mathrm{a}}$ calculation along the membrane normal}

To calculate the residues $\mathrm{p} K_{\mathrm{a}}$ values along the membrane normal, we split our conformations according to their relative depth to the average position of membrane "P" atoms within a $6 \AA$ radius from pHLIP. This method describes better the local

deformations induced by the peptide, since it only uses neighboring "P" atoms to obtain the reference average position.

After sorting the conformations in $1 \AA$ insertion slices, we separate them by protonation states of the group of interest. Here, we apply a minimum criteria of 50 frames in at least $2 \mathrm{pH}$ values in order to be able to calculate the $\mathrm{p} K_{\mathrm{a}}$ values and estimate their standard errors. The protonation states in each slice are used in a Hill fitting procedure to obtain the respective $\mathrm{p} K_{\mathrm{a}}$ value.

Assuming that a peptide stability in the membrane is regulated by the protonation of a single titrable residue, then the most inserted $\mathrm{p} K_{\mathrm{a}}$ value of this residue can be regarded as our "in silico" estimation of the experimentally measured thermodynamic parameter, $\mathrm{p} K^{\exp }$. The rationale is that, upon membrane insertion, this $\mathrm{p} K^{\mathrm{memb}}$ value, at the last moment while the group is still in contact with solvent and senses the $\mathrm{pH}$ value, will define the peptide stability in the membrane-inserted state.

\subsection{Analyses and error calculations}

The thickness of membrane bilayers is often calculated as the distance between the average $\mathrm{Z}$ coordinate of the "P" atoms for each monolayer. However, the presence of a peptide may induce local membrane deformations, which will affect these 
calculations. To circumvent these issues and to quantify membrane perturbations, we developed a method that calculates monolayer thickness values, for different annulus regions in the $x y$ plane moving radially away from the peptide. First, we define an unaffected region, loosely called "bulk", which (in our simulations) corresponds to all "P" atoms beyond a $15 \AA$ radius from pHLIP. The membrane center is then calculated using only these bulk phosphate atoms as reference. The membrane center allows the splitting of the peptide atoms between the two monolayers, which can now be used in two separate thickness calculations. Moving a sliding annulus (by increasingly changing its radii) away from the peptide in the $x y$ plane (2 dimensions), we calculate the distance between the average "P" atoms (contained in the annulus) $\mathrm{Z}$ position and the membrane center. This procedure is applied to all snapshots of our simulations and, at longer radii, both monolayer thickness values should converge to a "bulk" value, i.e. half the thickness value for pure POPC.

All error values shown in the $\mathrm{p} K_{\mathrm{a}}$ profile plots were obtained using a modified jackknife resampling method. We generated 5 sub-set combinations of our total sampling by using only 4 out of 5 replicates $(1234,1235,1245,1345$, and 2345). We used these combinations for the slicing and Hill fitting procedure. The final standard errors were calculated using the generalized formula:

$$
S E=\left\{\frac{1}{2} \sum\left(\frac{x-x_{i}}{n-1}\right)^{2}\right\}^{1 / 2}
$$

In the equation, $\mathrm{n}$ is the number of simulation replicates, $\bar{x}$ is the predicted $\mathrm{p} K_{\mathrm{a}}$ value and $x_{i}$ is the $\mathrm{p} K_{\mathrm{a}}$ value obtained in each $i$ combination of replicates. We also apply the previous criteria to the $\mathrm{p} K_{\mathrm{a}}$ values calculation, namely, each $i$ sub-set requires at least 50 frames for each protonation state and a minimum of two different $\mathrm{pH}$ 
values. Note that this standard error calculation procedure introduces a new restriction criterion to the final $\mathrm{p} K_{\text {a }}$ profile plots, where all protonation/insertion values need to be originated from more than

one replicate. Finally, all error values above $2 \mathrm{p} K$ units were excluded.

\subsection{Synthesis of pHLIP}

The L16H pHLIP variant was produced by solid-phase synthesis and purified by CS BioCo., and was characterized by reversed-phase high performance liquid chromatography (RT- HPLC) using Zorbax SB-C18 and Zorbax SB-C8, $4.6 \times 250 \mathrm{~mm}$ $5 \mu \mathrm{m}$ columns (Agilent Technologies). Peptide solution concentrations were determined using absorbance at $280 \mathrm{~nm}$, where $c_{280}=13940 \mathrm{M}^{-1} \mathrm{~cm}^{-1}$.

\subsection{Liposome preparation}

Small unilamellar vesicles were used as model membranes and were prepared via thin film formation, rehydration, and extrusion. A thin lipid film was prepared by dissolving 1palmitoyl-2-oleoyl-sn-glycero-3-phosphocholine (POPC; Avanti Polar Lipids) in chloroform at a concentration of $33 \mathrm{mg} \mathrm{mL}^{-1}$, then desolvated using rotary evaporation and placed under vacuum for 2 hours. The resulting thin POPC film was rehydrated using $2 \mathrm{mM}$ citrate-phosphate buffer at $\mathrm{pH}$ 8. Finally, the liposome solution was vortexed and extruded 21 times through a membrane with a pore size of $50 \mathrm{~nm}$.

\section{$2.8 \mathrm{pH}$ dependence measurements}

The $\mathrm{pH}$ dependence measurements were carried out by monitoring the shift of the position of maximum of peptide fluorescence as a characteristic of changes of the peptide environment by varying $\mathrm{pH}$. Peptide fluorescence spectra were measured using a PC1 spectrofluorometer (ISS) with temperature control set to $25.0{ }^{\circ} \mathrm{C}$. Tryptophan residues were excited using an excitation wavelength of $295 \mathrm{~nm}$. Both excitation and emission slits were set to $4 \mathrm{~nm}$ widths; excitation and emission polarizers were set to $54.7^{\circ}$ (magic angle) and $0.0^{\circ}$, respectively. Samples were prepared 24 hours prior to 
running experiments to allow for equilibration in State II.

The $\mathrm{pH}$ of solutions containing $7 \mu \mathrm{M}$ peptide and $1.4 \mathrm{mM}$ POPC was lowered using citric acid and measured using an Orion PerHecT ROSS Combination pH Micro Electrode and an Orion Dual Star pH and ISE Benchtop Meter (Thermo Fisher Scientific) before and after spectrum measurement to ensure equilibration. At each $\mathrm{pH}$, the tryptophan fluorescence spectrum was recorded, and the spectra were analyzed using the Protein Fluorescence and Structural Toolkit (PFAST) to determine the positions of spectral maxima. ${ }^{18}$ The obtained

positions of spectral maxima were plotted as a function of $\mathrm{pH}$. The $\mathrm{pH}$-dependence curve was fit using Levenberg Marquardt iteration algorithm of the bi-dose response module in Origin 2017 to determine parameters of cooperativity and mid-point of the transitions.

\subsection{Oriented circular dichroism measurements}

Oriented circular dichroism (OCD) measurements were performed on an MOS-450 spectrometer (Bio-Logic Science Instruments) in the range of 190 to $260 \mathrm{~nm}$ with a step size of $1 \mathrm{~nm}$, and with temperature control set to $25.0{ }^{\circ} \mathrm{C}$. OCD was conducted using supported planar POPC bilayers prepared using a Langmuir-Blodgett system (KSV Nima). Fourteen quartz slides with $0.2 \mathrm{~mm}$ spacers were used; after sonicating the slides in 5\% cuvette cleaner(Con- trad 70; Decon Labs) in deionized water $(\geq 18.2$ $\mathrm{M} \Omega \mathrm{cm}$ at $25^{\circ} \mathrm{C}$; Milli-Q Type 1 Ultrapure Water System, EMD Millipore) for fifteen minutes, then rinsing with deionized water, the slides were immersed and sonicated for ten minutes in 2-propanol, sonicated again for ten minutes in acetone, sonicated once more in 2-propanol for ten minutes, and rinsed carefully with deionized water. 
Lastly, the slides were immersed in a 3:1 solution of sulfuric acid to hydrogen peroxide for five minutes and rinsed thoroughly deionized water. The slides were stored in deionized water until they were used. POPC bilayers were deposited on the fourteen slides using a Langmuir-Blodgett minitrough: a $2.5 \mathrm{mg} \mathrm{mL}^{-1}$ solution of POPC in chloroform was spread on the subphase (deionized water) and fifteen minutes was allotted for the evaporation of the chloroform, after which the POPC monolayer was compressed to $32 \mathrm{mN} \mathrm{m}^{-1}$. A lipid monolayer was deposited on the slides by drawing them from the sub- phase, after which a solution of $10 \mu \mathrm{M}$ peptide and 500 $\mu \mathrm{M}$ of $50 \mathrm{~nm}$ POPC liposomes at $\mathrm{pH} 4$ was added to the slides, producing supported bilayer by fusion between the monolayer on the slides and the peptide-laden lipid vesicles. After incubation for six hours at $100 \%$ humid- ity, the slides were rinsed with buffer solution to remove residual liposomes, and the spaces between the cuvettes were filled with buffer of appropriate $\mathrm{pH}$. Measurements were taken at three points during the experiment: directly after the addition of the peptide/lipid solution $(0 \mathrm{~h})$, after the slides were rinsed to remove excess liposomes after the six-hour incubation time (6 $\mathrm{h}$ ), and after an additional twelve-hour incubation time and rinse with buffer $(18 \mathrm{~h})$; these measurements were recorded on the MOS-450 spectrometer with sampling times of 1 second at each wavelength.

\section{RESULTS AND DISCUSSION}

\subsection{Molecular details of membrane inserted pHLIP}

The main goal of our work is to elucidate the role of titrable residues in the stability of $w t$-pHLIP membrane-inserted state (State III). Our calculations should correlate with 
the equilibrium biophysical studies on liposomes, where $\mathrm{pH}$ outside and inside of a liposome equilibrates quickly and is considered to be the same at both sides of a lipid bilayer. ${ }^{65}$ We carried out simulations, at different $\mathrm{pH}$ values (4.0-7.0), with the peptide inserted in a POPC lipid bilayer. Within the time scale of our simulations (100 ns), the peptide is expected to remain stable in the membrane-inserted state (the withdrawal process occurs in a much larger time scale ${ }^{65}$ ), which allow us to characterize the effect of $\mathrm{pH}$ on the membrane-inserted state. There is a multitude of experimental data regarding the characterization of pHLIP in- serted in lipid bilayers. ${ }^{1-8,65}$ In particular, the original transmembrane region (residues 9- $30^{66}$ ) has often been assumed to be conserved with Asp14 and Asp25 inserted in the lipid bilayer. Although, the helical content is conserved in the membrane-inserted state at all sim- ulated $\mathrm{pH}$ values (Figure S1 in Supporting Information), the overall preferred position of the peptide is significantly shifted towards the N-terminus monolayer (Figure 1 and Figure S2). At all $\mathrm{pH}$ values, the peptide bends at the membrane/water interface, consistently losing helical content around residues 15-18. Interestingly, the proline residue at the 20th position is not directly involved in this loss of secondary structure. The presence of Arg11 in the N-terminus domain, close to the interface, and the presence of two segments of hydrophobic residues, 21-24 and 26-30, seem to be the main factors determining both the position and orientation of $w t$-pHLIP in the lipid bilayer. At $\mathrm{pH}$ 6.0, which is the experimentally observed $\mathrm{pK}^{\mathrm{exp}}$, Asp25 is preferably located at the bilayer center, thus not exchanging protons with water. Concomitantly, Asp14 is only partially inserted in the membrane, singling it out as the key proton active residue. Interestingly, the peptide $\mathrm{N}$-terminus is interchanging between the water phase and the water/membrane interface, suggesting that residues 1-13 are either solvated or adsorbed to the membrane. Varying $\mathrm{pH}$ leads to slightly different preferred positions for the transmembrane region of pHLIP, where the ionization of Asp14 seems to be the driving factor for the destabilization of the membrane-inserted state. Nevertheless, 
even at lower $\mathrm{pH}$ values, Asp14 is always able to reach water accessible regions and sense the $\mathrm{pH}$ value. At the C-terminus, we observe that the four acidic groups (Asp31, Asp33, Glu34, and C-ter) are also titrating and their preferred positions relative to the membrane center seem to be a consequence of their topological order and ionization states. At high $\mathrm{pH}$ values, when these residues are mostly ionized, they are not deeply inserted as Figure S2 suggests, but rather induce a significant local deformation on the closer monolayer. In fact, the mono- layer thickness profiles around pHLIP show a clear local depression in the C-terminus side (Figure 2). A small bilayer deformation ( $110 \%)$ occurs at $\mathrm{pH}<7.0$, however, a larger effect is observed at $\mathrm{pH} 7.0(\sim 20 \%-$ Figure S3 in Supporting Information), since, at this $\mathrm{pH}$ value, the more stable thermodynamic state is not the fully inserted (State III) but rather the membraneadsorbed (State II). In both cases, the observed deformations are only local being completely dissipated at $\sim 30 \AA$ radially away from the peptide. At the $\mathrm{N}$-terminus side, there is only a small membrane perturbation almost within the error bars. Also, beyond

$\sim 15 \AA$ from the peptide, both monolayers thicknesses reach a plateau and the sum of their values correspond roughly to the experimental POPC thickness (36.5 $\AA) .{ }^{67}$

\section{$3.2 \mathrm{pK}^{\mathrm{a}}$ profile of Asp14}

We calculated the $\mathrm{p} K_{\mathrm{a}}$ values of Asp14 using average protonation values obtained from the constant-pH molecular dynamics simulations (CpHMD-L). This method allows for the titrable residues to update their protonation states depending on the $\mathrm{pH}$ and their microenvironment. Hence, it is possible to measure the proton affinity of a given group along the membrane normal. Indeed, we have previously observed that aspartic acid, in the middle of a capped alanine pentapeptide (AADAA), has its $\mathrm{p} K_{\mathrm{a}}$ value shifted when inserting in a lipid bilayer, favoring its neutral form. ${ }^{21}$ The $\mathrm{p} K_{\mathrm{a}}$ values, varying with the level of residue insertion into the membrane, can be called 
$\mathrm{p} K_{\mathrm{a}}$ profiles. A key feature of this method is a good estimation of the depth of insertion of a particular residue, which correlates with its solvent exposure, taking into consideration the membrane local deformation. In a $\mathrm{p} K_{\mathrm{a}}$ profile, the value calculated at the deepest membrane-inserted location of a residue, the $\mathrm{p} K_{\mathrm{a}}$ value at the limit of our sampling, could be considered as an estimation of the $\mathrm{p} K^{\mathrm{memb}}$. It should correspond to a region of scarce solvent exposure, when the residue does not exchange protons with water anymore, and it is no longer able to sense $\mathrm{pH}$. If we know which residue is responsible for the stability of the peptide membrane-inserted state, then its $\mathrm{p} K^{\text {memb }}$ value is our estimation of the experimental $\mathrm{p} K^{\exp }$. The $\mathrm{pK}^{\mathrm{a}}$ profile of Asp14 shows significant shift along the membrane normal, reaching a $\mathrm{pK}^{\mathrm{memb}}$ value of $6.0 \pm 0.1$, at the deepest membrane inserted position (Figure 3A), which is in excellent agreement with the experimentally observed $\mathrm{pK}^{\exp }$ value $\left(6.0^{24}\right)$.

The C-terminus region of pHLIP has five carboxylic acids, including Asp25. In the membrane-inserted configuration, Asp31, Asp33, Glu34 and C-ter are accessing the solvent on the other side of the bilayer, opposite to Asp14. Therefore, in this configuration, their $\mathrm{p} K_{\mathrm{a}}$ profiles are only related to the exit pathway insertion process of pHLIP, the protonation order of these acidic residues, is most likely related to their topological position in the peptide sequence (Figure 1). Furthermore, their $\mathrm{p} K_{\mathrm{a}}$ values have contributions from the desolvation effects ${ }^{21}$ and the electrostatic repulsion between the negatively charged residues. Hence, the observed trend in the $\mathrm{p} K_{\mathrm{a}}$ profiles is in agreement with the expected for an anionic group (Figure 3B). The protonation (charge neutralization) of each residue, reduces the local negative potential, decreasing the $\mathrm{p} K_{\mathrm{a}}$ shift of the remaining residues when they reach similar (despite its lack of sampling) because, at this point, all other carboxylic groups are ionized. On the contrary, C-terminus exhibits a small $\mathrm{p} K_{\mathrm{a}}$ shift, since it is measured in the absence of other negative charges. Along these lines, Asp25 would show an even higher $\mathrm{p} K^{\mathrm{memb}}$ value, but not enough (de)protonation events were observed in our simulations, precluding an accurate $\mathrm{p} K_{\mathrm{a}}$ calculation. 
pHLIP is in equilibrium between the membrane membrane-inserted states and the experimental $\mathrm{p} K^{\exp }$ value is an average of these populations ratio. According to our results, the occurrence of the membrane-inserted state requires complete protonation of both Asp25 and Asp14, even though the stability of this state is regulated only by the (de)protonation of Asp14, which is able to exchange protons with water. The double pro- tonation is in agreement with isothermal calorimetry (ITC) data, which estimates that 1.8 protons are required for the insertion process. ${ }^{19}$ The four carboxylic acids at the C-terminus domain are at the water/membrane interface in both end states, hence, their $\mathrm{p} K_{\mathrm{a}}$ values should not have a direct effect on the equilibrium populations. However, the membrane crossing energetic barrier for a charged group is usually unsurmountable. ${ }^{68,69}$ Therefore, in the kinetic process of the peptide insertion (or exit) into (from) the membrane, all acidic residues in the $\mathrm{C}$ terminus region would need to, at least transiently, protonate. To obtain a fully neutral C-terminus domain, the acidic groups will likely become neutral sequentially, following their topological order. Hence, these protonations can be slow, depending

on the number of anionic residues and their $\mathrm{p} K^{\mathrm{memb}}$ values. This is in agreement with the experi- mentally observed slow kinetics for $w t$-pHLIP, when compared with other variants with fewer acidic residues in the aforementioned region. ${ }^{24}$

\subsection{The L16H variant shows two $\mathrm{pK}^{\exp }$ values}

The ionization of residues in pHLIP TM region induces a transition between State III and II. In the $w t$-pHLIP variant, Asp14 preferentially ionizes at $\mathrm{pH}$ values larger than 6.0, which leads to the destabilization of the membrane-inserted state and peptide exit from the

. However, below pH 6.0 the peptide membrane-inserted state is well stabilized. By introducing a cationic residue (such as histidine) we observe the opposite effect, i.e. the peptide withdrawal from the membrane now occurs at lower $\mathrm{pH}$ values when the residue is ionized. ${ }^{70}$ Hence, with a combination of these two strategies, we can design 
a peptide with

two transitions, each having its own $\mathrm{p} K^{\exp }$ value. In this case, provided that the $\mathrm{p} K^{\mathrm{memb}}$

of the cationic group is lower than that of the anionic, the peptide will be stabilized in its membrane-inserted state in the $\mathrm{pH}$ range within the two $\mathrm{p} K^{\mathrm{memb}}$ values (Figure 4). To test this hypothesis, we designed the L16H pHLIP variant, where the cationic residue (His16) is deeply inserted in the membrane and facing an opposite direction from Asp14. We have performed CpHMD simulations with this variant and calculated the corresponding $\mathrm{p} K_{\mathrm{a}}$ val- ues (Figure 5). The obtained profiles are similar to the observed for pentapeptides inserting into a lipid bilayer. ${ }^{21}$ The $\mathrm{p} K_{\mathrm{a}}$ value of His16 (Asp14) decreases (increases) with insertion into the membrane, since the membrane stabilizes their neutral forms. Although the profile of Asp14 is similar to $w t$-pHLIP, we observe a $\mathrm{p} K_{\mathrm{a}}$ increase in the membrane-inserted state. This suggests that the histidine residue slightly alters Asp14 microenvironment upon insertion (even though the conformational properties are not significantly altered - Figure S5 and S6 in Supporting Information). The two $\mathrm{p} K_{\mathrm{a}}$ profiles show that the $\mathrm{L} 16 \mathrm{H}$ peptide has two $\mathrm{p} K^{\mathrm{memb}}$ values $(6.8 \pm 0.2$ for Asp14 and $4.7 \pm 0.3-$ or $\sim 3.1$ without error bars - for His16), thus the peptide is expected to be stabilized in the membrane-inserted state only within the $3.1-6.8 \mathrm{pH}$ range.

The L16H pHLIP variant was synthesized and its interaction with POPC liposomes was studied employing spectroscopic techniques. The $\mathrm{pH}$-dependence of L16H pHLIP variant was observed by measuring the shift in the peptide fluorescence spectra maximum between $\mathrm{pH} 1.5$ and 8.5 (Figure 6A). The position of the maximum of the emission spectra mainly reflects the solvent exposure of the tryptophan residues, hence, providing information on the degree of the membrane penetration. The data were fitted assuming two transitions and confirm the existence of two $\mathrm{p} K^{\exp }$ in $\mathrm{L} 16 \mathrm{H}$ pHLIP variant (5.9 and 3.3), which can be attributed to the $\mathrm{p} K^{\mathrm{memb}}$ values of Asp14 and His16, respectively. To identify conformational states of L16H pHLIP at $\mathrm{pH} 2,4$ and 8 we measured OCD spectra (Figure 6B). At pH 8 no helical structure was 
observed, while at $\mathrm{pH} 4$ the transmembrane orientation of helix was confirmed. When $\mathrm{pH}$ was lowered to 2 , the peptide helical content is still preserved. However, contrarily to the observed at $\mathrm{pH} 4$, a surface helical orientation is predominant. Overall, the obtained results support the two-p $K^{\text {memb }}$ insertion mechanism (Figure 4). Below the lowest $\mathrm{p} K^{\text {exp }}$, the His residue in the TM region becomes positively charged, while at a $\mathrm{pH}$ value above the highest $\mathrm{p} K^{\text {exp }}$, the Asp residue becomes negatively charged. In both cases, it leads to the destabilization of the peptide membrane-inserted state and peptide exit from the bilayer. This inserted state is only stabilized in the $\mathrm{pH}$ range between the two $\mathrm{p} K^{\exp }$ values.

for

Despite on the fact that the membrane-inserted $\mathrm{pH}$ range is too wide to be useful practical applications, the obtained results should be regarded as a proof-of-concept. Hence, they can prompt the design of new pHLIP sequences, with different cationic residues, that might narrow down the $\mathrm{p} \mathrm{K}^{\mathrm{exp}}$ range to $\sim 1 \mathrm{pH}$ unit, so pHLIP might be able to discriminate between different cells in an organism. 


\section{CONCLUSIONS}

In this work, we studied the protonation profile of all titrable amino acids in pHLIP when inserted in a lipid bilayer, and identified Asp14 as the key residue to act as a sensor of the extracellular $\mathrm{pH}$ in the membrane-inserted state. The peptide adopts a preferential position in the membrane such that Asp25 remains mainly at the bilayer center, away from water and unable to sense the $\mathrm{pH}$ value, i.e. it is not able to exchange protons with the solvent. The $\mathrm{pK}^{\mathrm{memb}}$ value calculated for Asp14 in wtpHLIP is in excellent agreement with the experimentally measured $\mathrm{p} K^{\exp }$. Our simulations also helped to understand the role of the acidic residues at the $\mathrm{C}$-terminus flanking sequence. These residues need to be fully protonated to allow the transition of pHLIP from the membrane-adsorbed (State II) to the membrane-inserted (State III) conformation. Consequently, the number of anionic groups can have a direct influence on the kinetics of the peptide insertion process, as already observed experimentally. ${ }^{24,65}$

The information obtained at the molecular level helped to understand the peptide stability in the membrane and will also give important hints to devise new pHLIP variants with specific features. An example is L16H pHLIP variant, with a histidine residue located in the TM region, near Asp14. Our simulations predicted that this mutation adds a second

proto- nation event, at lower $\mathrm{pH}$ values, leading to the peptide withdrawal from the membrane. The simulations were validated by spectroscopic data indicating the presence of two transitions in L16H pHLIP variant. Although this proof-of-concept mutation seems to generate a too large range between the two $\mathrm{p} K^{\exp }$ values, it opens an opportunity for the design of new variants to achieve fine tuning of $\mathrm{pH}$ insertion range, hence increasing the potential medical significance of pHLIP technology. 
In the future, we also plan to use new enhanced sampling strategies coupled with CpHMD- L simulations in order to improve the accuracy of these $\mathrm{p} K_{\mathrm{a}}$ calculations.

\section{ACKNOWLEDGEMENT}

António M. Baptista, Ana S. Grosso and Vítor H. Teixeira for fruitful discussions. We acknowledge financial support from Fundação para a Ciência e a Tecnologia through grant SFRH/BPD/110491/2015, and projects UID/MULTI/00612/2013, and PTDC/QEQ- COM/5904/2014. This work was also supported by the General Medical Sciences of the National Institutes of Health grant R01GM073857 to OAA and YKR. O. A. Andreev and Y. K. Reshetnyak have founded and have a financial interest in a company, pHLIP, Inc., with the aim of bringing pHLIP technology to the clinic. The company has had no involvement in funding the studies reported here.

\section{SUPPORTING INFORMATION AVAILABLE}

Table with used pHLIP peptides sequences. Figures with: helicity content, distances to membrane center of key residues, and monolayer thickness profiles for both $w t$ and $\mathrm{L} 16 \mathrm{H}$ variants. $\mathrm{p} K_{\mathrm{a}}$ profile of C-terminus acidic residues of $\mathrm{L} 16 \mathrm{H}$ variant.

\section{REFERENCES}

(1) Hunt, J. F.; Rath, P.; Rothschild, K. J.; Engelman, D. M. Spontaneous, pHdependent membrane insertion of a transbilayer $\alpha$-helix. Biochemistry-US 1997, $36,15177-15192$.

(2) Reshetnyak, Y. K.; Andreev, O. A.; Lehnert, U.; Engelman, D. M. Translocation of molecules into cells by $\mathrm{pH}$-dependent insertion of a transmembrane helix. Proc. Natl. Acad. Sci. USA 2006, 103, 6460-6465. 
(3) Reshetnyak, Y. K.; Segala, M.; Andreev, O. A.; Engelman, D. M. A monomeric mem- brane peptide that lives in three worlds: in solution, attached to, and inserted across lipid bilayers. Biophys. J. 2007, 93, 2363-2372

(4) Yao, L.; Daniels, J.; Moshnikova, A.; Kuznetsov, S.; Ahmed, A.; Engelman, D. M.; Reshetnyak, Y. K.; Andreev, O. A. pHLIP peptide targets nanogold particles to tumors. Proc. Natl. Acad. Sci. USA 2013, 110, 465-470.

(5) Andreev, O. A.; Engelman, D. M.; Reshetnyak, Y. K. Targeting diseased tissues by pHLIP insertion at low cell surface pH. Front. Physiol. 2014, 5 .

(6) Kyrychenko, A.; Vasquez-Montes, V.; Ulmschneider, M. B.; Ladokhin, A. S. Lipid Headgroups Modulate Membrane Insertion of pHLIP Peptide. Biophys. J. 2015, 108, 791-794.

(7) Hanz, S. Z.; Shu, N. S.; Qian, J.; Christman, N.; Kranz, P.; An, M.; Grewer, C.; Qiang, W. Protonation-Driven Membrane Insertion of a pH-Low Insertion Peptide. Angew. Chem. Int. Ed. 2016, 55, 12376-12381.

(8) Scott, H. L.; Westerfield, J. M.; Barrera, F. N. Determination of the Membrane Translo- cation $\mathrm{p} K$ of the $\mathrm{pH}-\mathrm{Low}$ Insertion Peptide. Biophys. J. 2017, 113, 869879 .

(9) Andreev, O. A.; Karabadzhak, A. G.; Weerakkody, D.; Andreev, G. O.; Engelman, D. M.; Reshetnyak, Y. K. pH (low) insertion peptide (pHLIP) inserts across a lipid bilayer as a helix and exits by a different path. Proc. Natl. Acad. Sci. USA 2010, 107, 4081-4086.

(10) Vasquez-Montes, V.; Gerhart, J.; King, K. E.; Thévenin, D.; Ladokhin, A. S. Com- parison of lipid-dependent bilayer insertion of pHLIP and its P20G variant. Biochem. Biophys. Acta, Biomembr. 2018, 1860, 534-543. 
(11) Shu, N. S.; Chung, M. S.; Yao, L.; An, M.; Qiang, W. Residue-specific structures and membrane locations of $\mathrm{pH}$-low insertion peptide by solid-state nuclear magnetic resonance. Nat. Commun. 2015, 6

(12) de Planque, M. R.; Bonev, B. B.; Demmers, J. A.; Greathouse, D. V.; Koeppe, R. E.; Separovic, F.; Watts, A.; Killian, J. A. Interfacial anchor properties of tryptophan residues in transmembrane peptides can dominate over hydrophobic matching effects in peptide- lipid interactions. Biochemistry 2003, 42, 53415348.

(13) Killian, J. A. Synthetic peptides as models for intrinsic membrane proteins. FEBS Lett.

2003, 555, 134-138.

(14) Vostrikov, V. V.; Daily, A. E.; Greathouse, D. V.; Koeppe, R. E. Charged or aromatic anchor residue dependence of transmembrane peptide tilt. J. Biol. Chem. 2010, 285, 31723-31730.

(15) Gleason, N. J.; Vostrikov, V. V.; Greathouse, D. V.; Grant, C. V.; Opella, S. J.; Koeppe, R. E. Tyrosine replacing tryptophan as an anchor in GWALP peptides. Bio- chemistry 2012, 51, 2044-2053.

(16) Gleason, N. J.; Vostrikov, V. V.; Greathouse, D. V.; Koeppe, R. E. Buried lysine, but not arginine, titrates and alters transmembrane helix tilt. Proc. Natl. Acad. Sci. USA 2013, 110, 1692-1695.

(17) Panahi, A.; Brooks III, C. L. Membrane Environment Modulates the $\mathrm{p} K_{\mathrm{a}}$ Values of Transmembrane Helices. J. Phys. Chem. B 2015, 119, 4601-4607.

(18) Shen, C.; Menon, R.; Das, D.; Bansal, N.; Nahar, N.; Guduru, N.; Jaegle, S.; Peck- ham, J.; Reshetnyak, Y. K. The protein fluorescence and structural toolkit: Database and programs for the analysis of protein fluorescence and structural 
data. Proteins Struct. Funct. Bioinf. 2008, 71, 1744-1754.

(19) Reshetnyak, Y. K.; Andreev, O. A.; Segala, M.; Markin, V. S.; Engelman, D. M. Energetics of peptide (pHLIP) binding to and folding across a lipid bilayer membrane. Proc. Natl. Acad. Sci. USA 2008, 105, 15340-15345

(20) -Musial-Siwek, M.; Karabadzhak, A.; Andreev, O. A.; Reshetnyak, Y. K.; Engel- man, D. M. Tuning the insertion properties of pHLIP. BBABiomembranes 2010, 1798, 1041-1046.

(21) Teixeira, V. H.; Vila-Viçosa, D.; Reis, P. B. P. S.; Machuqueiro, M. pKa Values of Titrable Amino Acids at the Water/Membrane Interface. J. Chem. Theory Comput. 2016, 12, 930-934.

(22) Fendos, J.; Barrera, F. N.; Engelman, D. M. Aspartate Embedding Depth Affects pHLIP's Insertion $\mathrm{p} K_{\mathrm{a}}$. Biochemistry-US 2013, 52, 4595-4604.

(23) Andreev, O. A.; Dupuy, A. D.; Segala, M.; Sandugu, S.; Serra, D. A.; Chichester, C. O.; Engelman, D. M.; Reshetnyak, Y. K. Mechanism and uses of a membrane peptide that targets tumors and other acidic tissues in vivo. Proc. Natl. Acad. Sci. USA 2007, 104, 7893-7898.

(24) Weerakkody, D.; Moshnikova, A.; Thakur, M. S.; Moshnikova, V.; Daniels, J.; Engel- man, D. M.; Andreev, O. A.; Reshetnyak, Y. K. Family of pH (low) insertion peptides for tumor targeting. Proc. Natl. Acad. Sci. USA 2013, 110, $5834-5839$.

(25) Deng, Y.; Qian, Z.; Luo, Y.; Zhang, Y.; Mu, Y.; Wei, G. Membrane binding and insertion of a pHLIP peptide studied by all-atom molecular dynamics simulations. 2013, 14, 14532-14549.

(26) Kong, C. P.; Cui, Y. L.; Zhang, J. L.; Zheng, Q. C.; Zhang, H. X. Mechanism of 
A pH-induced Peptide Inserting into a POPC Bilayer: A Molecular Dynamic Study. Curr. Pharm. Biotechno. 2014, 15, 814-822.

(27) Gupta, C.; Mertz, B. Protonation Enhances the Inherent Helix-Forming Propensity of pHLIP. ACS Omega 2017, 2, 8536-8542

(28) Burgi, R.; Kollman, P. A.; van Gunsteren, W. F. Simulating proteins at constant pH: An approach combining molecular dynamics and Monte Carlo simulation. Proteins Struct. Funct. Bioinf. 2002, 47, 469-480.

(29) Lee, M. S.; Salsbury, F. R.; Brooks III, C. L. Constant-pH molecular dynamics using continuous titration coordinates. Proteins Struct. Funct. Bioinf. 2004, 56, $738-752$.

(30) Baptista, A. M.; Teixeira, V. H.; Soares, C. M. Constant-pH molecular dynamics using stochastic titration. J. Chem. Phys. 2002, 117, 4184-4200.

(31) Dlugosz, M.; Antosiewicz, J. M. Constant-pH molecular dynamics simulations: a test case of succinic acid. Chem. Phys. 2004, 302, 161-170.

(32) Dlugosz, M.; Antosiewicz, J. M.; Robertson, A. D. Constant-pH molecular dynamics study of protonation-structure relationship in a heptapeptide derived from ovomucoid third domain. Phys. Rev. E 2004, 69 .

(33) Mongan, J.; Case, D. A.; McCammon, J. A. Constant pH molecular dynamics in gen- eralized Born implicit solvent. J. Comput. Chem. 2004, 25, 2038-2048.

(34) Machuqueiro, M.; Baptista, A. M. Constant-pH Molecular Dynamics with Ionic Strength Effects: Protonation-Conformation Coupling in Decalysine. J. Phys. Chem. B 2006, 110, 2927-2933.

(35) Machuqueiro, M.; Baptista, A. M. Molecular Dynamics Constant-pH and Reduction Potential: Application to Cytochrome $c_{3}$. J. Am. Chem. Soc. 2009, 
$131,12586-12594$.

(36) Itoh, S. G.; Damjanović, A.; Brooks, B. R. pH replica-exchange method based on discrete protonation states. Proteins Struct. Funct. Bioinf. 2011, 79, $3420-3436$.

(37) Machuqueiro, M.; Baptista, A. M. Is the prediction of $\mathrm{p} K_{\mathrm{a}}$ values by constant$\mathrm{pH}$ molecular dynamics being hindered by inherited problems? Proteins Struct. Funct. Bioinf. 2011, 79, 3437-3447

(38) Vorobjev, Y. N. Potential of mean force of water-proton bath and molecular dynamic simulation of proteins at constant pH. J. Comput. Chem. 2012, 33, 832-842.

(39) Swails, J. M.; Roitberg, A. E. Enhancing conformation and protonation state sampling of hen egg white lysozyme using $\mathrm{pH}$ replica exchange molecular dynamics. J. Chem. Theory Comput. 2012, 8, 4393-4404.

(40) Lee, J.; Miller, B. T.; Damjanovic, A.; Brooks, B. R. Constant pH molecular dynamics in explicit solvent with enveloping distribution sampling and Hamiltonian exchange. J. Chem. Theory Comput. 2014, 10, 2738-2750.

(41) Swails, J. M.; York, D. M.; Roitberg, A. E. Constant pH replica exchange molecular dynamics in explicit solvent using discrete protonation states: implementation, testing, and validation. J. Chem. Theory Comput. 2014, 10, $1341-1352$.

(42) Magalhães, P. R.; Machuqueiro, M.; Baptista, A. M. Constant-pH Molecular Dynamics Study of Kyotorphin in an Explicit Bilayer. Biophys. J. 2015, 108, 2282-2290.

(43) Vila-Viçosa, D.; Teixeira, V. H.; Baptista, A. M.; Machuqueiro, M. Constant- 
pH MD simulations of an oleic acid bilayer. J. Chem. Theory Comput. 2015, 11, 2367-2376.

(44) Santos, H. A.; Vila-Viçosa, D.; Teixeira, V. H.; Baptista, A. M.; Machuqueiro, M. Constant-pH MD simulations of DMPA/DMPC lipid bilayers. J. Chem. Theory Com- put. 2015, 11, 5973-5979.

(45) Reis, P. B.; Vila-Viçosa, D.; Campos, S. R.; Baptista, A. M.; Machuqueiro, M. Role of Counterions in Constant-pH Molecular Dynamics Simulations of PAMAM Dendrimers. ACS Omega 2018, 3, 2001-2009.

(46) Wallace, J. A.; Shen, J. K. Charge-leveling and proper treatment of long-range elec- trostatics in all-atom molecular dynamics at constant pH. J. Chem. Phys. 2012, 137,184105

(47) Bennett, W. F. D.; Chen, A. W.; Donnini, S.; Groenhof, G.; Tieleman, D. P. Constant $\mathrm{pH}$ simulations with the coarse-grained MARTINI model - Application to oleic acid aggregates. Can. J. Chemistry 2013, 91, 839-846.

(48) Chen, W.; Wallace, J. A.; Yue, Z.; Shen, J. K. Introducing titratable water to allatom molecular dynamics at constant pH. Biophys. J. 2013, 105, L15-L17.

(49) Goh, G. B.; Hulbert, B. S.; Zhou, H.; Brooks III, C. L. Constant pH molecular dynamics of proteins in explicit solvent with proton tautomerism. Proteins Struct. Funct. Bioinf. 2014, 82, 1319-1331.

(50) Stern, H. A. Molecular simulation with variable protonation states at constant pH. J. Chem. Phys. 2007, 126, 164112.

(51) Radak, B. K.; Chipot, C.; Suh, D.; Jo, S.; Jiang, W.; Phillips, J. C.; Schulten, K.; Roux, B. Constant-pH Molecular Dynamics Simulations for Large Biomolecular Sys- tems. J. Chem. Theory Comput. 2017, 13, 5933-5934. 
(52) Schmid, N.; Eichenberger, A. P.; Choutko, A.; Riniker, S.; Winger, M.; Mark, A. E.; Van Gunsteren, W. F. Definition and testing of the GROMOS force-field versions 54A7 and 54B7. Eur. Biophys. J. 2011, 40, 843-856.

(53) Hess, B.; Kutzner, C.; van der Spoel, D.; Lindahl, E. GROMACS 4: Algorithms for Highly Efficient, Load-Balanced, and Scalable Molecular Simulation. J. Chem. Theory Comput. 2008, 4, 435-447.

(54) Tironi, I. G.; Sperb, R.; Smith, P. E.; van Gunsteren, W. F. A generalized reaction field method for molecular dynamics simulations. J. Chem. Phys. 1995, $102,5451-5459$.

(55) Poger, D.; Mark, A. E. On the Validation of Molecular Dynamics Simulations of Sat- urated and cis-Monounsaturated Phosphatidylcholine Lipid Bilayers: A Comparison with Experiment. J. Chem. Theory Comput. 2010, 6, 325-336

(56) Chen, W.; Shen, J. K. Effects of system net charge and electrostatic truncation on all-atom constant pH molecular dynamics. J. Comput. Chem. 2014, 35, 1986-1996.

(57) Smith, P. E.; van Gunsteren, W. F. Consistent dielectric properties of the simple point charge and extended point charge water models at 277 and 300 K. J. Chem. Phys. 1994, 100, 3169-3174.

(58) Hess, B. P-LINCS: A Parallel Linear Constraint Solver for Molecular Simulation. J. Chem. Theory Comput. 2008, 4, 116-122.

(59) Miyamoto, S.; Kollman, P. A. SETTLE: An analytical version of the SHAKE and RATTLE algorithm for rigid water models. J. Comput. Chem. 1992, 13, 952-962.

(60) Hermans, J.; Berendsen, H. J. C.; van Gunsteren, W. F.; Postma, J. P. M. A 
Consistent Empirical Potential for Water-Protein Interactions. Biopolymers 1984, 23, 1513-1518.

(61) Bussi, G.; Donadio, D.; Parrinello, M. Canonical sampling through velocity rescaling.

J. Chem. Phys. 2007, 126, 014101.

(62) Parrinello, M.; Rahman, A. Polymorphic transitions in single crystals: A new molecular dynamics method. J. Appl. Phys. 1981, 52, 7182-7190.

(63) Rocchia, W.; Sridharan, S.; Nicholls, A.; Alexov, E.; Chiabrera, A.; Honig, B. Rapid grid-based construction of the molecular surface and the use of induced surface charge to calculate reaction field energies: Applications to the molecular systems and geometric objects. J. Comput. Chem. 2002, 23, 128-137.

(64) Baptista, A. M.; Soares, C. M. Some Theoretical and Computational Aspects of the Inclusion of Proton Isomerism in the Protonation Equilibrium of Proteins. $J$. Phys. Chem. B 2001, 105, 293-309.

(65) Karabadzhak, A. G.; Weerakkody, D.; Wijesinghe, D.; Thakur, M. S.; Engelman, D.M, Andreev, O. A.; Markin, V. S.; Reshetnyak, Y. K. Modulation of the pHLIP transmem- brane helix insertion pathway. Biophys. J. 2012, 102, 18461855.

(66) Henderson, R.; Baldwin, J. M.; Ceska, T. A.; Zemlin, F.; Beckmann, E.; Downing, K. H. Model for the structure of bacteriorhodopsin based on highresolution electron cryo- microscopy. J. Mol. Biol. 1990, 213, 899-929.

(67) Kučerka, N.; Nieh, M.-.; Katsaras, J. Fluid phase lipid areas and bilayer thicknesses of commonly used phosphatidylcholines as a function of 
temperature. Biochem. Biophys. Acta, Biomembr. 2011, 1808, 2761-2771.

(68) Huang, K.; Garc'ia, A. E. Free energy of translocating an arginine-rich cellpenetrating peptide across a lipid bilayer suggests pore formation. Biophys. $J$. 2013, 104, 412-420.

(69) Lazaridis, T.; Leveritt, J. M.; PeBenito, L. Implicit membrane treatment of buried charged groups: Application to peptide translocation across lipid bilayers. Biochem. Biophys. Acta, Biomembr. 2014, 1838, 2149-2159.

(70) Barrera, F. N.; Weerakkody, D.; Anderson, M.; Andreev, O. A.; Reshetnyak, Y. K.; Engelman, D. M. Roles of carboxyl groups in the transmembrane insertion of peptides. J. Mol. Biol. 2011, 413,

\section{FIGURES}



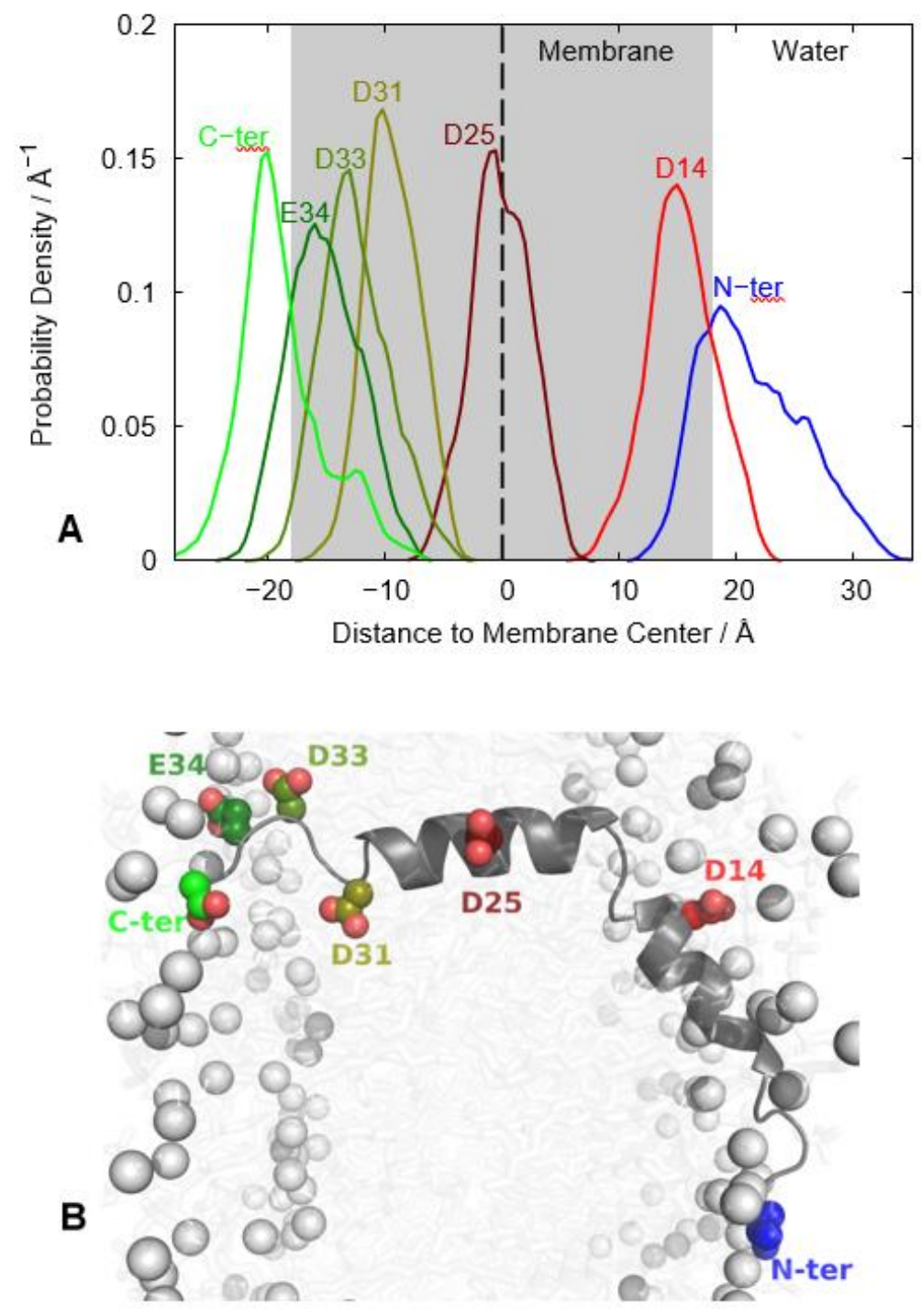

Figure 1: Probability density of distance to membrane center of key titrable groups in $w t$ pHLIP at $\mathrm{pH} 6.0$ (A). The membrane region is marked as gray with a dashed line at its center. For the remaining $\mathrm{pH}$ values, see Figure $\mathrm{S} 2$ of Supporting Information. Representative conformation of membrane-inserted state of $w t$-pHLIP with the titrable groups highlighted (B). Lipid tails are represented as transparent sticks with $\mathrm{P}$ atoms as grey spheres. pHLIP secondary structure is represented as a dark grey cartoon with key titrable groups side chains in spheres. 


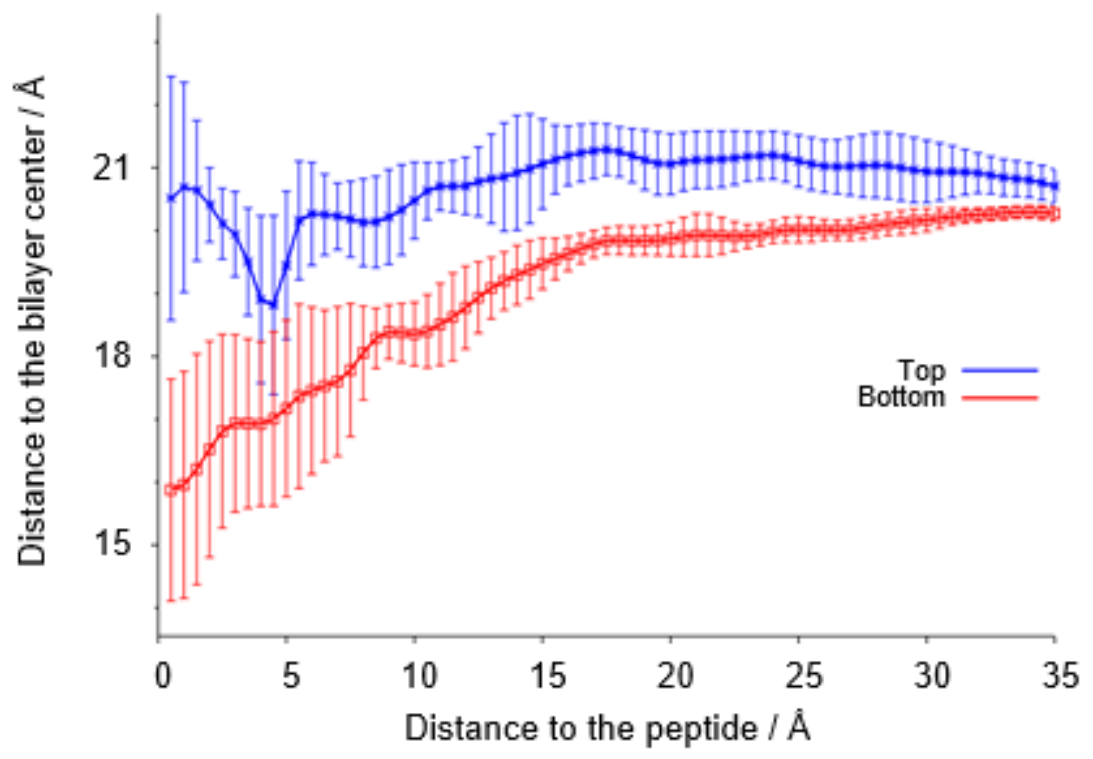

Figure 2: Monolayer thickness profiles for $w t$-pHLIP at $\mathrm{pH}$ 6.0. The top monolayer is the one interacting with Asp14 and the bottom is the one interacting with the C-terminus acidic residues. For the remaining $\mathrm{pH}$ values, see Figure S3 of Supporting Information. 

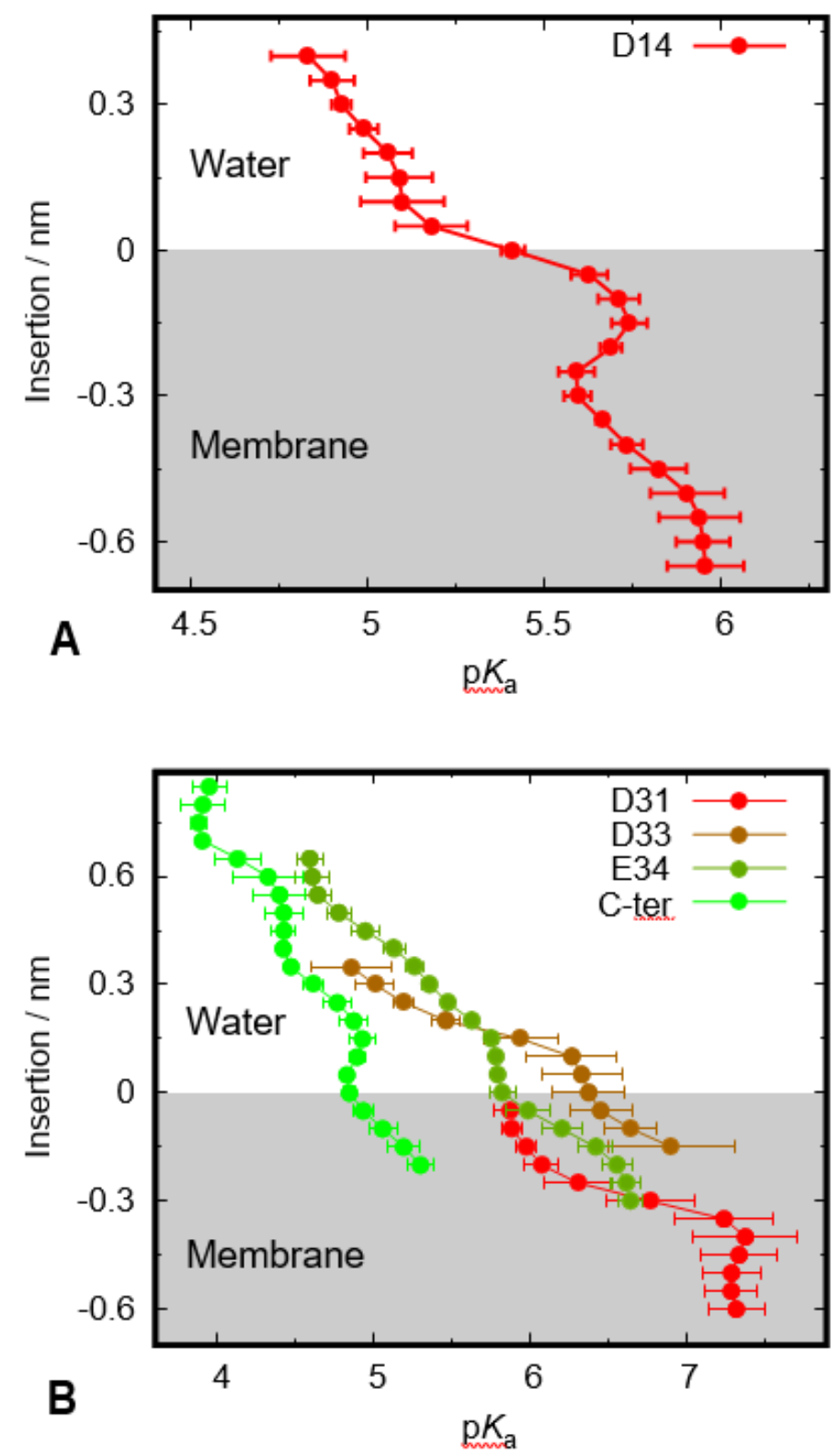

Figure 3: $\mathrm{p} K_{\mathrm{a}}$ profile of Asp14 (A) and C-terminus acidic residues (B) along the membrane normal obtained with CpHMD simulations of $w t$-pHLIP. The negative insertion values correspond to membrane inserted positions, while positive values correspond to more shallow locations. The insertion values were measured between the titrable group and the average position of the selected phosphate groups within a $6^{\circ} \mathrm{A}$ radius. 


\section{Adsorbed Inserted Adsorbed}

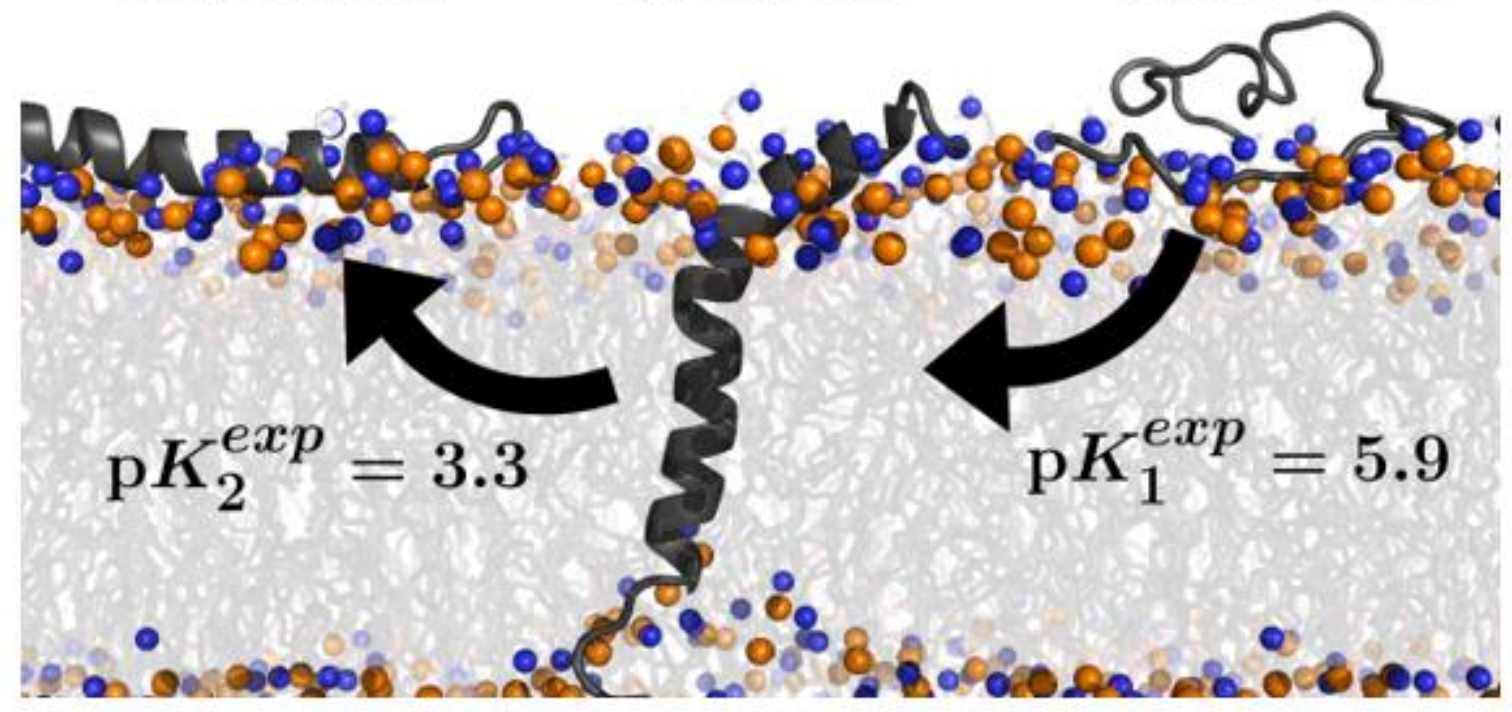

Figure 4: Schematic representation of the $\mathrm{pH}$-dependent mechanism for membrane insertion/withdrawal of L16H pHLIP. 


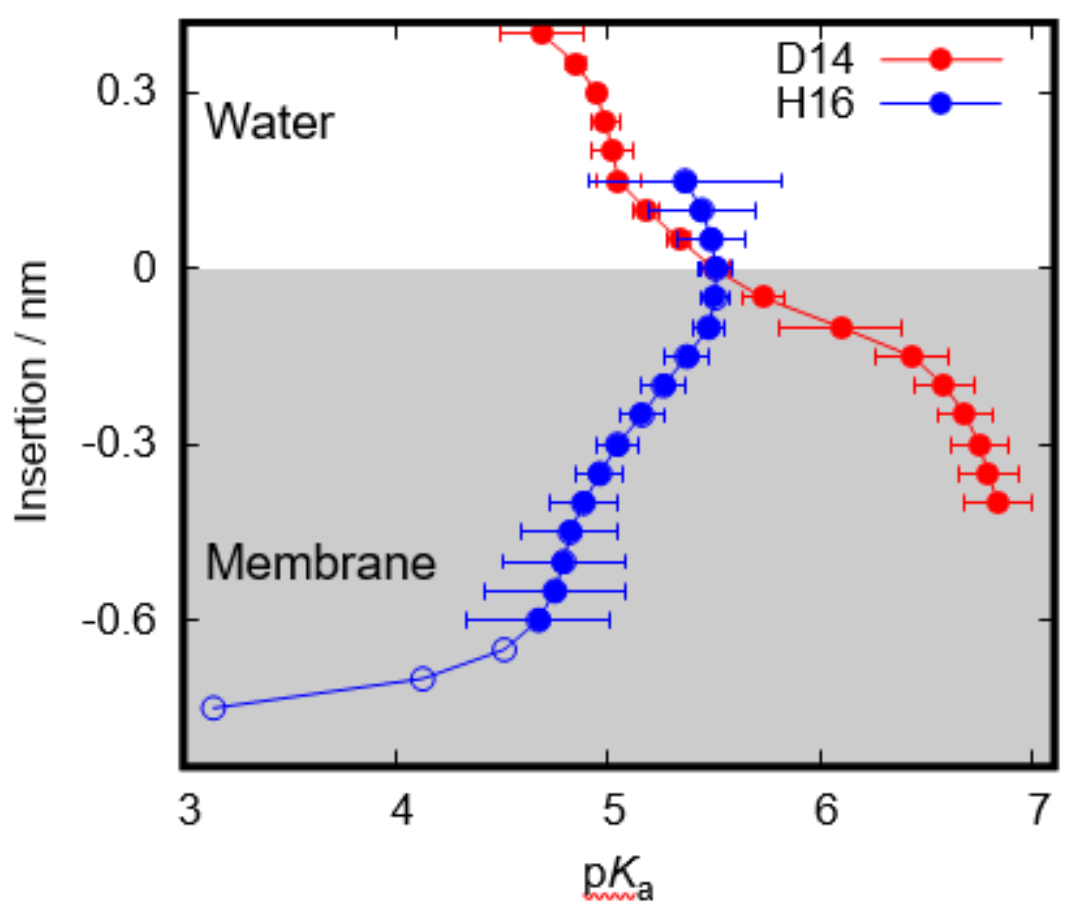

Figure 5: $\mathrm{p} K_{\mathrm{a}}$ profiles of Asp14 and His16 along the membrane normal obtained with CpHMD simulations of L16H pHLIP variant. The unfilled circles in the His16 profile correspond to a deep inserted region for which we did not have enough sampling to compute the error bars. They are shown to qualitatively illustrate the profile tendency. The negative insertion values correspond to membrane inserted positions, while positive values correspond to more shallow locations. The insertion values were measured between the titrable group and the average position of the selected phosphate groups within a $6^{\circ} \mathrm{A}$ radius. For residues at the C-terminus domain see Figure S4 in Supporting Information. 

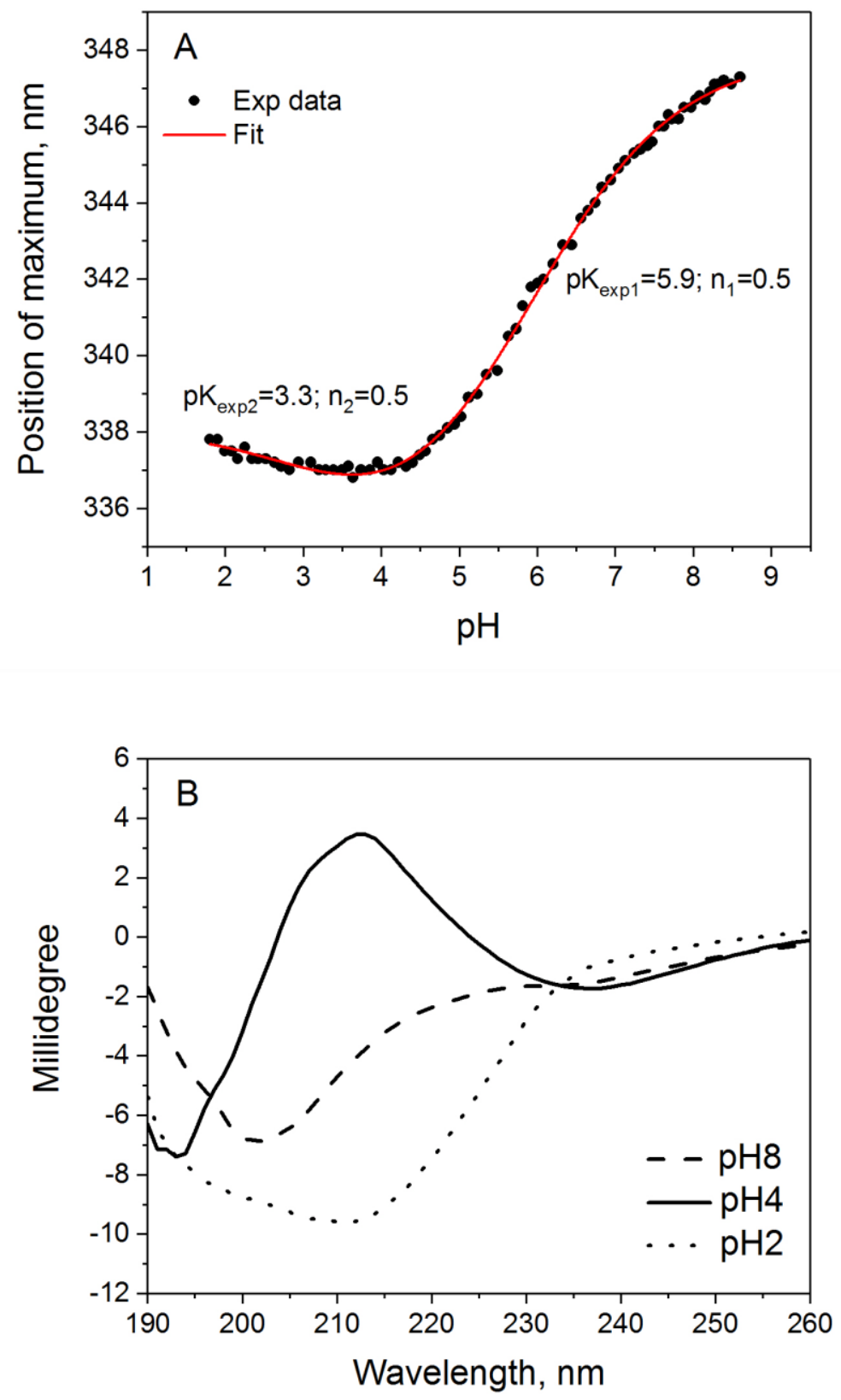

Figure 6: $\mathrm{pH}$-dependence of the position of the maximum shift of Trp fluorescence spectra of L16H pHLIP variant (A). The experimental data were fitted using the bi-dose response module in Origin 2017, to establish cooperativity (n) and mid transition (p $K^{\exp }$ ). OCD spectra of L16H pHLIP variant measured on POPC-supported bilayers at $\mathrm{pH} \mathrm{2,4}$ and 8 (B) 


\section{CHAPTER 3}

Under review in PNAS: Biophysics and Computational Biology

\section{Kinetics of pHLIP peptide insertion into and exit from a membrane}

$$
\text { Gregory Slaybaugh }{ }^{\mathrm{a}} \text {, Dhammika Weerakkody }{ }^{\mathrm{a}} \text {, }
$$

Donald M. Engelman ${ }^{\mathrm{b}}$, Oleg A. Andreev ${ }^{\mathrm{a}}$, Yana K. Reshetnyak ${ }^{\mathrm{a}, 1}$

aPhysics Department, University of Rhode Island, Kingston, RI 02881;

${ }^{b}$ Department of Molecular Biophysics and Biochemistry, Yale, New Haven, CT 06511

\section{Corresponding Author}

${ }^{1}$ To whom correspondence should be addressed, e-mail: reshetnyak@uri.edu

\section{Keywords}

membrane-associated folding, tumor acidity, kinetics, fluorescence, pHLIP 


\section{Author Contributions}

O.A.A., D.M.E and Y.K.R. designed research; G.S. and D.W. performed experiments; G.S. and Y.K.R. analyzed data; D.M.E., O.A.A. and Y.K.R. wrote the paper.

\section{Conflict of Interest Statement}

D.M.E., O.A.A. and Y.K.R. are founders of pHLIP, Inc. They have shares in the company, but the company did not fund any part of the work reported in this paper, which was carried out in their academic laboratories. 


\begin{abstract}
To advance mechanistic understanding of membrane-associated peptide folding and insertion, we have studied the kinetics of three single tryptophan pHLIP (pH-Low Insertion Peptide) variants, where tryptophan residues are located near the $\mathrm{N}$ terminus, near the middle, and near the inserting C-terminal end of the pHLIP transmembrane helix. Singletryptophan $\mathrm{pHLIP}$ variants allowed us probing different parts of the peptide in the pathways of peptide insertion into the lipid bilayer (triggered by a $\mathrm{pH}$ drop) and peptide exit from the bilayer (triggered by a rise in $\mathrm{pH}$ ). By using $\mathrm{pH}$ jumps of different magnitudes, we slowed down the processes, and established the intermediates that helped us to understand the principles of insertion and exit. The obtained results should also aid the applications in medicine that are now entering the clinic.
\end{abstract}

\title{
SIGNIFICANCE
}

The process of peptide insertion across a membrane is of fundamental interest. It also illuminates our thinking about the ways that lipid boundaries can interact with the molecules they encounter. Obtained in this study results, combined with our recent constant-pH molecular dynamics simulations and kinetics experiments with liposomes of different bilayer thicknesses allowed us to complete a generalized model of the insertion and folding of polypeptides of the pHLIP family, and expand the general view of peptide conformations and dynamic excursions of the bilayer that can accompany interactions with peptides. While the insertion of pHLIPs across membrane bilayers has basic scientific interest, the possibility of clinical applications for tumor imaging and therapy is also 
emerging as a reality. By understanding the principles of pHLIP properties, the future applications can be broadened and improved.

\section{INTRODUCTION}

pH-Low Insertion Peptides (pHLIPs ${ }^{\circledR 1}$ ) are being increasingly studied to gain insights concerning peptide folding and insertion into membranes, and to apply them in medicine. Because their membrane insertion from a water-soluble state is triggered by $\mathrm{pH}$ changes, a rich opportunity is created for chemical, kinetic and computational studies, as shown by the expanding literature from a growing number of laboratories and ongoing efforts to use them as medically useful acidity sensors in vivo. Currently, pHLIPs are being used in studies of membrane-associated folding and unfolding as a model system (1-10), and in a variety of biomedical applications for targeted delivery of imaging and therapeutic agents (11-14). In this paper, we position Tryptophans (Trp) as sensors in the flanking and central regions of a pHLIP and exploit kinetic analysis to study the pathways of membrane entry and exit.

Metabolically active cells, like cancer cells and tumor-associated macrophages within tumors, or activated macrophages in inflamed tissues, are known to acidify their environments (15-18). The extracellular $\mathrm{pH}$ in the vicinity of cells in normal healthy tissue is about 7.2-7.4, while $\mathrm{pH}$ at the surface of cancer cells could be as low as pH 6.0 (19). Acidity is a possible biomarker for specific targeting of these cells in diseased tissues, but the extracellular $\mathrm{pH}$ is only about one $\mathrm{pH}$ unit lower than the extracellular $\mathrm{pH}$ in healthy 
organs, creating a challenge for $\mathrm{pH}$-sensitive agents to discriminate between them. A family of pHLIPs was designed to have a variety of properties while sharing the characteristic pHLIP insertion into membrane lipid bilayers at low pHs $(<\mathrm{pH} 7.0)(11,20$, 21). A pHLIP's affinity for a membrane leads to a reversible membrane-adsorbed surface state at high and neutral pHs, which allows a pHLIP to sense the $\mathrm{pH}$ at the surfaces of cells (1), triggering insertion if the $\mathrm{pH}$ is low. Weak surface binding is useful for a $\mathrm{pH}$-sensing agent, since the $\mathrm{pH}$ at the surfaces of cancer cells is $0.5-0.7 \mathrm{pH}$ units lower than the bulk extracellular $\mathrm{pH}$ and independent of tumor (tissue) perfusion $(19,22)$. Another feature of the pHLIP delivery system is that these peptides undergo a cooperative coil-helix transition in response to a $\mathrm{pH}$ change, and the $\mathrm{pK}$ and cooperativity of the transition are tunable by sequence variation. Further, the activation barrier for insertion into bilayers can be adjusted, pre-determining the time required for cellular targeting and insertion $(2,5,23)$. These parameters have utility for pHLIP applications to real biological systems.

To advance understanding of the mechanism of the membrane-associated pHLIP folding we have extended our kinetics studies of single-Trp pHLIP variants. Observations using single-Trp variants have allowed us to observe intermediate steps in the pathways of peptide insertion into the lipid bilayer triggered by a $\mathrm{pH}$ drop and the peptide exit from the bilayer triggered by a rise in $\mathrm{pH}$.

\section{MATERIALS AND METHODS}

pHLIP variants were synthesized and purified by CS Bio Co, and tested for purity by HPLC upon receipt. Small unilamellar vesicles were prepared by extrusion. Steady-state 
fluorescence and circular dichroism (CD) measurements were performed using a PC1 spectrofluorometer (ISS, Inc) and a MOS-450 spectrometer (Biologic, Inc.), respectively, with temperature control set to $25.0^{\circ} \mathrm{C}$. Oriented $\mathrm{CD}(\mathrm{OCD})$ measurements were conducted on the supported bilayers placed on quartz slides using the Langmuir-Blodgett system (KSV Nima) as described previously (3). Tryptophan fluorescence and CD kinetics were measured using an SFM-300 mixing system (Bio-Logic Science Instruments) connected to the MOS-450 spectrometer with temperature control set to $25.0^{\circ} \mathrm{C}$. All data were fit to the appropriate equations by nonlinear least squares curve fitting procedures employing the Levenberg Marquardt algorithm using Origin 8.5. Detailed descriptions of all methods are presented in the Supporting Information.

\section{RESULTS}

We studied the kinetics of insertion into and exit from the lipid bilayer of POPC liposomes using three single Trp pHLIP variants, with the Trp reporters positioned in each flanking region and in the membrane inserted region. pHLIP peptides with a single tryptophan residue allow a "clean" photophysical signals originating from single fluorophores, avoiding spectral heterogeneity. pHLIP variants were designed based on the closely related group of the WT sequences (24), which contains several protonatable residues at the membrane inserting C-terminal end of the peptide. As we demonstrated previously, the presence of protonatable groups at the C-terminus of the peptide slows down the process of insertion of the peptide across a lipid bilayer, as well as slowing exit from the membrane $(2,3)$. These processes are completed within seconds, as opposed to milliseconds for truncated pHLIPs (2), which allows resolution of structural details along the insertion and 
exit pathways. The following single Trp pHLIP variants were designed and used in the current study:

pHLIP-W6: ADNNPWIYARYADLTTFPLLLLDLALLVDFDD

pHILP-W17: ADNNPFIYARYADLTTWLPLLLLDLALLVDFDD

pHLIP-W30: ADNNPFIYARYADLTTFPLLLLDLALLVDWWDD

The length of the designed variants is 32 residues and Trp residues are placed at positions 6, 17 and 30 in the pHLIP sequence in order to be located at the beginning, middle and end of the peptide in its helical inserted form. Phe was replacing other two Trp residues in each variant, which considered to be the best possible substitution of Trp. Using these designs, we can monitor the propagation of different parts of the peptide into and out of the bilayer by recording the changes of their fluorescence signals within single-Trp pHLIP variants.

First, we performed equilibrium measurements presented in Figures 1 and 2. Steady-state fluorescence, $\mathrm{CD}$ and $\mathrm{OCD}$ measurements were used to ensure that each variant is responsive to $\mathrm{pH}$ and adopts a $\mathrm{TM}$ helical orientation in a POPC bilayer at low $\mathrm{pH}$, which is the main feature of the peptides of pHLIP family (Supplementary Figure S1). Fluorescence spectra were analyzed using the Protein Fluorescence and Structural Tool Kit (PFAST) to determine the positions of spectral maxima $\left(\lambda_{\max }\right)(25,26)$. The transition from the membrane-adsorbed state at high $\mathrm{pH}$ to the membrane-inserted state at low $\mathrm{pH}$ was assessed from changes of the position of the Trp fluorescence maximum and the ellipticity measured at $222 \mathrm{~nm}$ in response to a pH drop from 8.5 to 4 (Figure 1 and Table 1). Analysis of Trp fluorescence reveals the presence of two transitions, which are especially noticeable for the W6 pHLIP variant. The mid-points of the first transition for all variants are 
established to be around $\mathrm{pH} 6$ with high cooperativity (parameter $n$ is from the equation given in the Supplementary Methods section), ranging from 2.4 to 3.5 for different pHLIPs. The second transition is found to be around $\mathrm{pH} 7.2$ with a cooperativity of ranging from 0.5 to 1.6. Interestingly, the $\mathrm{CD}$ data reporting the coil-helix transformation are clearly indicative of a single transition with its midpoint at $\mathrm{pH}$ 5.8-5.9 and cooperativity ranging from 1.8 to 2.4 for the different pHLIP variants. Note that the transition midpoint is a relatively well defined and stable parameter, while the measured cooperativity is less well determined and might vary over a relatively wide range within experimental error.

The local changes reported by the Trp locations and the general peptide changes reported by $\mathrm{CD}$ might be expected to vary from each other, since these parameters might reflect different processes. The high $\mathrm{pH}$ transition observed in the fluorescence signal reflects the protonation-deprotonation event, which might be associated with partitioning of regions of the peptide into the lipid bilayer, but not directly associated with the coil-helix transition. The most significant differences occur at the N-terminal part of the pHLIP peptide.

To gain more insight into the locations of Trp residues at different $\mathrm{pHs}$, we carried out Trp fluorescence quenching measurements (Figure 2 and Table 1). The emission of Trp residues was measured at different $\mathrm{pHs}$ at increasing concentrations of acrylamide, which is an effective quencher of Trp fluorescence. PFAST analysis was used to calculate SternVolmer constants $(25,26)$ and to calculate the percentage of quenching. At $\mathrm{pH} 8$ and $\mathrm{pH} 5$ the Stern-Volmer plots for all peptide variants demonstrate linear behavior with some upward curvature (Figure 2A and 2D). The upward curvature in quenching by acrylamide was observed before and attributed to the exponential distance-dependent rate of quenching (27). At intermediate $\mathrm{pH}$ of 6 a deviation from linearity is observed (Figure 2C), 
potentially reflecting the existence of different populations of pHLIPs, where Trp residues are located in different environments and their emission is quenched differently by acrylamide (28). Figure 2E and Table 1 reflect gradual decreases of acrylamide quenching of Trp fluorescence with decreases of $\mathrm{pH}$, which can be attributed to the partitioning of Trp residues into the membrane at lower $\mathrm{pH}$ and reduction of accessibility to the quencher. The smallest quenching among all pHLIP variants at low $\mathrm{pH}$ was observed for the W6 pHLIP variant, reflecting a more solvent-exposed position for Trp6, which correlates well with its higher long-wavelength emission at low pH compared to Trp17 and Trp30.

Insertion and exit kinetics measurements were triggered by a $\mathrm{pH}$ drop from 8 to 4 and a $\mathrm{pH}$ raise from 4 to 8, respectively (Supplementary Figure S2). Prior to the $\mathrm{pH}$ shift, peptide $(14 \mu \mathrm{M})$ and POPC $(2.8 \mathrm{mM})$ samples were incubated for $24 \mathrm{hrs}$ to reach equilibrium, when most of the peptide is associated with the liposomes (1). As we found previously, the peptide exit from the membrane is much faster than the insertion into the membrane $(2,3)$. All (or most) protonatable residues in the TM part and at the inserting end of the peptide need to be protonated and became neutral to enter the lipid bilayer, which takes time. On the other hand, the de-protonation of Asp13 may be enough to induce helix destabilization and peptide exit (4), especially when the C-terminal end of the inserted peptide is in its neutral state due to the fast equilibration of the $\mathrm{pH}$ established between the exterior and interior of the liposomes after the $\mathrm{pH}$ drop (2). Some differences were observed between variants for the insertion and exit kinetics.

To slow down the kinetic processes and enhance the observed differences we also used intermediate $\mathrm{pH}$ jumps: from $\mathrm{pH} 8$ to 5.9-6.2 and from $\mathrm{pH} 4$ to 5.8-6.2, monitoring changes of the fluorescence intensity and the position of maxima of fluorescence spectra during 
peptide insertion and exit. The changes of fluorescence were recorded at different wavelengths in a global mode, and fluorescence spectra were restored by data processing (Supplementary Figure S3 presents data obtained for Trp30 as an example). Changes of Trp emission intensity recorded at different intermediate $\mathrm{pH}$ jumps are shown on Figure 3.

The rates of peptide insertion decrease with decreases of the magnitudes of the $\mathrm{pH}$ jumps, and the differences in kinetics pathways between variants become more pronounced (Figure 3 A-C). Trp6 exhibits insertion kinetics with a reversal "kink" where the fluorescence signal first increases, then decays around $15-20 \mathrm{sec}$ after the initiation and is then followed by an emission increase (Figure $3 \mathrm{~A}$ and $4 \mathrm{~A}$ ). Trp17 reaches its final destination in the membrane rather quickly (Figure 3B). The insertion of $\operatorname{Trp} 30$ into the membrane occurs on the time scale of Trp6 and Trp17 insertions. The presence of a "kink" for Trp6 was also observed in the kinetics of the CD signal (Figure 4A) and on the graph of the intensity ratio (Figure 4B) from the fluorescence spectra recorded in the global mode. The ratio is a sensitive measure of the shift of the position of the emission maximum of W6 pHLIP variant insertion. A "kink" was also observed for the Trp30 insertion kinetics by monitoring intensity changes (Figure 4C) and using the intensity ratio (Figure 4D). The data clearly indicate that the propagation of pHLIP peptides into the membrane are associated with a series of changes in the microenvironments of the Trp residues.

The most interesting behavior during the exit of pHLIP variants was observed for Trp30 (Figure 3F and Figure 5). The fluorescence intensity first increased, then was followed by signal decay. The time of the increasing signal was shifted from $1.5 \mathrm{sec}$ in the case of $\mathrm{pH}$ jump from $\mathrm{pH} 4$ to 5.8 to $0.4 \mathrm{sec}$ in the case of $\mathrm{pH}$ jump from $\mathrm{pH} 4$ to 6.2 (with an intermediate time of $0.92 \mathrm{sec}$ - for the $\mathrm{pH}$ jump from 4 to 6.0). While the build up, which 
is completed within $<2 \mathrm{sec}$, is difficult to resolve in the global mode, the overall intensity decay (Figure 5B) correlates with the $333 \mathrm{~nm}$ to $351 \mathrm{~nm}$ ratio of emission. As with the insertion measurements, the exit kinetics reveal subtle features not previously observed.

\section{DISCUSSION}

To gain understanding of how a peptide can enter and leave a lipid bilayer, we used the $\mathrm{pH}$-triggered insetion and exit of three single-Trp pHLIP variants. We would like to outline that the study is a model biophysical and extreme $\mathrm{pHs}$ are set to observe completion of the transitions. Previously it was shown direct correlation between biophysical studies, experiments on cells for delivery of cargo molecules by pHLIP and animal studies for targeting of acidic tumors $(23,24)$. We found a previously unknown transition at high $\mathrm{pH}$ values that is especially pronounced for the N-terminal part of pHLIP. The transition correlates with our recent constant-pH molecular dynamics (MD) calculations, which suggest a high flexibility of the N-terminal flanking sequence of pHLIP (4). At different $\mathrm{pH}$ values in the range of 8.5 to 6.5 , pHLIP can adopt various conformational states at a bilayer surface, as was noticed previously $(6,8)$. These conformational changes are not associated with helix formation. A further drop of $\mathrm{pH}$ induces the familiar bilayerassociated coil-helix transition, leading to the stabilization of the TM helix at low $\mathrm{pH}$. Trp residues at positions 6 and 30 in the pHLIP sequences adopt similar, partially exposed positions within the lipid bilayer at the outer and inner leaflets, respectively, after peptide insertion, while Trp at position 17 is located near the center. Acrylamide quenching of Trp fluorescence confirmed single component emission at high and low pHs, when peptides are predominantly equilibrated in the inserted or bilayer-adsorbed states, but heterogeneity 
was observed at intermediate $\mathrm{pH}$ of 6 . By monitoring signals from single-Trp pHLIP variants, we were able to resolve ambiguities created by the interplay of signals from the two Trps in the WT peptide (9).

By using $\mathrm{pH}$ jumps of different magnitudes, we found intermediates that help us to better understand the principles of insertion and exit. If the $\mathrm{pH}$ jump is large enough, e.g. a change from $\mathrm{pH} 8$ to $\mathrm{pH} 4$, it can simultaneously protonate all (or most) of the protonatable residues in the membrane inserting part, and the peptide quickly inserts in a TM orientation. We previously found that truncation of the C-terminal, inserting part of WT pHLIP can enhance the rate of insertion by two orders of magnitude, revealing that protonated but still polar C-terminal carboxyl groups can pose a significant barrier for transit of the $\mathrm{C}$-terminus across the bilayer, but that entry can still proceed on a timescale of seconds $(2,23)$. However, if the $\mathrm{pH}$ jump is to an intermediate value, the concentration of protons in solution is not enough to fully shift the equilibrium toward the protonated form of residues at the C-terminal part of the peptide, and the peptide is trapped into intermediate states. At intermediate $\mathrm{pH}$ jumps $\mathrm{N}$ - and C-terminal parts of pHLIP alter their positions toward the bilayer center, while Trp17 adopts a position deep within the membrane rather quickly, as would be consistent with a bent but not inserted conformation. The insertion is completed slowly, consistent with a requirement that protonation of most of the Asp/Glu residues is needed for peptide insertion to proceed at a significant rate. As suggested by MD calculations, and as reasonably expected from the progressively lower dielectric environment, the $\mathrm{pKa}$ of protonation is shifted toward higher values as Asp, Glu and the C-terminus move deeper into the bilayer (4). 
As previously reported, the exit pathway resulting from a $\mathrm{pH}$ raise is different from the pathway of insertion (3). Changes in emission of tryptophan at the C-terminal part of pHLIP sequence (Trp30) during exit add to our understanding of the process, in which an increase of $\mathrm{pH}$ leads to the de-protonation of key Asp residues, destabilizing the bilayerinserted state, and triggering peptide exit. We observed an increase or "build up" of the fluorescence signal, followed by its decay, which clearly documents the exposure of Trp30 to the non-polar bilayer environment along the pathway of peptide exit from the bilayer. The propagation of the C-terminal part of pHLIP through the membrane slows down with a decrease of the magnitudes of the $\mathrm{pH}$ jumps.

We believe that our kinetics study, together with recent kinetics experiments on liposomes of different thickness of bilayer (5), theoretical (29) and computational (4) work, frames an improved understanding of the mechanism of pHLIP peptide insertion and exit from a bilayer in response to $\mathrm{pH}$ jumps. Figure 6 represents the general scheme of the processes as we now understand it. The membrane-adsorbed state is defined as predominantly unstructured (extended coil) with the C-terminus facing to the outside of a liposome (or extracellular space). The exact position of the peptide at the surface of the bilayer at high and neutral $\mathrm{pH}$ depends on the pHLIP sequence and lipid composition $(6,7,24,30)$. The inserted state is characterized by a transmembrane orientation of the peptide, with the Cterminal end of the peptide facing the liposome interior (or intracellular space). The transition from membrane-adsorbed to inserted states is triggered by $\mathrm{pH}$, which leads to the protonation of at least some Asp and Glu residues, increase of peptide hydrophobicity, deeper partition into bilayer associated with coli-helix transition. We now recognize a set of possible intermediate states, characterized by partially folded structures at the bilayer 
surface, where the $\mathrm{C}$-terminus is not translocated across the bilayer. The number and nature (transient, semi-stable or stable) of intermediate states is dependent on the number of protonatable groups or polar (charged) cargoes located at the peptide inserting end (2). Charged (or polar) residues and cargoes create forces directed away from the bilayer, which reduces the rate of peptide insertion. As we proposed (2) and recently verified (5), the predominant driving force for the transition from the helical surface intermediate state to the stable membrane inserted state is a relaxation of the membrane distortion created by the inclusion of helical structure at the bilayer surface. The presence of helical instability around the Pro residue in the middle of the helix provides additional flexibility to complete the transition toward a TM orientation. Figure 6 is not a simplified two-state model, it is a generalized model to include the behaviors of various pHLIP sequences within membranes of different lipid compositions.

Recently, a multistage model of WT-pHLIP insertion with distinct equilibrium thermodynamic intermediates has been proposed (8). While it is interesting to think there is a linear progression of states, the fact is that an ensemble of all peptide states exists at each $\mathrm{pH}$, so it remains challenging to define a unique succession. At high and low $\mathrm{pH}$ values the predominant, but still not unique states are the peptide membrane-adsorbed and membrane-inserted states, respectively, each of which has a variety of dynamic excursions. However, at intermediate $\mathrm{pH}$ values a more distributed mixture of states is present as can be seen in the kinetics measurements, and complexity is shown by the reversal of the fluorescence signal. Of course, in a biological system of living cells in diseased tissues, $\mathrm{pH}$ gradients exist across cell membranes, with a low $\mathrm{pH}$ at the outside surface of a cell and a higher $\mathrm{pH}$ in the cytoplasm (31). In a tumor cell, the $\mathrm{pH}$ at the cell surface can be below 
6 while the $\mathrm{pH}$ inside the cell is thought to be around 7.4. The $\mathrm{pH}$ gradient tends to stabilize the inserted state, since any $\mathrm{C}$-terminal protonatable residues translocated across the membrane into the cytoplasm will be relatively de-protonated in the environment of the normal $\mathrm{pH}$ of the cytoplasm, which leads to a significant reduction of the rate of peptide exit from the membrane.

Thermodynamics is not limiting for the intracellular delivery of cargo conjugated to pHLIP C-terminal inserting end, since the equilibrium of the pHLIP peptide in a cell with an acidic diseased phenotype will be as a TM helix and the chemical potential of the cargo will be about the same on either side of the membrane. Given enough time for equilibration, even polar or charged cargoes could be delivered into cells and trapped in the cytoplasm. However, in a living biological system the circulatory and other dynamics will tend to remove uninserted pHLIP complexes, so the kinetics of insertion becomes an important factor for tumor targeting and cargo delivery. Since pHLIPs have a significant affinity for bilayer surfaces, they sense the $\mathrm{pH}$ at the surfaces of cells in diseased tissues, and when $\mathrm{pH}$ is low, pHLIPs insert into cellular membrane. The rate of insertion depends on several factors: i) the level of acidity in the vicinity of cell membrane; ii) number of polar/charged residues at the membrane-inserting end of the peptide and/or polarity/charge of cargo molecule (if any), which peptide is translocating (flipping) across membrane, and iii) composition, thickness and fluidity of membrane $(2,5)$.

While the insertion of pHLIPs across membrane bilayers is of basic scientific interest, the possibility of clinical applications for tumor imaging and therapy is emerging as a reality. Clinical trials for applications to the targeting of imaging agents are about to start, with the first patients being scheduled at the time of this writing, and trials based on targeting tissues 
with a therapeutic agent are anticipated in 2020. By understanding the principles of pHLIP properties, it is likely that future applications can be broadened and improved.

\section{REFERNCES}

1. Reshetnyak YK, Andreev OA, Segala M, Markin VS, \& Engelman DM (2008) Energetics of peptide (pHLIP) binding to and folding across a lipid bilayer membrane. Proceedings of the National Academy of Sciences 105(40):15340-15345.

2. Karabadzhak AG, et al. (2012) Modulation of the pHLIP transmembrane helix insertion pathway. Biophys $J$ 102(8):1846-1855.

3. Andreev OA, et al. (2010) $\mathrm{pH}$ (low) insertion peptide (pHLIP) inserts across a lipid bilayer as a helix and exits by a different path. Proc Natl Acad Sci U S A 107(9):40814086.

4. Vila-Vicosa D, et al. (2018) Membrane-Induced p Ka Shifts in wt-pHLIP and Its L16H Variant. J Chem Theory Comput 14(6):3289-3297.

5. Karabadzhak AG, et al. (2018) Bilayer Thickness and Curvature Influence Binding and Insertion of a pHLIP Peptide. Biophys J 114(9):2107-2115.

6. Vasquez-Montes V, Gerhart J, King KE, Thevenin D, \& Ladokhin AS (2018) Comparison of lipid-dependent bilayer insertion of pHLIP and its P20G variant. Biochim Biophys Acta Biomembr 1860(2):534-543. 
7. Kyrychenko A, Vasquez-Montes V, Ulmschneider MB, \& Ladokhin AS (2015) Lipid headgroups modulate membrane insertion of pHLIP peptide. Biophys $J$ 108(4):791794.

8. Otieno SA, et al. (2018) pH-dependent thermodynamic intermediates of pHLIP membrane insertion determined by solid-state NMR spectroscopy. Proc Natl Acad Sci U S A 115(48):12194-12199.

9. Hanz SZ, et al. (2016) Protonation-Driven Membrane Insertion of a pH-Low Insertion Peptide. Angew Chem Int Ed Engl 55(40):12376-12381.

10. Shu NS, Chung MS, Yao L, An M, \& Qiang W (2015) Residue-specific structures and membrane locations of pH-low insertion peptide by solid-state nuclear magnetic resonance. Nat Commun 6:7787.

11. Wyatt LC, Lewis JS, Andreev OA, Reshetnyak YK, \& Engelman DM (2017) Applications of pHLIP Technology for Cancer Imaging and Therapy. Trends Biotechnol 35(7):653-664.

12. Bernardo BC, Ooi JY, Lin RC, \& McMullen JR (2015) miRNA therapeutics: a new class of drugs with potential therapeutic applications in the heart. Future Med Chem 7(13):1771-1792.

13. Andreev OA, Engelman DM, \& Reshetnyak YK (2014) Targeting diseased tissues by pHLIP insertion at low cell surface pH. Front Physiol 5:97.

14. Pereira MC, Reshetnyak YK, \& Andreev OA (2015) Advanced targeted nanomedicine. J Biotechnol 202:88-97. 
15. Pillai SR, et al. (2019) Causes, consequences, and therapy of tumors acidosis. Cancer Metastasis Rev 38(1-2):205-222.

16. Damgaci S, et al. (2018) Hypoxia and acidosis: immune suppressors and therapeutic targets. Immunology 154(3):354-362.

17. Kato Y, et al. (2013) Acidic extracellular microenvironment and cancer. Cancer Cell Int 13(1):89.

18. Netea-Maier RT, Smit JWA, \& Netea MG (2018) Metabolic changes in tumor cells and tumor-associated macrophages: A mutual relationship. Cancer Lett 413:102-109.

19. Anderson M, Moshnikova A, Engelman DM, Reshetnyak YK, \& Andreev OA (2016) Probe for the measurement of cell surface pH in vivo and ex vivo. Proc Natl Acad Sci U S A 113(29):8177-8181.

20. Andreev OA, Engelman DM, \& Reshetnyak YK (2010) pH-sensitive membrane peptides (pHLIPs) as a novel class of delivery agents. Mol Membr Biol 27(7):341-352.

21. Andreev OA, Engelman DM, \& Reshetnyak YK (2009) Targeting acidic diseased tissue: New technology based on use of the pH (Low) Insertion Peptide (pHLIP). Chim Oggi 27(2):34-37.

22. Wei D, Engelman DM, Reshetnyak YK, \& Andreev OA (2019) Mapping pH at Cancer Cell Surfaces. Mol Imaging Biol.

23. Weerakkody D, et al. (2013) Family of pH (low) insertion peptides for tumor targeting. Proc Natl Acad Sci U S A 110(15):5834-5839. 
24. Wyatt LC, et al. (2018) Peptides of pHLIP family for targeted intracellular and extracellular delivery of cargo molecules to tumors. Proc Natl Acad Sci U SA 115(12):E2811-E2818.

25. Shen C, et al. (2008) The protein fluorescence and structural toolkit: Database and programs for the analysis of protein fluorescence and structural data. Proteins 71(4):17441754.

26. Burstein EA, Abornev SM, \& Reshetnyak YK (2001) Decomposition of protein tryptophan fluorescence spectra into log-normal components. I. Decomposition algorithms. Biophys J 81(3):1699-1709.

27. Zelent B, Kusba J, Gryczynski I, Johnson ML, \& Lakowicz JR (1993) Distancedependent fluorescence quenching ofN-acetyl-L-tryptophanamide by acrylamide. $J$ Fluoresc 3(3):199-207.

28. Reshetnyak YK \& Burstein EA (2001) Decomposition of protein tryptophan fluorescence spectra into log-normal components. II. The statistical proof of discreteness of tryptophan classes in proteins. Biophys $J$ 81(3):1710-1734.

29. Sharma GP, Reshetnyak YK, Andreev OA, Karbach M, \& Muller G (2015) Coilhelix transition of polypeptide at water-lipid interface. J Stat Mech 2015.

30. Scott HL, Heberle FA, Katsaras J, \& Barrera FN (2019) Phosphatidylserine Asymmetry Promotes the Membrane Insertion of a Transmembrane Helix. Biophys $J$ 116(8):1495-1506. 
31. Swietach P, Vaughan-Jones RD, Harris AL, \& Hulikova A (2014) The chemistry, physiology and pathology of $\mathrm{pH}$ in cancer. Philos Trans $R$ Soc Lond B Biol Sci 369(1638):20130099. 


\section{TABLES}

Table 1. Tryptophan emission parameters obtained from steady-state fluorescence and CD measurements (mean \pm standard deviation) are presented. The tryptophan fluorescence spectra were processed by PFAST to identify positions of spectral maxima $\left(\lambda_{\max }\right)$. Values of $\lambda_{\max }$ were averaged over several different steady-state fluorescence measurements. The parameters representing transitions induced by a $\mathrm{pH}$ drop from 9 to 3 , including the midpoint of the $\mathrm{pH}$ transition $(p K)$ and cooperativity $(n)$, were calculated by fitting values of the position of maximum of fluorescence (Fluor) and ellipticity at $222 \mathrm{~nm}$ (CD) measured at different pHs. The Stern-Volmer constants $\left(K_{\mathrm{Sv}}, \mathrm{M}^{-1}\right)$ for acrylamide quenching of tryptophan fluorescence of peptides in POPC liposomes at different $\mathrm{pHs}$ were obtained after PFAST analysis of fluorescence spectra.

\begin{tabular}{|l|l|l|l|}
\hline & W6 & W17 & W30 \\
\hline$\lambda_{\max }, \mathrm{pH} 8(\mathrm{~nm})$ & $349.5 \pm 0.4$ & $349.2 \pm 0.3$ & $352.1 \pm 0.4$ \\
$\lambda_{\max }, \mathrm{pH} 8+\mathrm{PC}(\mathrm{nm})$ & $347.9 \pm 0.9$ & $346.9 \pm 0.8$ & $350.4 \pm 0.3$ \\
$\lambda_{\max }, \mathrm{pH} 5+\mathrm{PC}(\mathrm{nm})$ & $340.4 \pm 0.7$ & $332.3 \pm 1.6$ & $339.7 \pm 0.9$ \\
\hline Fluor, $p K_{1}$ & $6.0 \pm 0.0$ & $6.0 \pm 0.0$ & 6.1 (fixed) \\
Fluor, $n_{1}$ & $3.5 \pm 0.3$ & $2.6 \pm 0.1$ & $2.4 \pm 0.2$ \\
\hline Fluor, $p K_{2}$ & $7.2 \pm 0.1$ & $7.3 \pm 0.1$ & 7.2 (fixed) \\
Fluor, $n_{2}$ & $1.6 \pm 0.4$ & $1.2 \pm 0.4$ & $0.5 \pm 0.1$ \\
\hline $\mathrm{CD}, p K$ & $5.9 \pm 0.0$ & $5.8 \pm 0.0$ & $5.8 \pm 0.0$ \\
$\mathrm{CD}, n$ & $2.2 \pm 0.2$ & $2.4 \pm 0.2$ & $1.8 \pm 0.2$ \\
\hline$K_{\text {sv }}, \mathrm{pH} 7.9-8.1 \mathrm{PC}\left(\mathrm{M}^{-1}\right)$ & $20.5 \pm 3.5$ & $20.1 \pm 2.1$ & $21.2 \pm 3.9$ \\
$K_{\mathrm{sv}}, \mathrm{pH} 7.0-7.3 \mathrm{PC}\left(\mathrm{M}^{-1}\right)$ & $19.3 \pm 0.5$ & $18.2 \pm 1.1$ & $18.1 \pm 0.4$ \\
$K_{\mathrm{sv}}, \mathrm{pH} 5.9-6.2 \mathrm{PC}\left(\mathrm{M}^{-1}\right)$ & $8.0 \pm 0.6$ & $11.6 \pm 1.7$ & $12.6 \pm 0.7$ \\
$K_{\mathrm{sv}}, \mathrm{pH} 4.8-5.0 \mathrm{PC}\left(\mathrm{M}^{-1}\right)$ & $6.2 \pm 0.9$ & $2.4 \pm 0.1$ & $2.9 \pm 0.2$ \\
\hline
\end{tabular}




\section{FIGURE LEGENDS}

Figure 1. pH-dependent bilayer insertion of pHLIP variants. The pH-dependent insertion of W6 (A and D), W17 (B and E) and W30 (C and F) pHLIP variants into the lipid bilayers of POPC liposomes was studied by monitoring the changes in the position of maxima of tryptophan fluorescence spectra (A-C) and ellipticity of CD signals measured at $222 \mathrm{~nm}(\mathrm{D}-\mathrm{F})$ as function of $\mathrm{pH}$. The data were fitted using the Henderson-Hasselbalch equation, the fitting curves and $95 \%$ confidence interval are shown by red and pink areas, respectively.

Figure 2. Acrylamide quenching. Quenching of tryptophan fluorescence of W6, W17 and W30 pHLIP variants in presence of POPC liposomes at the range of $\mathrm{pH}$ values: $\mathrm{pH} 7.9-8.1$ (A), $\mathrm{pH} 7.0-7.3$ (B), pH5.9-6.2 (C), $\mathrm{pH} 4.8-5.0$ (D) are presented. The percentage of quenching at different pHs calculated for different pHLIP variants is shown in panel E, assuming quenching of tryptophan in solution by acrylamide $\left(21 \mathrm{M}^{-1}\right)$ to be $100 \%$.

Figure 3. Kinetics of insertion and exit. Representative kinetic curves for the insertion (A-C) of W6 (A, D), W17 (B, E) and W30 (C, F) pHLIP variants into the lipid bilayer triggered by drops of $\mathrm{pH}$ from $\mathrm{pH} 8$ to $\mathrm{pHs} 5.8,6.0$ and 6.2, and for the exit (D-F) of W6 (A, D), W17 (B, E) and W30 (C, F) pHLIP variants out of the lipid bilayer triggered by raises of $\mathrm{pH}$ from $\mathrm{pH} 4$ to $\mathrm{pHs} 5.8,6.0$ and 6.2 are shown. The normalized fluorescence measured via 320 cut off filter is presented. 
Figure 4. Kinetics of insertion. Representative kinetic curves for the insertion of W6 (A, B) and W30 (C, D) pHLIP variants into the lipid bilayer triggered by drops of pH from $\mathrm{pH} 8$ to $\mathrm{pH} 5.8-5.9$, and from $\mathrm{pH} 8$ to $\mathrm{pH} 6.2$, respectively, are shown. The peptides insertion was monitored by changes of fluorescence intensity $(\mathrm{A}, \mathrm{C})$ and ratios of fluorescence measured at different wavelengths in the global mode kinetics experiments (B, D). The W6 pHLIP variant folding and unfolding was monitored by changes of the CD signal (A). Red curves in panels B, C and D represent averages of the measured signal shown in black.

Figure 5. Kinetics of exit. Representative kinetic curves for the exit of the W30 pHLIP variant from the lipid bilayer triggered by raises of $\mathrm{pH}$ from $\mathrm{pH} 4$ to $\mathrm{pHs} 5.8,6.0$ and 6.2 are shown. The peptide exit from the membrane was monitored by changes of fluorescence intensity (A, B) and ratio of fluorescence measured at different wavelengths in global mode kinetics experiments (C). Red curve at panel $\mathrm{C}$ represents averaged of the measured signal shown in black.

Figure 6. Model of pHLIP insertion and exit. Schematic presentation of pHLIP folding and insertion into a bilayer, as well as the pHLIP exit and unfolding are shown. Approximate locations of Trp6, Trp17 and Trp30 are shown by green, blue and yellow colors, respectively. The structure of WT pHLIP in the membrane-inserted state was taken from the results of MD simulations (15). 
Figures
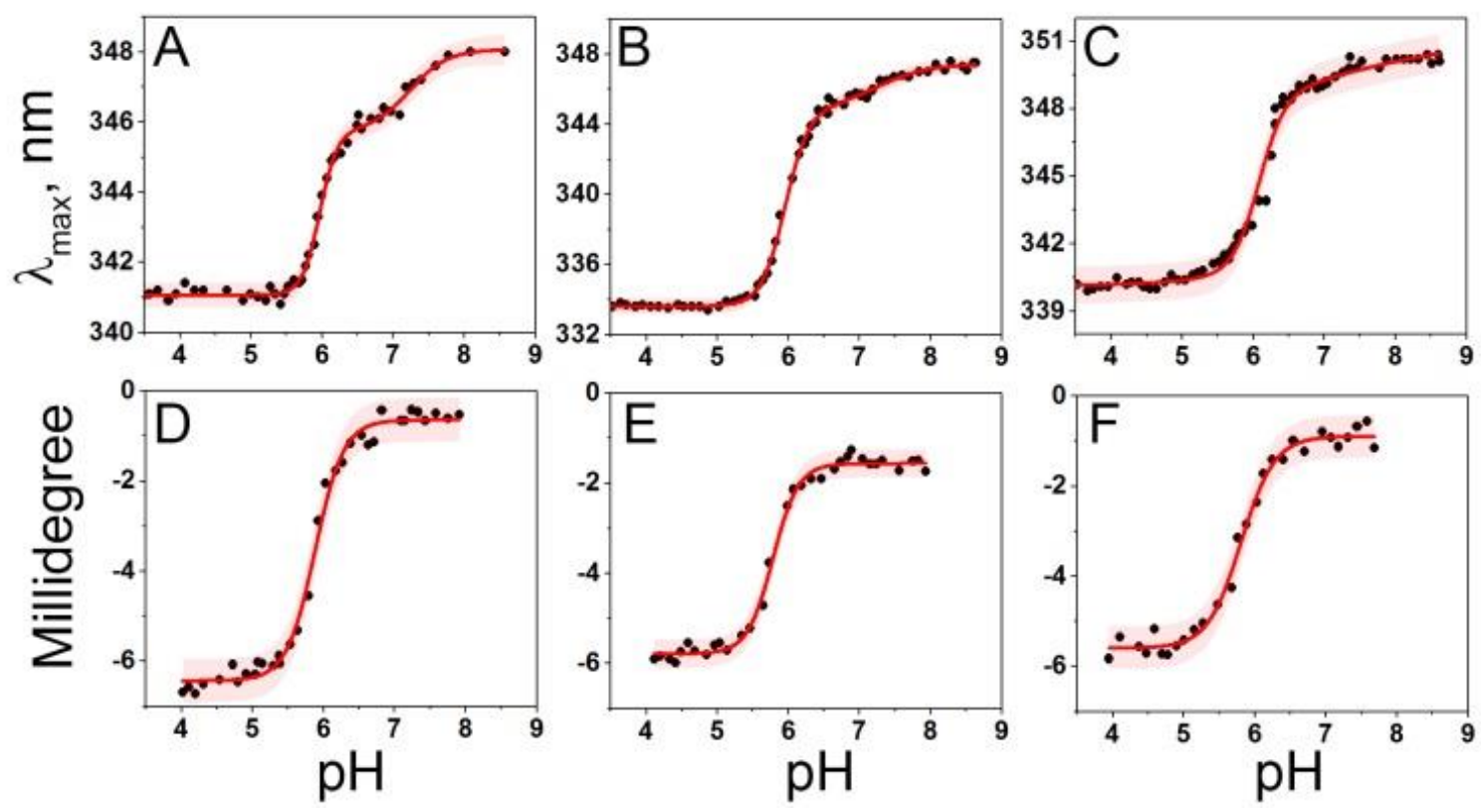

Figure 1 

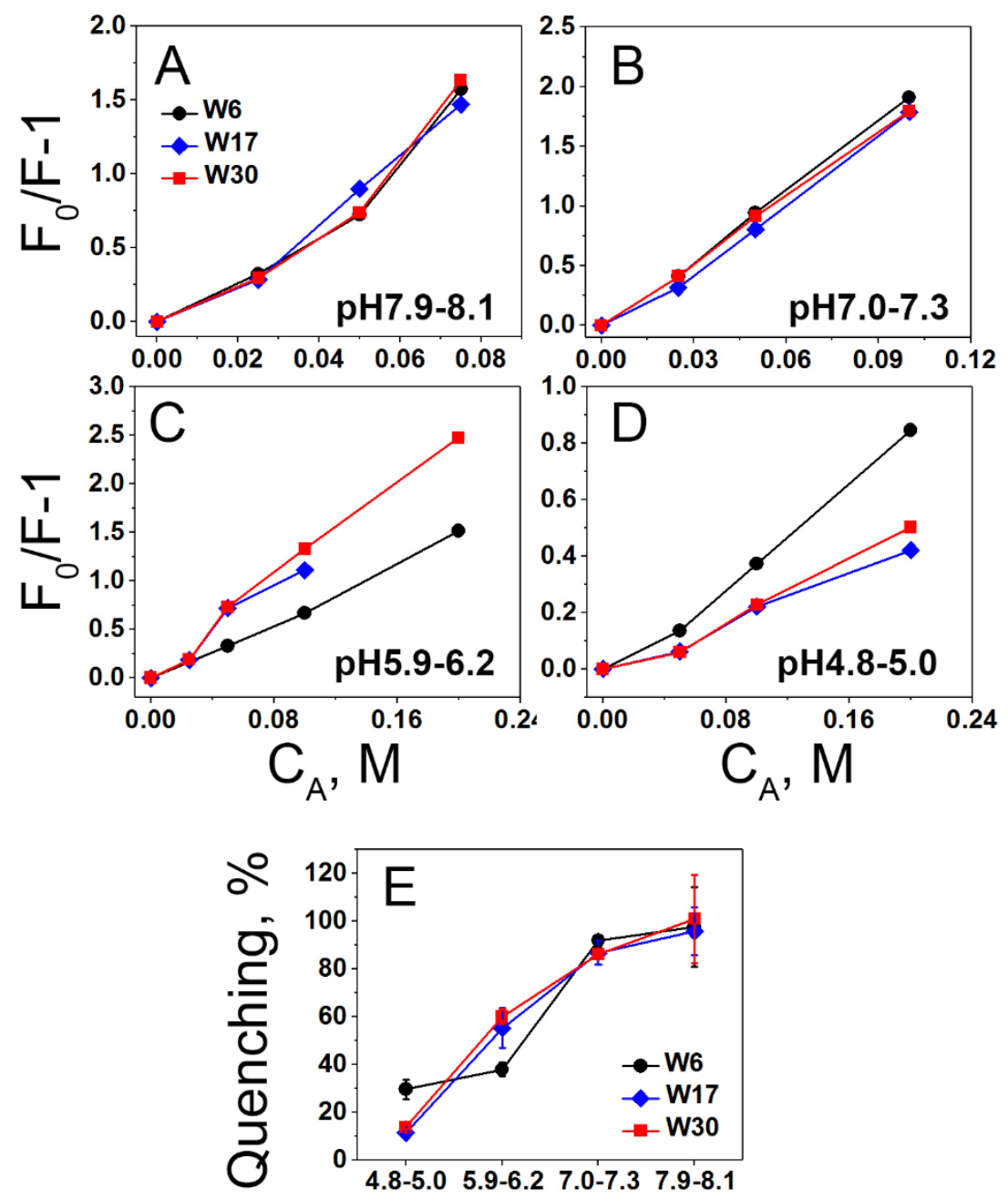

$\mathrm{pH}$

Figure 2 

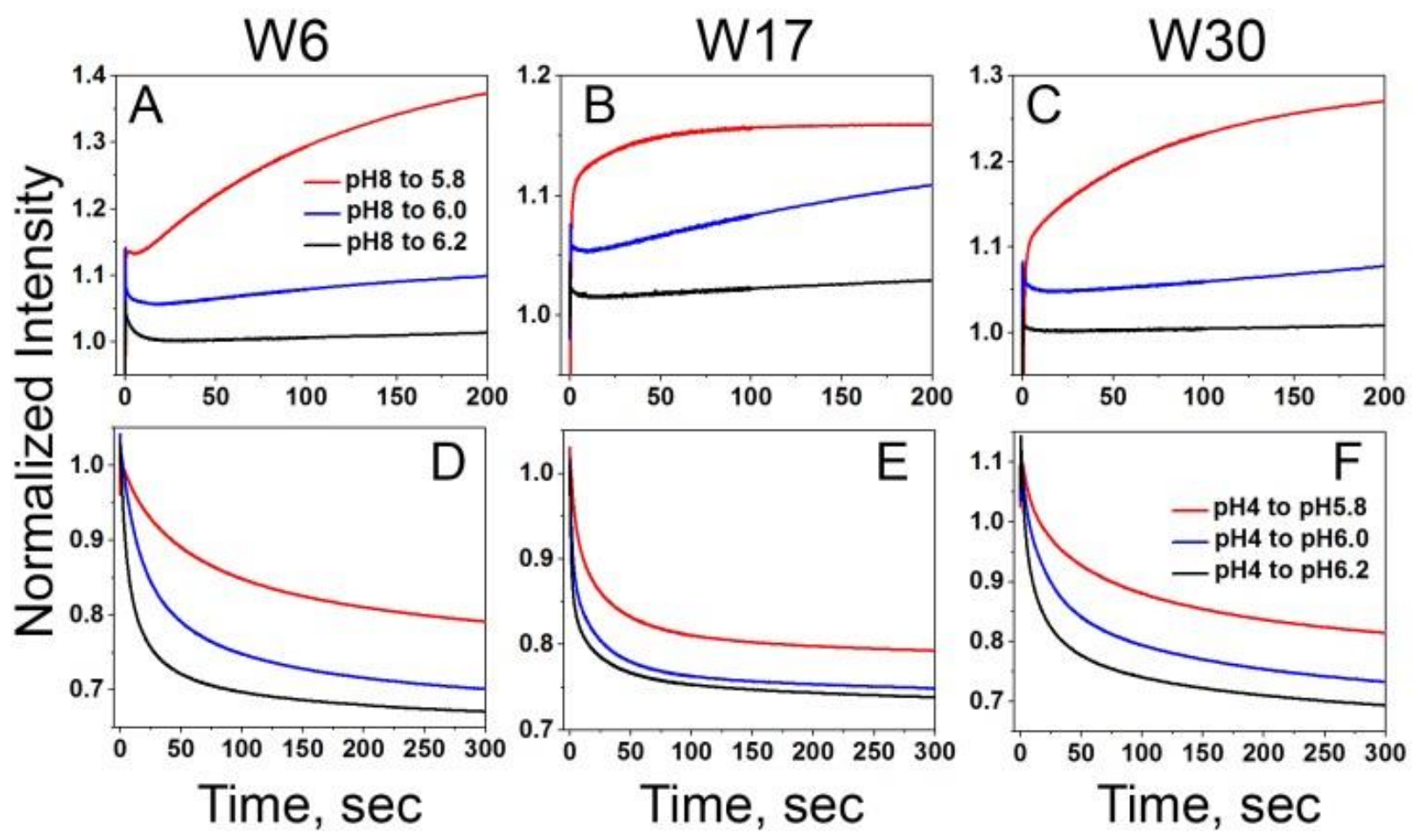

Figure 3 

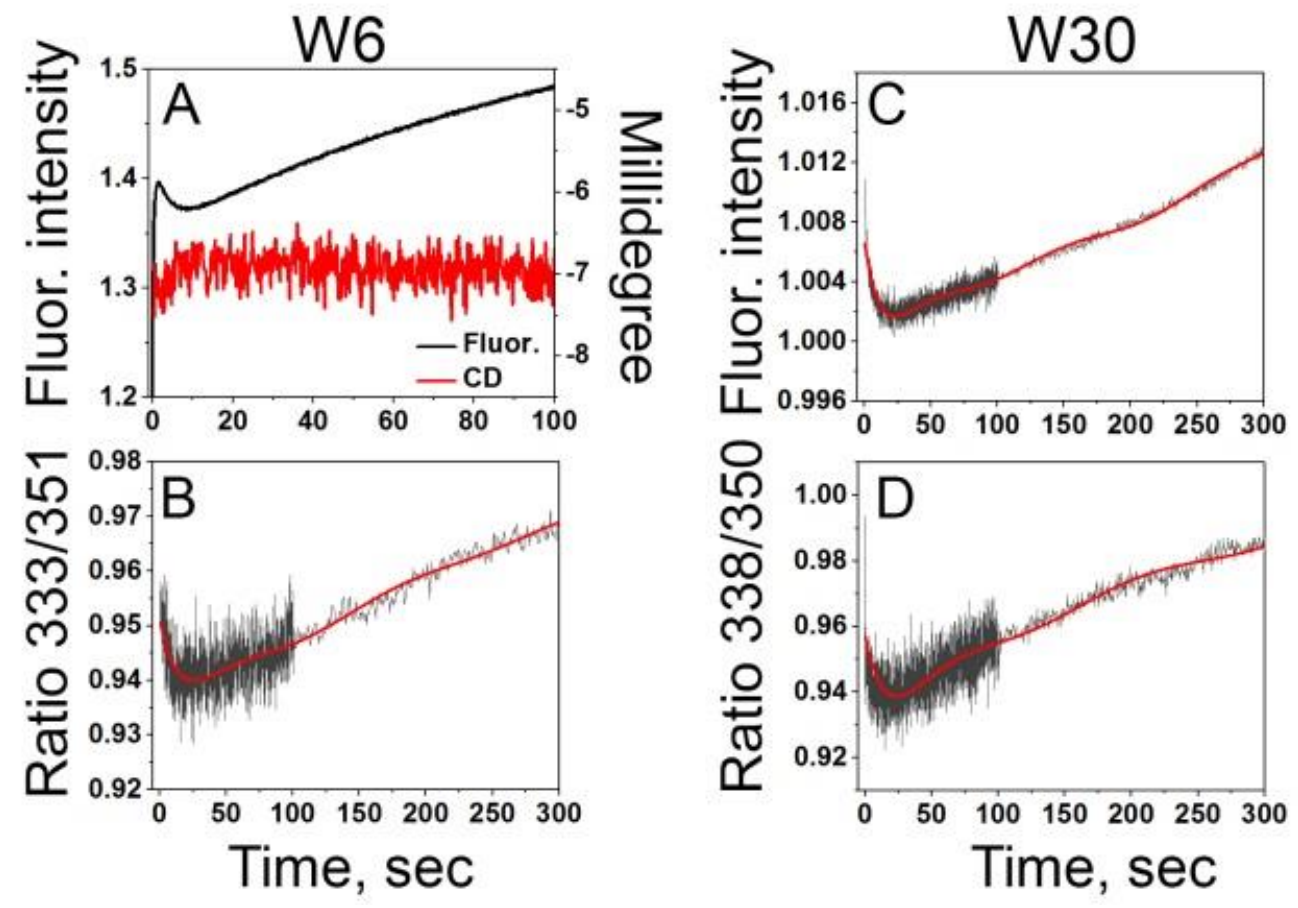

Figure 4 

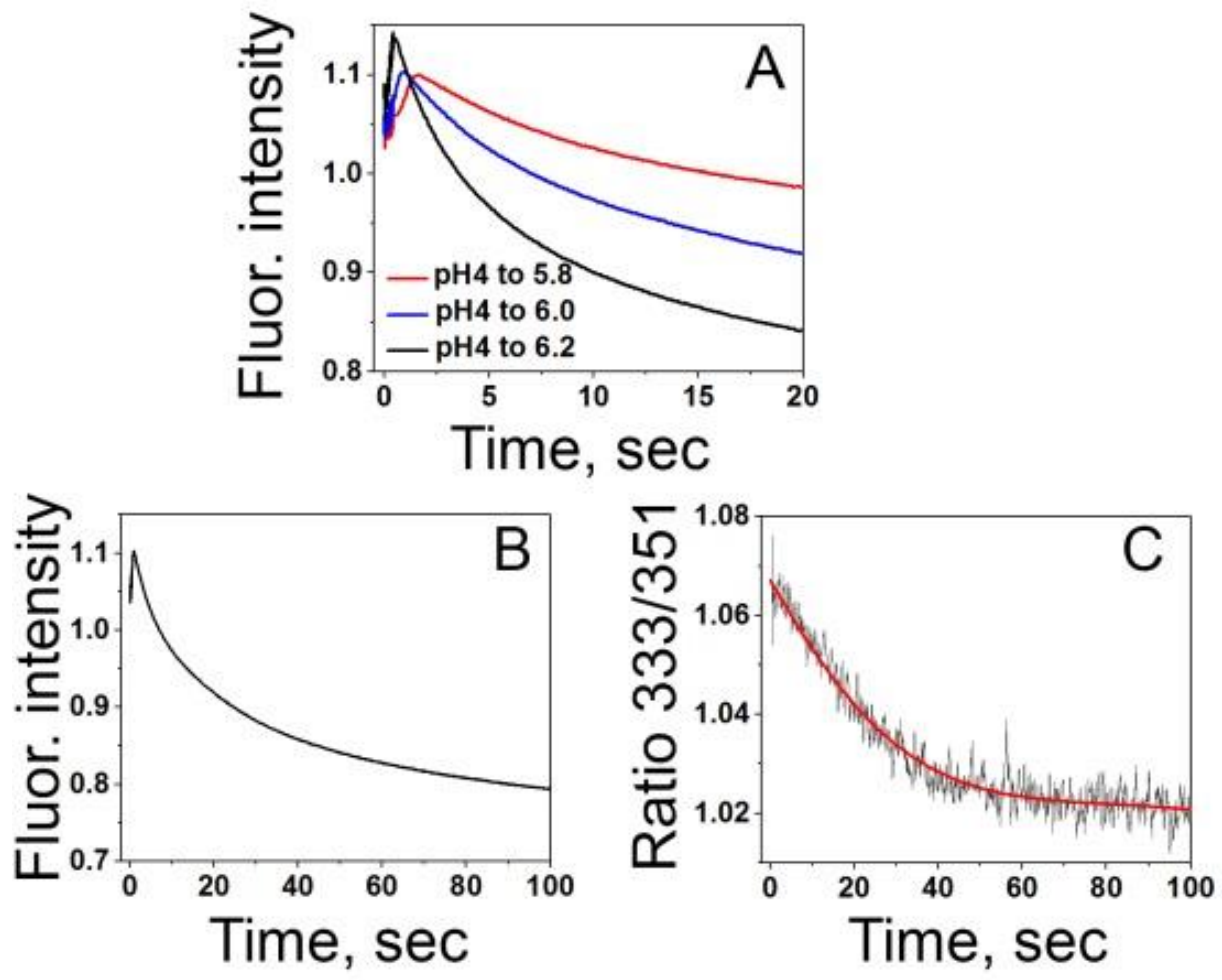

Figure 5 


\section{insertion/folding triggered by $\mathrm{pH}$ drop}

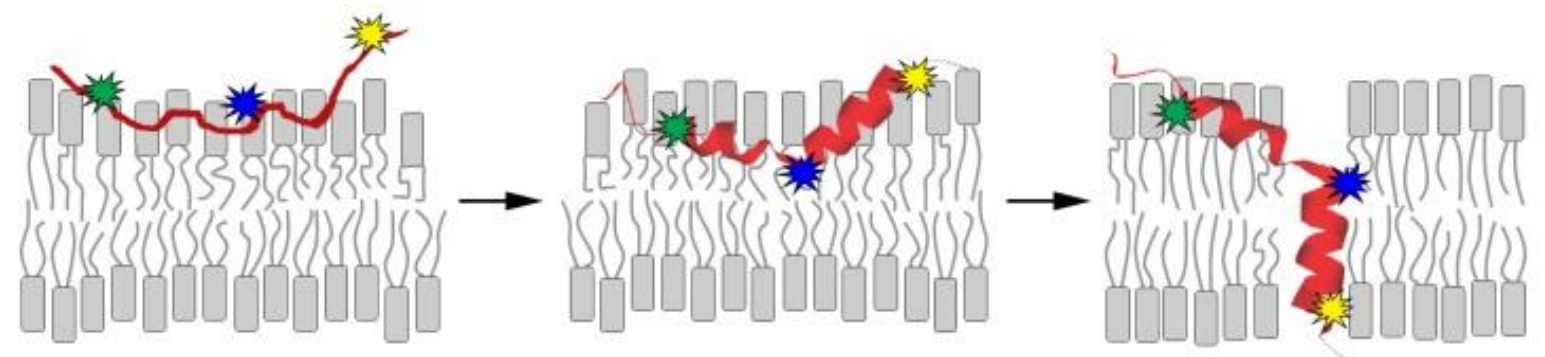

exit/unfolding triggered by $\mathrm{pH}$ increase

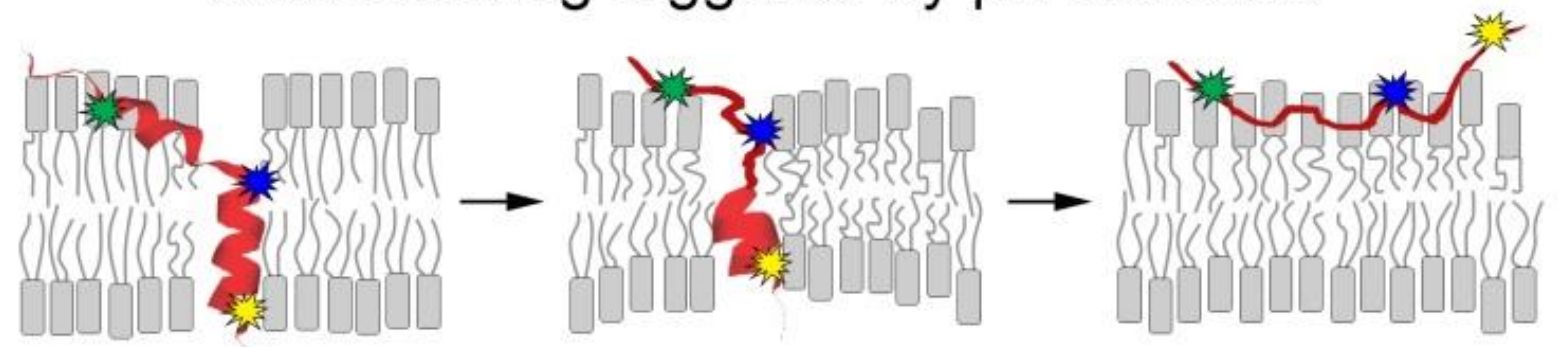

Figure 6 


\section{Supporting Information}

\section{METHODS}

\section{Peptide Preparation}

Peptides were synthesized and purified by CSBio (Menlo Park, CA). Purified peptides were dissolved in $6 \mathrm{M}$ urea and passed through a G-10 size exclusion spin column to transfer to $10 \mathrm{mM}$ phosphate buffer, $\mathrm{pH}$ 8. Peptide concentrations were calculated using absorbance measurements at $280 \mathrm{~nm}$, where $\varepsilon_{280}=8,520 \mathrm{M}^{-1} \cdot \mathrm{cm}^{-1}$.

\section{Liposome Preparations}

Small unilamellar vesicles were prepared by extrusion. 1-Palmitoyl-2-oleoyl-sn-glycero3-phosphocholine (POPC, Avanti Polar Lipids, Inc.) dissolved in chloroform at a concentration of $12.5 \mathrm{mg} / \mathrm{ml}$ was desolvated in a rotary evaporator to create a phospholipid film and placed under high vacuum for 2 hours. Lipids were then rehydrated in phosphate buffer ( $\mathrm{pH}$ 8) and extruded through membranes with pore size of $50 \mathrm{~nm}$. The liposome size distribution was measured using a nanoparticle tracking system, Nanosight (NS300, Malvern).

\section{EQUILIBRIUM MEASUREMENTS}

\section{Steady-State fluorescence and CD}

All steady-state spectral measurments including fluorescence, circular dichroism (CD), oriented $\mathrm{CD}(\mathrm{OCD}), \mathrm{pH}$-dependence and acrylamide quenching were performed using a PC1 spectrofluorometer (ISS, Inc) and a MOS-450 spectrometer (Biologic, Inc with temperature control set to $25.0^{\circ} \mathrm{C}$. Tryptophan fluorescence spectra were recorded from 
310 to $390 \mathrm{~nm}$ with step of 1 or $2 \mathrm{~nm}$ using an excitation wavelength of $295 \mathrm{~nm}$. Excitation and emission polarizers were set to $54.7^{\circ}$ and $0.0^{\circ}$, respectively. CD and OCD spectra were recorded from 195 to $260 \mathrm{~nm}$ with step of $1 \mathrm{~nm}$. The concentration of peptide and liposomes were $7 \mu \mathrm{M}$ and $1.4 \mathrm{mM}$, respectively.

\section{Oriented CD}

OCD measurements were conducted on supported bilayers deposited on quartz slides using a Langmuir-Blodgett system (KSV Nima). Fourteen slides were cleaned using the following protocol; sonication for $10 \mathrm{~min}$ in cuvette cleaner solution (5\% Contrad in water), 2-propanol, acetone, 2-propanol, followed by rinsing in deionized water. Finally, the slides were immersed in a mixture of concentrated sulfuric acid and hydrogen peroxide (3:1 ratio) for 5 min to remove any remaining organic material and then rinsed three times in deionized water. The slides were stored in deionized water until the monolayers were applied. The POPC monolayers were deposited on the quartz slides using a KSV minitrough. For the Langmuir-Blodgett system, POPC dissolved in chloroform solution at $3 \mathrm{mg} / \mathrm{ml}$ was spread on subphase. After allowing chloroform to evaporate, the POPC monolayer was compressed to $32 \mathrm{mN} / \mathrm{m}$. The initial layers on the slides were deposited by retrieving the slide from the subphase at a rate of $15 \mathrm{~mm} / \mathrm{min}$, and the second layer was added by introducing a solution of $10 \mu \mathrm{M}$ peptide and $1 \mathrm{mM}$ POPC liposomes (50-nm in size) at $\mathrm{pH} 4$, resulting in the creation of the supported bilayer via fusion of one layer with liposomes. After incubation for $6 \mathrm{~h}$ at $100 \%$ humidity, excess vesicles were carefully removed, buffer at $\mathrm{pH} 4$ was added to the spaces between slides, and the slides were stacked with $0.2-\mathrm{mm}$ spacers. $\mathrm{CD}$ measurements were taken at three time points: immediately after 
the addition of the peptide/liposome solution $(0 \mathrm{~h})$, after $6 \mathrm{~h}$ and $12 \mathrm{~h}$ of incubation time (6 h and $12 \mathrm{~h}$ ).

\section{pH dependence}

The $\mathrm{pH}$-dependent insertion of the peptides into the lipid bilayer of liposomes was studied by monitoring either the changes in tryptophan fluorescence spectra or changes in the molar ellipticity at $222 \mathrm{~nm}$ as a function of $\mathrm{pH}$. After the addition of aliquots of citric acid, the pHs of solutions containing $7 \mu \mathrm{M}$ peptide and $1.4 \mathrm{mM}$ POPC liposomes were measured using an Orion PerHecT ROSS Combination pH Micro Electrode and an Orion Dual Star $\mathrm{pH}$ and ISE Benchtop Meter before and after each spectrum measurement to ensure that equilibrium is achieved. The tryptophan fluorescence at each $\mathrm{pH}$ was measured on a PC1 spectrofluorometer. Fluorescence spectra were analyzed using the Protein Fluorescence and Structural Tool Kit (PFAST) to determine the positions of spectral maxima $\left(\lambda_{\max }\right)$. Finally, $\lambda_{\max }$ or millidegree were plotted as a function of $\mathrm{pH}$. The $\mathrm{pH}$-dependence was fit with the Henderson-Hasselbach equation (using OriginLab software) to determine the cooperativity $\left(n_{i}\right)$ and the mid-point $(p K)$ of a single or two transitions: Normalized $p H$ dependence $=\frac{1}{1+10^{n_{i}\left(p H-p K_{i}\right)}}$

\section{Acrylamide quenching}

Tryptophan fluorescence quenching experiments were conducted using acrylamide in the cuvette of $3 \times 3 \mathrm{~mm}$. Solutions containing $7 \mu \mathrm{M}$ of pHLIP peptides and $1.4 \mathrm{mM}$ of POPC liposomes were adjusted to about $\mathrm{pH} 8,7,6$, or 5. Tryptophan fluorescence quenching was achieved by addition of increasing amounts of acrylamide. Different amounts of acrylamide used for different $\mathrm{pH}$ values (the maximum was $0.2-0.3 \mathrm{M}$ of acrylamide for 
measurements performed at low $\mathrm{pH}$ ). The obtained data were corrected for the dilution and inner filter effect taking into account that the exctiction coefficient for acrylamide at 295 $\mathrm{nm}$ is $0.25 \mathrm{M}^{-1} \mathrm{~cm}^{-1}$. PFAST analysis was employed to calculate Stern-Volmer constants and to calculate the percentage of quenching (100\% was assigned to the quenching of tryptophan in solution, $\mathrm{K}_{\mathrm{SV}}=21 \mathrm{M}^{-1}$ ).

\section{Kinetics Measurements}

Tryptophan fluorescence and CD kinetics were measured using a SFM-300 mixing system (Bio-Logic Science Instruments) in combination with the MOS-450 spectrometer with temperature control set to $25.0^{\circ} \mathrm{C}$. All samples were degassed before measurements to minimize air bubbles in the samples. Peptide $(14 \mu \mathrm{M})$ and POPC $(2.8 \mathrm{mM})$ samples were incubated for $24 \mathrm{hrs}$ to reach equilibrium, when most of the peptide is associated with liposome lipid bilayers. To follow peptide insertion, equal volumes of peptide-POPC solution and citric acid were fast mixed (5-ms dead time) to lower the $\mathrm{pH}$ from $\mathrm{pH} 8$ to the desired lower $\mathrm{pH}$ value. To measure peptide exit, equal volumes of peptide-POPC solution and disodium phosphate were mixed to raise the $\mathrm{pH}$ from $\mathrm{pH} 4$ to the desired higher $\mathrm{pH}$ value. To monitor fluorescence intensity changes during peptide insertion or exit, the tryptophan emission signal was observed through a cut off $320 \mathrm{~nm}$ filter at an excitation of $295 \mathrm{~nm}$. To monitor the shift of the entire tryptophan spectra of the peptides during insertion and exit, (excited at $295 \mathrm{~nm}$ ) an emission monochromator was used. In the latter case, fluorescence kinetics spectra were recorded in a global mode at individual emission wavelengths from $321 \mathrm{~nm}$ to $366 \mathrm{~nm}$ with steps of $3 \mathrm{~nm}$. Three-dimensional plots were constructed reflecting changes in fluorescence intensity, time, and wavelength. Twodimensional plots were made by taking cross sections at particular times and plotting 
intensity vs. wavelength. To monitor coil-helix transition (and vice versa) the CD signal at $222 \mathrm{~nm}$ was recorded.

\section{Data analysis}

All data were fit to the appropriate equations by nonlinear least squares curve fitting procedures employing the Levenberg Marquardt algorithm using Origin 8.5.

\section{FIGURES}

W6

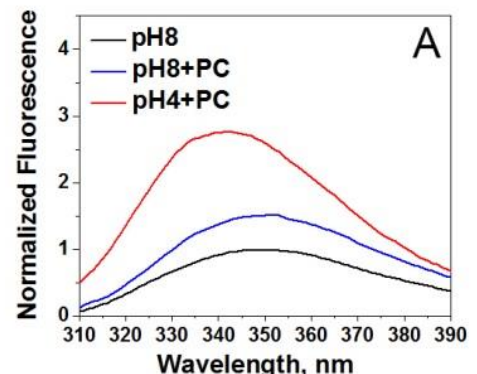

Wavelength, $\mathrm{nm}$

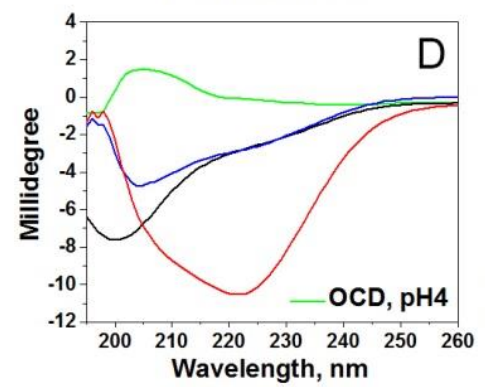

W17

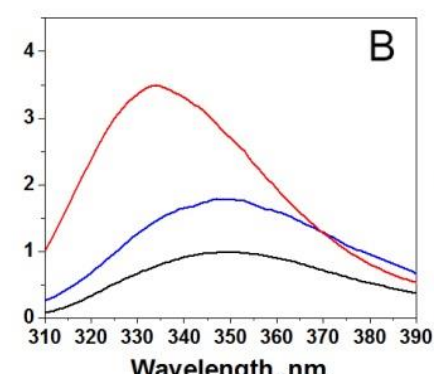

Wavelength, $\mathrm{nm}$

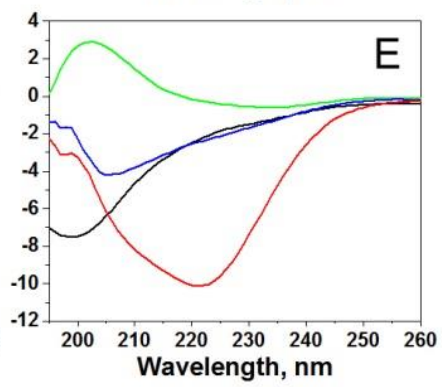

W30

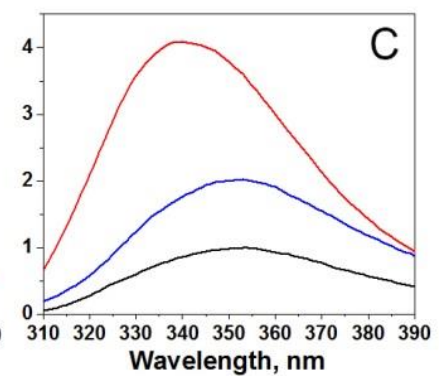

Wavelength, $\mathrm{nm}$

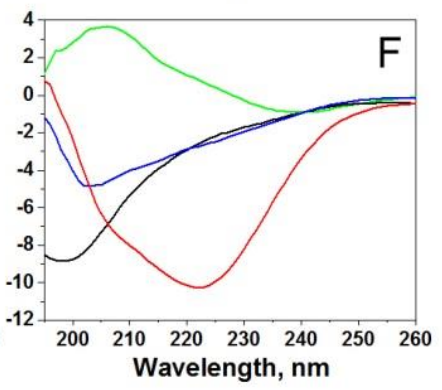

Figure S1. Tryptophan fluorescence (A-C), CD and OCD (D-F) spectra are shown from Trp6 (A, D), Trp17 (B, E) and Trp30 (C, F) pHLIP variants: in aqueous solution at pH 8 (black lines), at pH8 in the presence of POPC liposomes (blue lines) and at $\mathrm{pH} 4$ in the presence of POPC liposomes (red lines). Oriented circular dichroism (OCD) signals measured at low $\mathrm{pH}$ in supported bilayers are shown in panels D-F (green curves). 

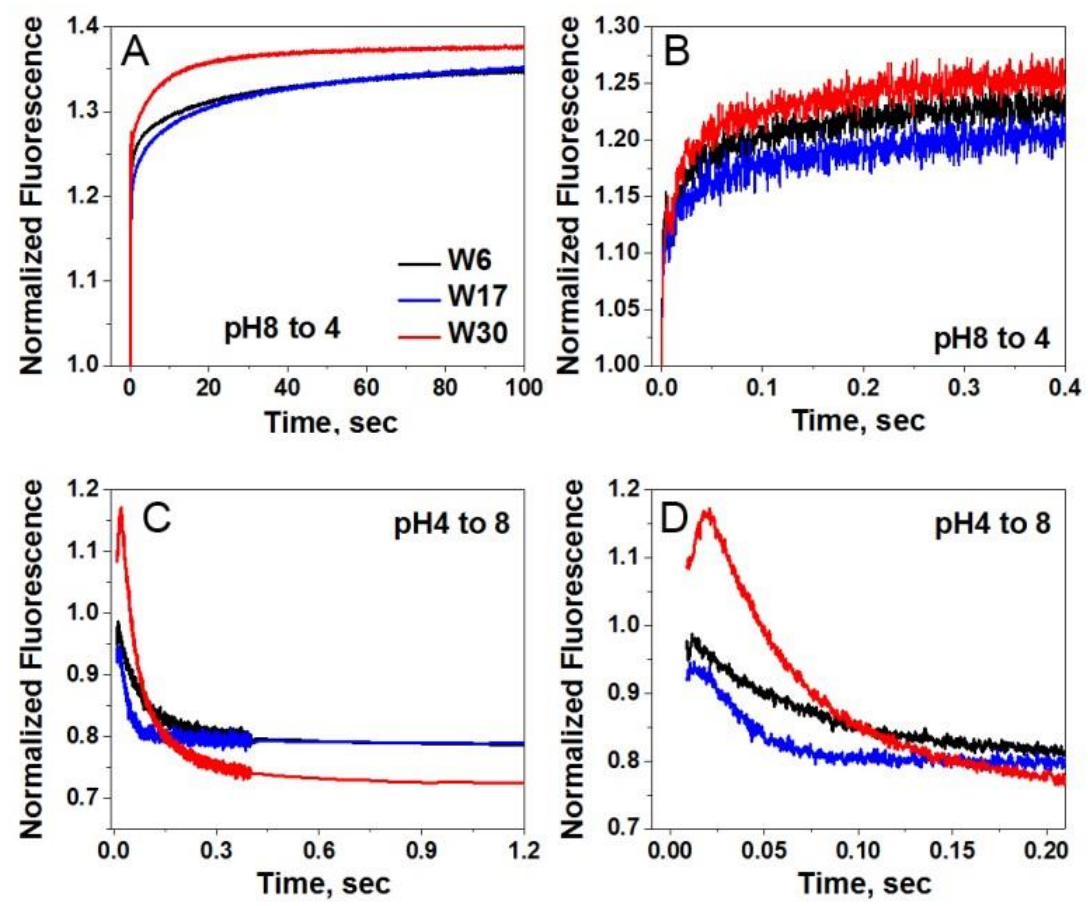

Figure S2. Trp fluorescence kinetics measurements of pHLIP peptide insertion and exit are shown over different time scales for Trp6 (black lines), Trp17 (blue lines), and Trp30 (red lines) pHLIP variants. Insertion is triggered by a $\mathrm{pH}$ jump from $\mathrm{pH} 8$ to $\mathrm{pH} 4(\mathrm{~A}, \mathrm{~B})$ and exit by a $\mathrm{pH}$ jump from $\mathrm{pH} 4$ to $\mathrm{pH} 8(\mathrm{C}, \mathrm{D})$. 
Insertion: $\mathrm{pH} 8.0$ to $\mathrm{pH} 6.2$
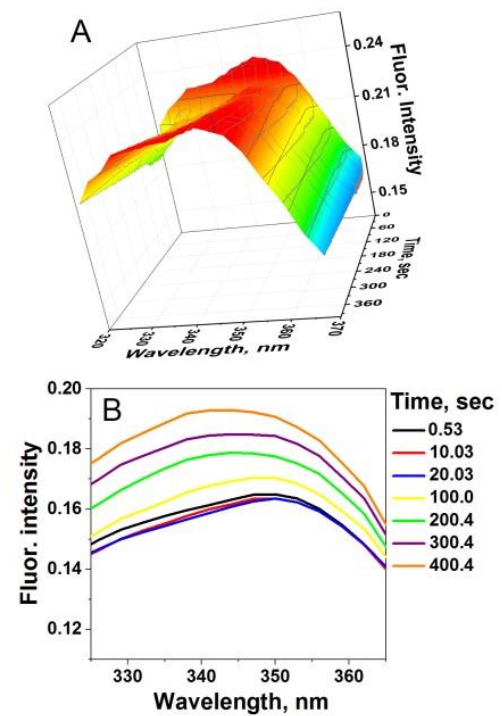

Exit: $\mathrm{pH} 4.0$ to $\mathrm{pH} 6.0$
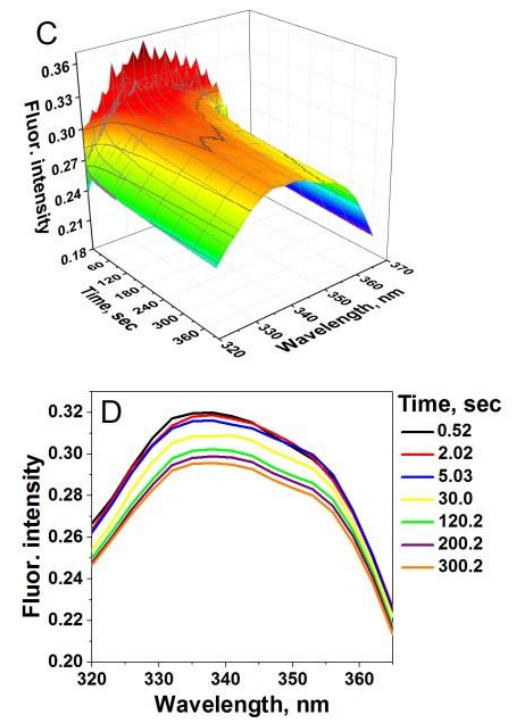

Figure S3. 3D (A, C) and 2D (B, D) representations are shown for the insertion (A, B) and exit $(C, D)$ kinetics of Trp30, on the inserting C-terminal flank of the pHLIP peptide. Spectral regions of the fluorescence reveal complex pathways, as in the short wavelengths for insertion seen in A.

The 3D plots $(\mathrm{A}, \mathrm{C})$ reflect changes in fluorescence intensity, time, and wavelength (the axis are the same on both panels, but angle views are different for better presentation). The 2D plots $(\mathrm{B}, \mathrm{D})$ show cross sections of the $3 \mathrm{D}$ plots at selected time points. 